\section{Article}

https://doi.org/10.11646/zootaxa.4362.4.1

http://zoobank.org/urn:lsid:zoobank.org:pub:350690F1-97E4-4FF5-B51A-E32118F95FFF

\title{
Review of the African genera Arantia Stål and Goetia Karsch (Orthoptera: Tettigoniidae: Phaneropterinae)
}

\author{
CLAUDIA HEMP ${ }^{1} \&$ BRUNO MASSA ${ }^{2}$ \\ ${ }^{1}$ Biodiversity and Climate Research Centre (BiK-F), Senckenberganlage 25, 60325 Frankfurt (Main), Germany. \\ E-mail: Claudia.Hemp@Senckenberg.de \\ ${ }^{2}$ Department of Agriculture, Food and Forest Sciences, University of Palermo, V.le Scienze Bd 4A, 90128 Palermo, Italy. \\ E-mail:bruno.massa@unipa.it
}

\section{Table of contents}

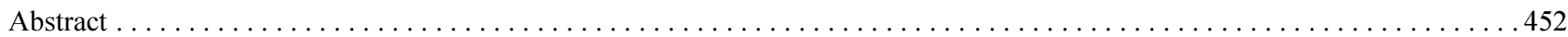

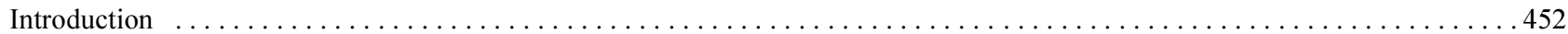

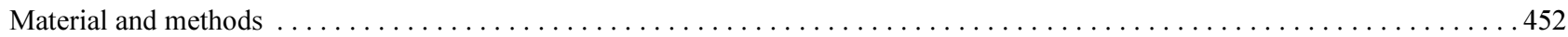

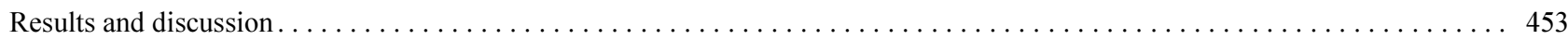

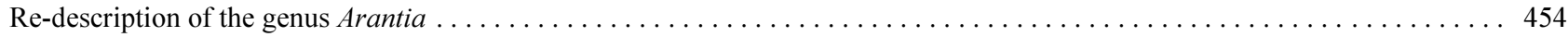

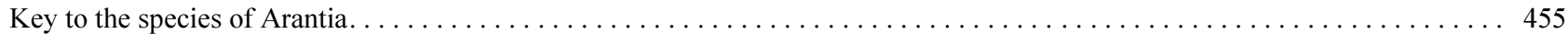

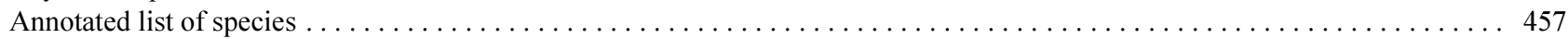

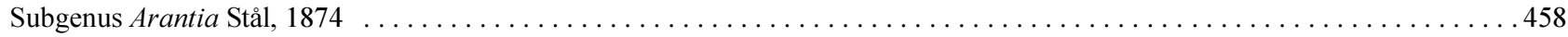

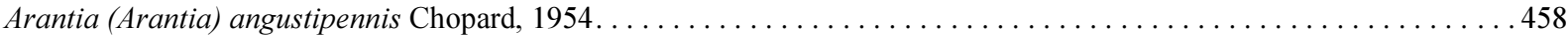

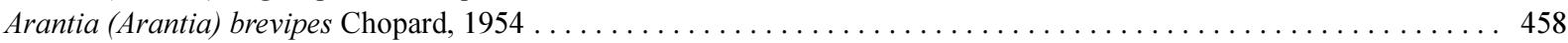

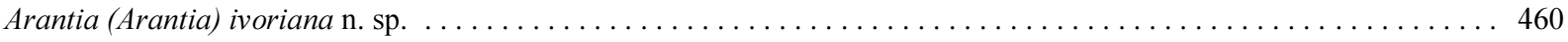

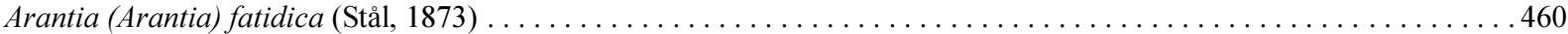

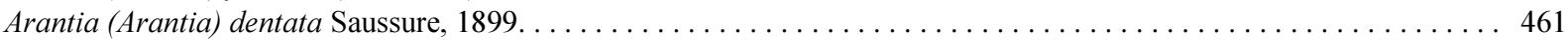

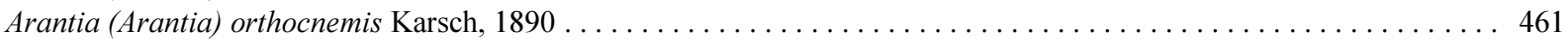

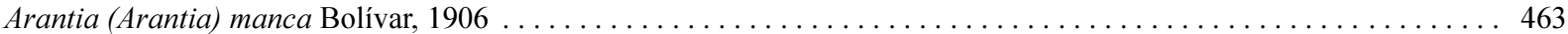

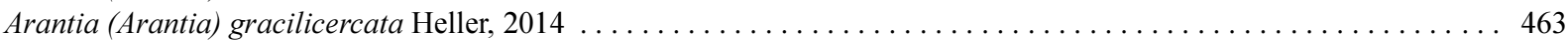

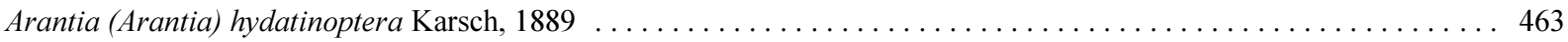

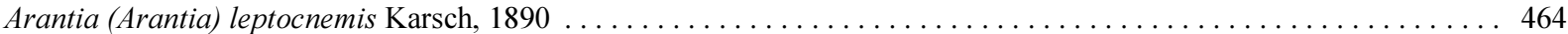

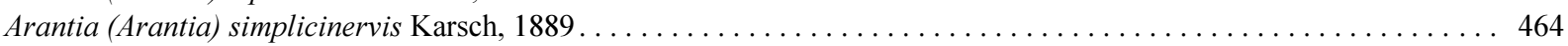

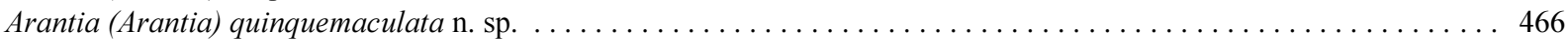

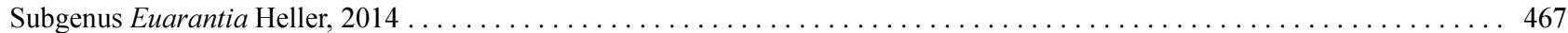

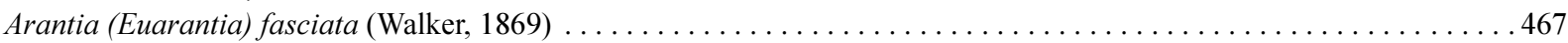

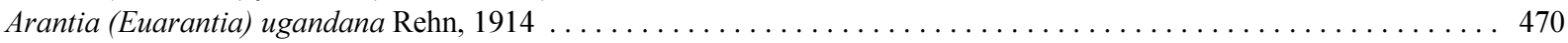

Arantia (Euarantia) rectifolia Brunner von Wattenwyl, $1878 \ldots \ldots \ldots \ldots \ldots \ldots \ldots \ldots \ldots \ldots \ldots \ldots \ldots \ldots \ldots \ldots$

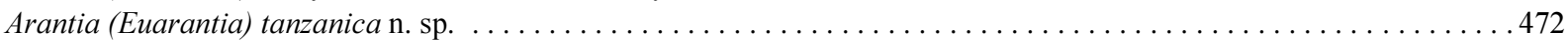

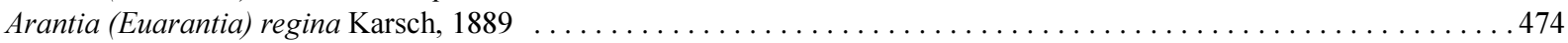

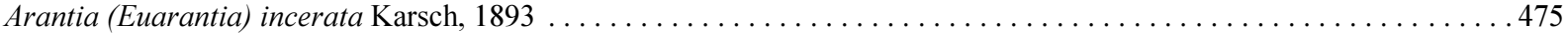

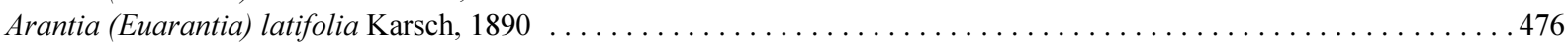

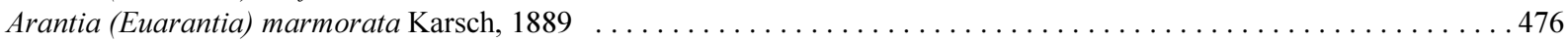

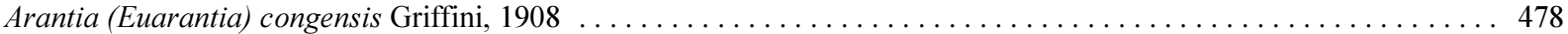

Arantia (Euarantia) melanota Sjöstedt, $1902 \ldots \ldots \ldots \ldots \ldots \ldots \ldots \ldots \ldots \ldots \ldots \ldots \ldots \ldots \ldots \ldots \ldots \ldots \ldots \ldots$

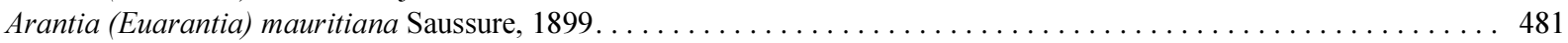

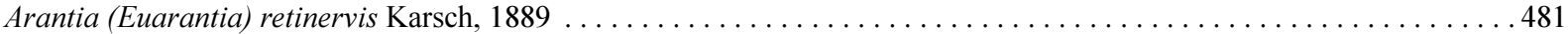

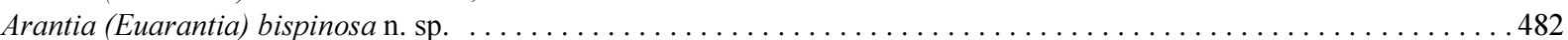

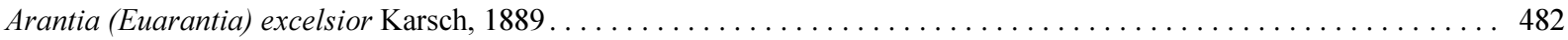

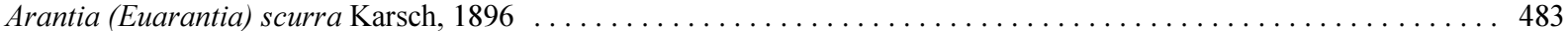

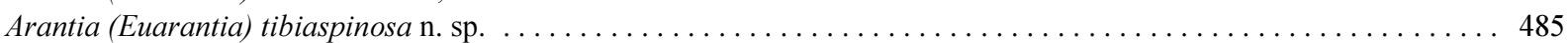

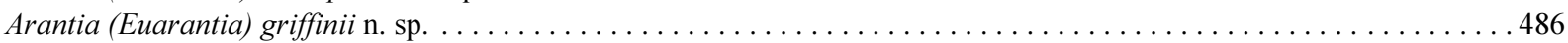

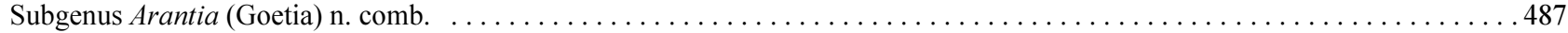

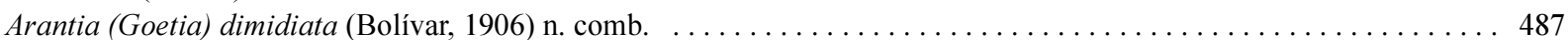

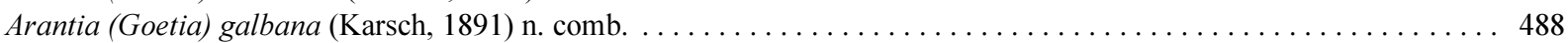

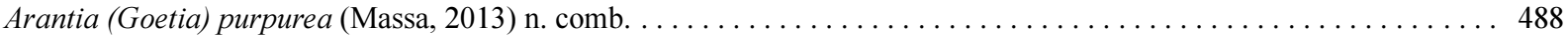

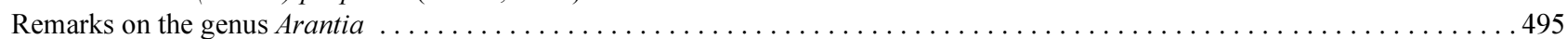




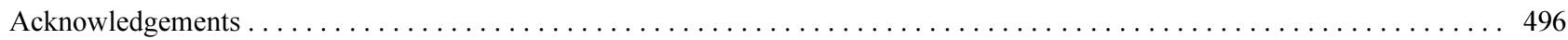

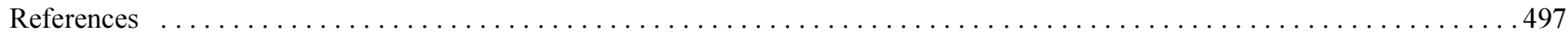

\begin{abstract}
The genus Arantia is reviewed, the distribution and distinguishing characters given. The three species of Goetia are assigned as subgenus to Arantia. Arantia gestri Griffini is transferred to this new subgenus and synonymized with $G$. dimidiata Bolívar. Other species synonymized are: A. accrana Karsch with A. rectifolia Brunner von Wattenwyl; A. gabunensis Brunner von Wattenwyl with $A$. regina Karsch; $A$. mammisignum Karsch and A. tigrina Bolívar with $A$. excelsior Karsch; A. ugandana Rehn is synonymized with $A$. fasciata (Walker). 6 species from Tropical Africa are newly described: $A$. (Arantia) quinquemaculata n. sp., A. (Arantia) ivoriana n. sp., A. (Euarantia) tanzanica n. sp., A. (Euarantia) tibiaspinosa n. sp., A. (Euarantia) bispinosa n. sp. and A. (Euarantia) griffinii n. sp. A key to the subgenera and species of Arantia is provided. The tribe Arantiini is synonymized with Holochlorini.
\end{abstract}

Key words: review, taxonomy, new species

\title{
Introduction
}

Currently 29 taxa of the genus Arantia Stål, 1874 are known from different countries of sub-Saharan Africa. Arantia species are comparatively large phaneropterids, many have leaf-like tegmina and thus are perfectly camouflaged in the vegetation. The alae are longer than the tegmina. The protruding part is pointed and of the same colour as the tegmina while the remaining part of the alae is hyaline. All species are fully winged. Especially the hind legs are long and the hind tibiae often strongly curved. Heller et al. (2014) described a new species of Arantia and subdivided the group into two subgenera mainly based on tegmina width and the curvature of the hind tibiae. Highest diversity of this genus is found in Central and West Africa. Few Arantia species are recorded from East and South Africa and Islands of the Indian Ocean. As true for various other groups of tropical insects for the majority of Arantia species little or no data are available on biogeography, habitat and biology. Some few species obviously are distributed over a large area, e.g. Arantia fasciata (Walker), and have been collected from West, Central, East to South Africa while the majority of species is just known from its type locality. Most museum collections hold only few Arantia species, mostly with a few specimens, larger series of specimens are only known for A. fasciata, A. gabunensis (= A. regina), A. rectifolia or A. orthocnemis. Often in several species only the female is described. The best characters to use to identify Arantia species is the outer genitalic morphology of males. Even though all Arantia species are fully alate and of large size compared to other Phaneropterinae, a high diversity is seen in this genus and often several species are found syntopically. Museum specimens are often faded being of tawny or yellowish colours while most Arantia species are probably more of less uniformly green in life. Few species have conspicuous colour patterns and fasciae and thus may be easily distinguished from other species.

The genus Goetia presently contains three species being distributed throughout West and Central Africa. It is distinguished from Arantia by the presence of a fore coxal spine absent in Arantia. Except for this character Goetia strongly resembles Arantia and thus it is proposed in this paper to accommodate it as a subgenus with Arantia. Aim of this study is to review Arantia and Goetia, provide information on their distribution and to describe new species.

\section{Material and methods}

Specimens from the following museums and collections were included in this study:

BMCP Bruno Massa Collection, Palermo

CHB Claudia Hemp Collection, Bayreuth

ISAM Iziko South African Museum, Cape Town

MfN Museum für Naturkunde, Berlin

MNCN Museo Nacional de Ciencias Naturales, Madrid

MRT Museo Regionale di Storia Naturale, Terrasini (Palermo) 


$\begin{array}{ll}\text { MSNG } & \text { Museo Civico di Storia Naturale 'G.Doria', Genoa } \\ \text { MSNM } & \text { Museo Civico di Storia Naturale, Milan } \\ \text { MSNP } & \text { Museo di Storia Naturale, University of Pavia } \\ \text { MSNT } & \text { Museo Regionale di Scienze Naturali, Turin } \\ \text { MZUF } & \text { Museo di Zoologia 'La Specola' of the University, Florence } \\ \text { NHM } & \text { British Museum of Natural History, London } \\ \text { NMHP } & \text { National Museum Natural History, Prague } \\ \text { NMW } & \text { Naturhistorisches Museum, Vienna } \\ \text { PACT } & \text { Philippe Annoyer Collection, Toulouse } \\ \text { RBINS } & \text { Royal Belgian Institute Natural Sciences, Bruxelles } \\ \text { ZMUC } & \text { Zoological Museum of the University, Copenhagen }\end{array}$

Some specimens were collected by P. Moretto in the Dzanga-Ndoki National Park of the Central African Republic, in the Ivory Coast, Togo and Burkina Faso in 2012-2017 with the aid of a UV lamp, both on the ground and in the canopy. Others were collected by Philippe Annoyer in the Dzanga-Ndoki National Park of the Central African Republic in 2009-2012 with the aid of a UV lamp, both on the ground and in the canopy.

Some specimens were photographed with a Nikon Coolpix 4500 digital camera, mounted on a Wild M5 Stereomicroscope, and photos were integrated using the freeware CombineZP (Hadley 2008). Mounted specimens were measured with a digital calliper (precision $0.01 \mathrm{~mm}$ ); the following measurements (in mm) were taken: Body length: dorsal length from the head to the apex of the abdomen (without ovipositor in females); Pronotum length: length of the pronotum along dorsal median line; Pronotum height: maximum height of the pronotum; Hind femur: length of hind femur; Hind tibia: length of hind tibia; Tegmina: length of tegmina; Ovipositor (the curvature of the ovipositor was not considered, measurements taken from the subgenital plate to the tip of the ovipositor).

\section{Results and discussion}

According to Brunner von Wattenwyl (1878) the genus Arantia is related to the American genera Philophyllia Stål, 1873, Phoebolampta Brunner von Wattenwyl, 1878, and others included within the genus-group Microcentra Brunner von Wattenwyl, 1878. However, Brunner von Wattenwyl preferred to establish the own genus-group Arantiae Brunner von Wattenwyl, 1878 (currently tribe Arantiini Brunner von Wattenwyl, 1878).

Since Arantia contained morphological heterogeneous taxa Griffini (1906, 1908) and Bolívar (1906) discussed erecting different genera, and recently Heller et al. (2014) separated the genus into two subgenera, Arantia and Euarantia Heller, 2014, with the type Arantia latifolia Karsch, 1890 for the subgenus Euarantia. According to Heller et al. (2014) Arantia species have narrow tegmina (7-12 mm width) and nearly straight hind tibiae, while Euarantia have broad tegmina (13.5-24 mm width) and curved hind tibiae.

The closest related genus to Arantia in Africa is Goetia Karsch, 1891. When Goetia was described, it was delimitated from Arantia by the following characters: the lateral lobes of the pronotum in Goetia are a slightly deeper than the median length of the pronotum, while in Arantia the pronotal lobes are considerably deeper than the median length. The fore coxae are armed in Goetia, while in Arantia they are unarmed, with the exception of $A$. gestri Griffini. In Goetia the subgenital plate lacks styli while in Arantia styli may be present or absent (Brunner von Wattenwyl 1878; Karsch 1891). However, the shape of the lateral lobes of the pronotum is very variable in species of both genera. Therefore only the presence/absence of the spine on the fore coxae remains distinguishing Goetia from Arantia (but not $A$. gestri). Otherwise the general morphology of both genera is the same and both taxa are closely related to each other. Therefore we here propose to synonymize Goetia Karsch, 1891 with Arantia Stål, 1874 placing Goetia into an own subgenus of Arantia. Considering the high variability of species and the impossibility to separate them morphologically in different genera, we considered the choice to use subgenera in this case a useful compromise for species identification.

Thirty-two taxa have been described in the genus. Kirby (1906) synonymized A. atrolineata Brunner von Wattenwyl with $A$. fasciata and Hemp (2013a) synonymized $A$. spinulosa with $A$. fasciata (Walker). Arantia curvata Griffini was described as subspecies of $A$. simplicinervis Karsch, but is considered as a synonym of $A$. simplicinervis by Cigliano et al. (2017). The type of A. ugandana Rehn is missing and could not be studied. 
However, specimens identified as $A$. ugandana in the collection of the NHM coming from localities near the type locality (Uganda) suggest that $A$. ugandana is synonymous with $A$. fasciata. Three taxa are currently known in the genus Goetia. In this paper 26 species are considered valid, and 6 species are newly described.

At present the genus Arantia is placed in the tribe Arantiini Brunner von Wattenwyl, 1878, while for the genus Goetia no tribe has been proposed. The genus Holochlora Stål, 1873 formerly contained two species, H. fatidica Stål, 1873 and H. venosa Stål, 1873; H. fatidica was used as type-species for the genus Arantia by Stål (1874), while H. venosa remained as type species for the genus Holochlora (Kirby 1906). Morphological characters of Arantia, Euarantia, Goetia and Holochlora are given in Table 1.

TABLE 1. Characters of the genus Arantia (subgenera Arantia, Euarantia and Goetia) and Holochlora.

\begin{tabular}{lllll}
\hline Character & Subgen. Arantia & Subgen. Euarantia & Subgen. Goetia & Gen. Holochlora \\
\hline Compound eyes & round & round & round & semi-spherical \\
Spine of fore coxae & absent & absent & yes & yes \\
Outer tympanum & open & open or closed & open & open \\
Last tergite & not modified & not modified & not modified & modified or not \\
Stridulatory vein of left & normal or elevated & normal & normal or elevated & normal or elevated \\
tegmen & above wing plane & & above wing plane & $\begin{array}{l}\text { above wing plane } \\
\text { bulging in middle or } \\
\text { Stridulatory file }\end{array}$ \\
& normal & normal & normal & normal \\
Ovipositor & small, reduced & small, reduced & small, reduced & robust, wide
\end{tabular}

Considering the small differences between Holochlora and Arantia (eyes, ovipositor) the correct tribe of Arantia should be Holochlorini instead of Arantiini, and consequently Arantiini has to be considered a synonym of Holochlorini. The genus Holochlora is distributed in the Oriental Region and only one species has been described from Madagascar (Liu et al. 2008). However, recently a species has been discovered in Zimbabwe and another in the Mauritius Is. (Massa in press); thus, its distribution is actually wider than previously assumed.

\section{Re-description of the genus Arantia}

Medium to large sized insects with a short head and wide round eyes. Fastigium verticis short, narrower than scapus of antenna. Prozona hardly narrower than metazona of pronotum; anterior margin of pronotum straight or slightly concave, posterior margin rounded, with evident lateral excisions where wings are inserted. Pronotum generally longer than high, in some cases as long as high or higher than long (e.g. A. fasciata, A. excelsior, A. regina). Lateral lobes of pronotum rounded or with a concavity. Tegmina much wider than pronotum length, leathery or more soft, with the apical margins obliquely cut. Hind wings longer than tegmina. Fore coxae unarmed (subgenera Arantia and Euarantia) or armed (new subgenus Goetia). Ventral margins of fore tibiae may wear small spines. Tympana of fore tibiae closed on inner, open on outer side except in the A. fasciata-complex and in some specimens of $A$. excelsior. Here the tympana are more or less closed both on the inner and the outer side. The ventral margins of fore and mid femora are furrowed, generally (but not always), fore femora with ventral spines, hind femora ventrally usually with some spines, in some species broad-based. Hind tibiae longer than the femora and more or less dorsally furrowed. Lower part of hind genicular lobe with accessory spine. Meso and metasterna rounded. The supra-anal plate of the male is triangular and rounded. The male cerci are variable, may be stout, sinuous, curved, with or without spines or indentations, branched, apically wrinkled or obtuse or club-shaped. The subgenital plate of the male is wide, three-keeled, with the posterior margin concave or straight and usually has styli. In some species where only the types are known styli are missing. However, this may be due to loss of these small and fragile structures. The ovipositor is reduced, strongly up-curved with the apex close to the abdomen, the upper valve is longer than the lower one. Also in the genus Arantia and its subgenera the female has transverse and longitudinal veins with small teeth on the dorsal area of the right tegmen (Figs 1-3), used for acoustical communication with the male. Analogous structures have been found in most females of Phaneropterinae (Heller $e t$ al. 2015). 


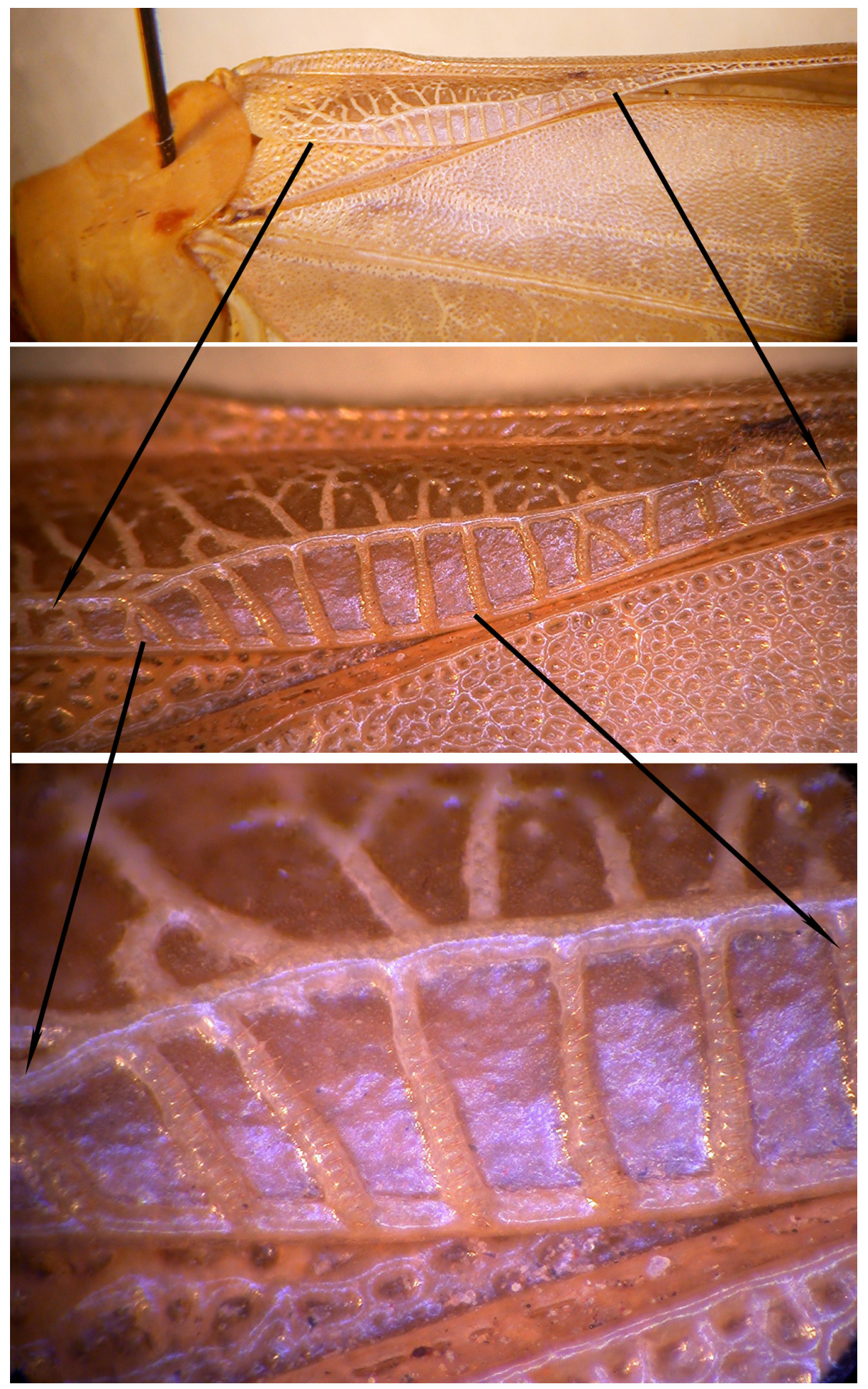

FIGURES 1-3. Right tegmen female Arantia (Euarantia) regina, at different magnifications. Visible are several rows of tiny teeth used for acoustical communication with the other sex. Note that the right tegmen was artifically placed over the left tegmen in order to photograph the structures.

\section{Key to the species of Arantia}

(only males, with some notes considering species known only from females)

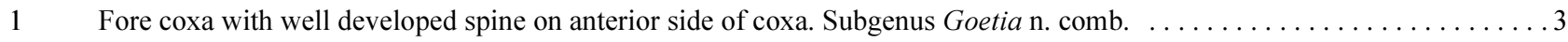

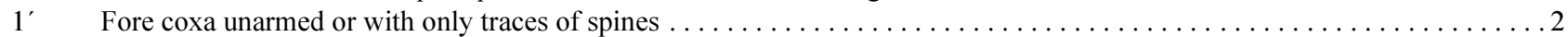

2 Tegmina broad (width $>12 \mathrm{~mm}$ ); tegmina leathery, leaf-like. Hind tibiae curved. Subgenus Euarantia Heller..........5 
Tegmina narrow $(<12 \mathrm{~mm})$. Mostly medium-sized species with light green tegmina. Hind tibiae little or not curved. Subgenus

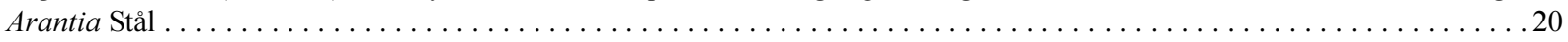

3. Tegmina purple. Conspicuous black spots on ventral side of femora. Central African Republic. . A. (Goetia) purpurea (Massa)

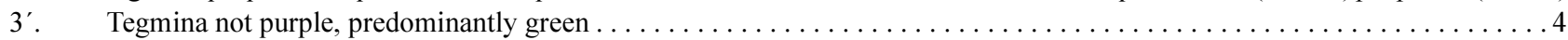

4. Tegmina without hexagons. Male cerci slender, dorso-ventrally compressed, with apical dent. West and Central Africa ...... At least one ventral broad-based spine on hind femora. Lateral lobes of the ovipositor with a pointed protuberance. Cerci long, up- and in-curved, stout with a central narrowing, a spoon-like expanded apex and a sclerotized apical spine. Democratic Republic Congo, Central African Republic ............................. (Euarantia) marmorata Karsch Spines ventrally on hind femora of normal shape

Abdominal tergites with small spines. Male cerci long and in-curved; a sclerotized dark bulge branches off before the upper apex, which has a long in-curved dark finger. Democratic Republic Congo, Central African Republic . . .

A. (Euarantia) congensis Griffini

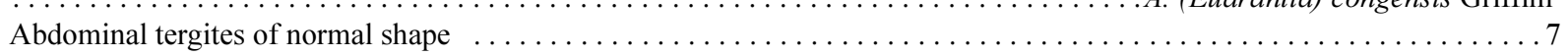

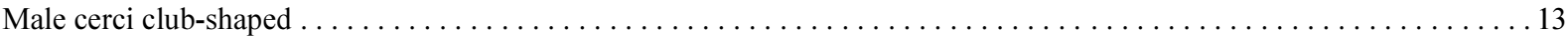

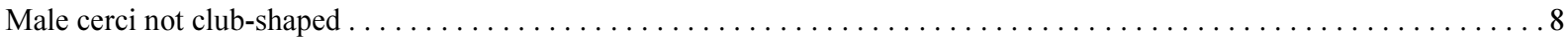

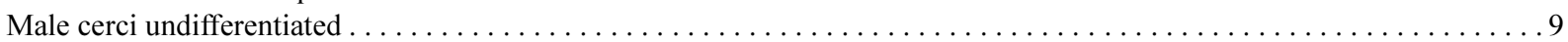

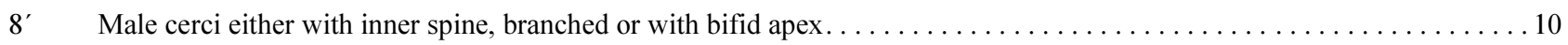

9 Apex of male cerci flattened and tips incurved. Posterior margin of pronotum wrinkled. Mauritius Is., Indian Ocean ....... $\ldots \ldots \ldots \ldots \ldots \ldots \ldots \ldots \ldots \ldots \ldots \ldots \ldots \ldots \ldots \ldots \ldots \ldots \ldots \ldots \ldots \ldots \ldots \ldots \ldots \ldots$. (Euarantia) mauritiana Saussure Apex of male cerci with sclerotized ridge. Cameroon, Equatorial Guinea. ............. (Euarantia) latifolia Karsch $^{1}$ Inner base of male cerci with one spine. Cerci stout with sclerotized ridge at inner side. Ivory Coast . .

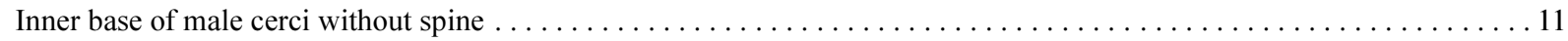
Midway on male cerci sclerotized inner spine. Dorsal furrow of tibiae expanded. Congo, Cameroon, Sierra Leone, Togo ....

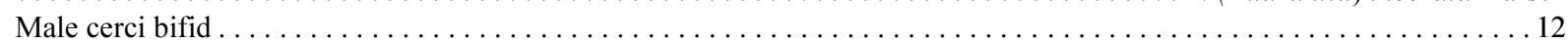
Outer part of tip of male cerci sclerotized and acute, inner part broad based and with tiny sclerotized spinule. Fore tibiae pitch black in area of tympana. Pronotum with thin transverse black line where pronotum is abruptly bent, posterior part of more yellowish to whitish colour. Cameroon, Central African Republic, Angola ............... (Euarantia) melanota Sjöstedt Both tips of male cerci about the same size, sclerotized. Fore tibiae green, infumate in area of tympana. Pronotal disc uniformly green. Guinea, Sierra Leone, Togo, Ivory Coast, Cameroon, Democratic Republic Congo, Central African Republic . .

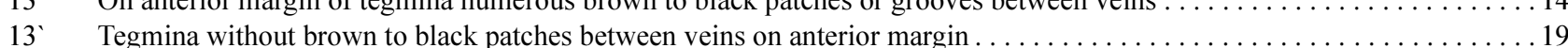

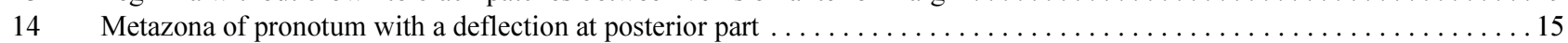

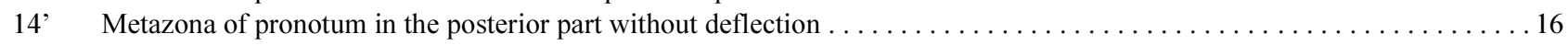

15 Hind tibia basally not modified. Posterior margin of pronotum partly or completely brown with conspicuous white fascia or two large white patches. Central and West Africa (Sierra Leone, Equatorial Guinea, Central African Republic and Cameroon)

A. (Euarantia) excelsior Karsch (= A. mammisignum Karsch = A. tigrina Bolívar)

15. Basally hind tibia with 3-5 closely set and enlarged spines so that this part seems expanded; marked dark brown. Posterior

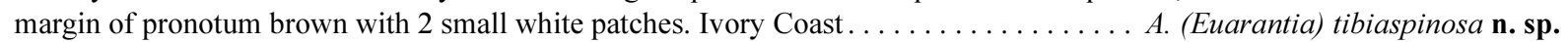
Posterior part of pronotum dark brown. Male cerci stout and slightly sinuous with club-shaped apex pitch black. Styli of subgenital plate present. Hind tibiae with brown markings. Cameroon, Central African Republic, Ivory Coast . . .

A. (Euarantia) scurra Karsch

16 Posterior part of pronotum not dark brown but sometimes with two lateral brown patches $\ldots \ldots \ldots \ldots \ldots \ldots \ldots \ldots$

17 Smaller size, ratio length/width tegmina $>4.0$. Fore tibiae ivory-coloured mixed with some dark traces in the area of the tympana. Tegmina with only faintly visible $4-5$ ivory or more tawny to orange spots, sometimes on dark to black ground $\ldots \ldots 18$

17 Larger size, ratio length/width tegmina $<4.0$. Sometimes 2 black spots on posterior margin of pronotum. Stridulatory file short and straight, consisting of ca. 40 teeth. Widely distributed throughout West and Central Africa.

$\ldots \ldots \ldots \ldots \ldots \ldots \ldots \ldots \ldots \ldots \ldots \ldots \ldots \ldots \ldots \ldots$. (Euarantia) regina Karsch (= gabunensis Brunner von Wattenwyl) Stridulatory file short, with $\mathbf{8 0 - 8 5}$ teeth. Stridulatory area on left tegmen as in Fig. 19. West and Central Africa (Cameroon, Equatorial Guinea, Central African Republic, Democratic Republic Congo, Senegal, Togo, Burkina Faso, Ivory Coast)...... A. (Euarantia) rectifolia Brunner von Wattenwyl (= A. accrana Karsch)

18 Stridulatory file long, with more than 100 teeth. Stridulatory area on left tegmen as in Fig. 20. Central Tanzania

A. (Euarantia) tanzanica n.

19 Inner and outer tympanum of fore tibia closed. Posterior margin of pronotum (measured at greatest distance of metazona) $>6$ $\mathrm{mm}$. Posterior part of pronotum with transverse dark fascia at broadest point, remaining part white. Tegmina wide $>15 \mathrm{~mm}$.

1. A. (Euarantia) ovalipennis Chopard (Guinea), known only from the female sex, is very similar to A. (Euarantia) latifolia, but according to Chopard (1954) it has more rounded tegmina. Nevertheless, we compared the type with A. (Euarantia) latifolia and propose the synonymy. 
Anterior margin of fore tegmina without row of dark dots but whole tegmen with numerous scattered impressed dots. Fore tibiae in area of tympana often more or less conspicuous white with some infumate to dark areas, especially at tympana. Hind femora with two rows of small evenly spaced spines, black tipped with broad base ${ }^{2}$. Male cerci decussate, comparatively stout with well developed clubs at apex, smooth and dark at inner side. From West throughout Central to East and South Africa ... ... A. (Euarantia) fasciata (Walker) (= atrolineata Brunner von Wattenwyl = spinulosa Brunner von Wattenwyl = ugandana Rehn)

19. Inner tympanum closed, outer open. Posterior part of pronotum differently coloured from the anterior part. Anterior margin of tegmina without row of tiny dots. Stridulatory file with more than 80 teeth. Legs covered with numerous short hairs. Male cerci long and in-curved, with an apical bulge with two small black spines, one of which very small. Central African Republic ....

. (Euarantia) griffinii $\mathbf{n} . \mathbf{s p}$

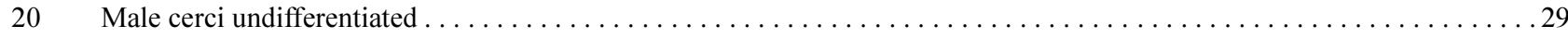

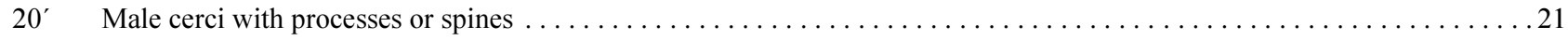

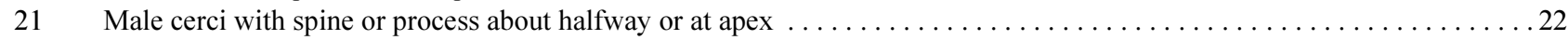

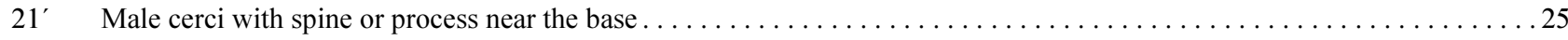

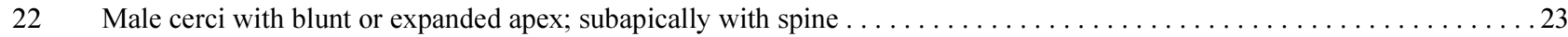

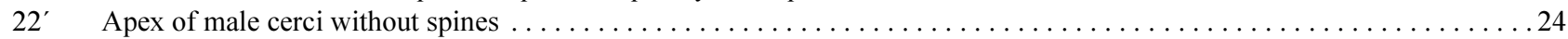

23 Male cerci with blunt apex with a ridge armed with 1 spinule and a hooked broad-based spine. Subapically with robust lateral spine with sclerotized tip. West Africa (Guinea, Ghana)....................... (Arantia) angustipennis Chopard

23' Male cerci with expanded apex with an inner broad-based stout spine and two outer spinules. Subapically with a long spine with sclerotized tip so that cerci almost look branched. Ivory Coast .................. (Arantia) ivoriana $\mathbf{n} . \mathbf{s p .}$

24 Apex of male cerci evenly rounded, laterally flattened. Strong spine dorsally about midway. West Africa (Guinea, Sierra

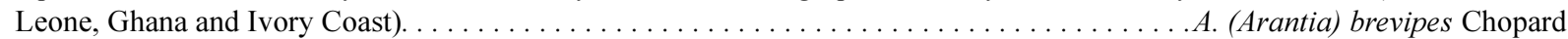

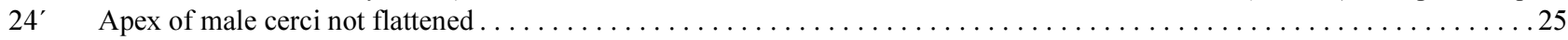

25 Spines near apex of male cerci. Tips of male cerci outward curled; before apex strong spine. Small size (đ 20-25 mm). Sierra

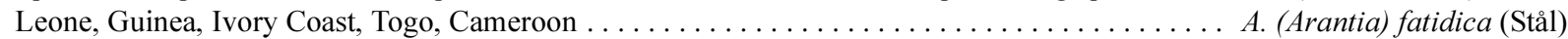

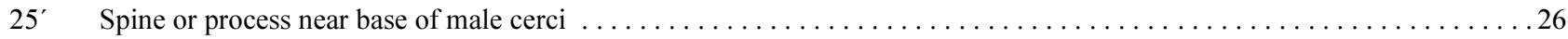

26 Process near base of male cerci. Basal process of male cerci round, with almost circular sclerotized ridge. Cerci with strongly

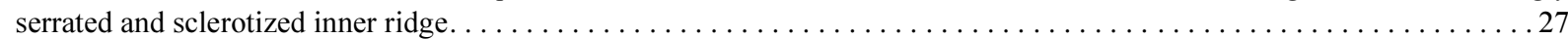

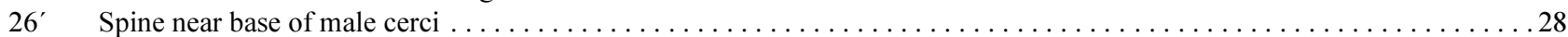

27 Tegmina more rounded and more leathery. Cameroon ........................ (Arantia) orthocnemis Karsch

27' Tegmina narrower and more translucent. Mauritius, Indian Ocean . . . . . . . . . . . . . . . A. (Arantia) dentata Saussure

28 Spine basally on male cerci slender; male cerci comparatively short, decussate, with an inner basal back-curved spine; inner chitinous ridge from base to apex. Cameroon, Democratic Republic of Congo and Angola ......A. (Arantia) manca Bolivar 28' Spine basally on male cerci laterally slightly flattened; cerci very long and slender, without inner sclerotized ridge. Democratic Republic Congo. . . . . . . . . . . . . . . . . . . . . . . . . . . . . . . . . . . . . . A. (Arantia) gracilicercata Heller Male cerci comparatively long and slender, apically with dents. Bases of male cerci stouter $\ldots \ldots \ldots \ldots \ldots \ldots \ldots$

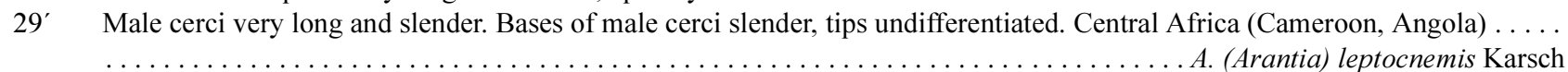

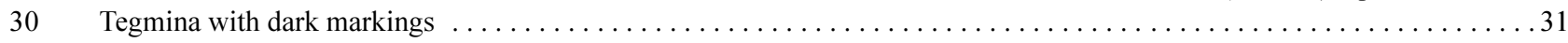

30' Tegmina without markings and very hyaline. Bases of male cerci stout, tips flattened and in-curved. Nigeria, Cameroon, Equa-

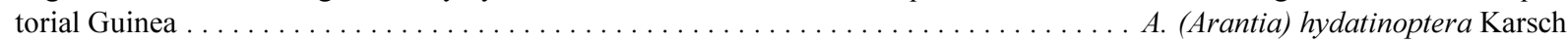

31 Markings on tegmina less than five. Stridulatory file with 48-50 teeth. West, Central and South-West Africa

A. (Arantia) simplicinervis Karsch

31, Five brown markings on tegmina. Stridulatory file with $28-30$ teeth, the inner 4 more spaced than the remaining outer ones.

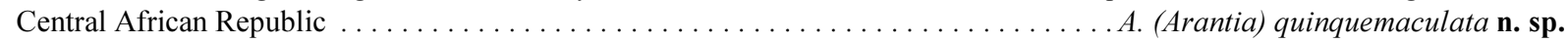

\section{Annotated list of species}

In the following list species are arranged into three groups: 1) species with unarmed fore coxae, closed tympana on inner and open on outer side of fore tibiae, narrow tegmina (7-12 mm width) and nearly straight hind tibiae (subgenus Arantia) 2) species with unarmed fore coxae, closed tympana on inner and outer or open on outer side of fore tibiae, broad tegmina (13.5-24 mm width) and curved hind tibiae (subgenus Euarantia) 3) species with armed fore coxae, closed tympana on inner and open on outer side of fore tibiae (Goetia subgen. new combination). Although the use of subgenera in taxonomy is controversial, due to the high variability of characters (e.g., wing width) we propose this classification for species of the genus Arantia to indicate relationships within the group until more information (e.g. molecularly) gets available. Thus, three subgenera are here proposed for Arantia: Arantia Stål, Euarantia Heller, and Goetia Karsch.

2. Arantia (Euarantia) excelsior sometimes may have closed tympana both on inner and outer sides of fore tibia, but it never has broad-based and black-tipped spines on the hind femora. 
Arantia (Arantia) angustipennis Chopard, 1954 (Figs. 4, 72a, b)

http://lsid.speciesfile.org/urn:Isid:Orthoptera.speciesfile.org:TaxonName:464820

Chopard (1954). Mem. Inst. franc. Afr. Noire, 40 (2): 36.

Type locality: GUINEA, Yanlé; depository: MNHN, Paris; kind of type: holotype male.

Material examined. GUINEA. Mt. Nimba, Yanlé (holotype đ) (MNHN).

Tegmina width: 8.7; tegmina width/pronotum length: 1.6 (Heller et al. 2014).

A. angustipennis is a small species (body length $\widehat{O} 21 \mathrm{~mm}$ ). Chopard (1954) described the male from Guinea (Yanlé). Naskrecki (2009) recorded it from Ghana. Tegmina are broad (ratio length/width: 4.3, Chopard 1954), fore femora are clearly longer than pronotum (10 vs. $5.5 \mathrm{~mm}$ ) (Fig. 4). Fore femora have 5 ventral spines, mid femora 4 and hind femora 7 ventral spines on both sides. Male cerci are stout, up- and in-curved, with a blunt apex with a ridge armed with 1 spinule and a hooked spine; before the apex a robust lateral spine is present (Figs 72a, 72b).

Distribution. Known from the type locality Yanlé, Guinea and Ghana, West Africa.

Arantia (Arantia) brevipes Chopard, 1954 (Figs. 4, 51, 75)

http://lsid.speciesfile.org/urn:lsid:Orthoptera.speciesfile.org:TaxonName:464826

Chopard (1954). Mem. Inst. franc. Afr. Noire, 40 (2): 37.

Type locality: GUINEA. Depository: MNHN, Paris. Kind of type: syntypes male and female.

Material examined. GUINEA. Mt. Nimba VI.1942, M. Lamotte ( $1 \sigma^{\lambda}$ and 4 ㅇ syntypes). Mt. Nimba

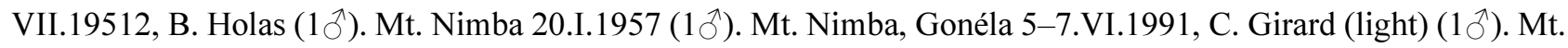
Nimba, Zoregué forest (800 m) 14-19.VI.1991, C. Girard (light) (1 ㅇ). IVORY COAST. $1 \mathrm{~km}$ before Lamto Forit

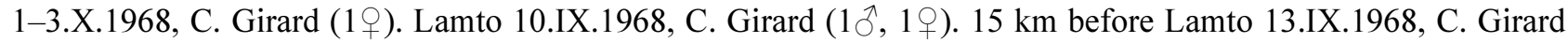

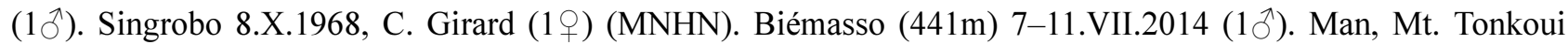
(1200m) 1-4.VII.2014 (light trap), P. Moretto (2ð); same locality, 13-15.VII.2014 (light trap), P. Moretto (2ð); same locality 24-28.VII.2015 (light trap), P. Moretto (1へ). Taï National Park, Res. Station 18.III.2017 (night), B.

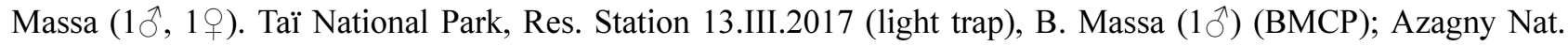
Park (59m) 26.XI-1.XII.2015, M. Aristophanous, P. Moretto, E. Ruzzier (1ठ) (NHM). Man, Cascades 26.XII.1979, A. Pauly (19) (RBINS).

Measurements. Males. Body length: $26.8 \pm 1.1$; pronotum length: $6.2 \pm 0.2$; pronotum height: $6.0 \pm 0.1$; hind femur: $22.0 \pm 1.6$; tegmina: $36.8 \pm 2.1$ (syntype: 38.2 ); tegmina width: $9.8 \pm 0.2$ (syntype: 11.4 ); tegmina length/width: 3.4-4.0 (syntype: 3.3 ); tegmina width/pronotum length: 1.4-1.7. Female (syntype). Body length: 30.5; pronotum length: 6.5; hind femur: 22.0; tegmina: 35.5; tegmina width: 12.0; tegmina length/width: 3.0; tegmina width/ pronotum length: 1.8 .

Chopard (1954) described both sexes from Guinea. Later, Ragge \& Roy (1971) recorded it from Sierra Leone, and Naskrecki (2009) from Ghana.

A. brevipes is a small species (body length $\widehat{\delta} 25-28 \mathrm{~mm}, \varnothing 30.5 \mathrm{~mm}$ ), related to A. angustipennis, but with broader tegmina and shorter legs [fore femora slightly longer than pronotum: $8 \mathrm{vs.} 7 \mathrm{~mm}$ according to Chopard (1954), 7.5-7.8 vs. 6.0-6.5 in the here investigated specimens] (Fig. 4). The anterior part of the pronotum is narrow and the general aspect from above is very narrow. Tegmina have a black marking at their base and the metanotum is darkened. The stridulatory file is very short (ca. $1.5 \mathrm{~mm}$ ) and consists of ca. 80 evenly spaced teeth (Fig. 51). Fore femora have 6-7 ventral spines on inner margin, mid femora 0-2 on inner and 3-6 on the outer margin, the hind femora 5-6 small ventral spines on the inner and outer sides. Male cerci have an inner spine about midway, are apically rounded and the tips are shaped like a flat blade (Fig. 75). Styli present.

Distribution. West Africa (records from Guinea, Sierra Leone, Ghana and Ivory Coast). 

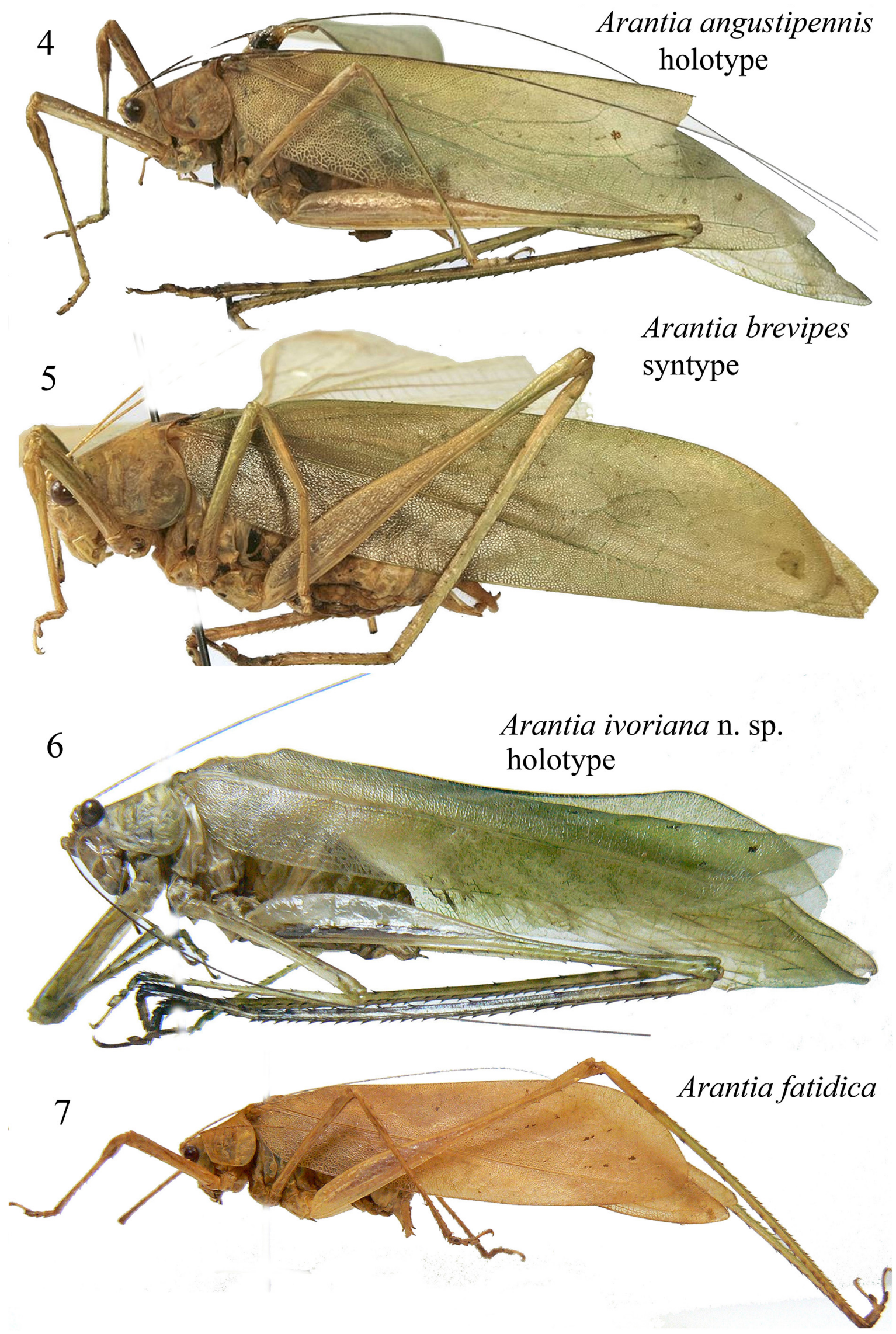

FIGURES 4-7. Habitus of Arantia (Arantia) angustipennis (holotype) (4), A. (Arantia) brevipes (syntype) (5), A. (Arantia) ivoriana n. sp. (holotype) (6) and A. (Arantia) fatidica (7). 
Material examined. IVORY COAST. Taï National Park, Res. Station 21.III.2017 (light trap), B. Massa ( ${ }^{\lambda}$ holotype) (BMCP).

Measurements of male. Body length: 25.3; pronotum length: 5.3; pronotum height: 4.8; hind femur: 28.0; tegmina: 40.0; tegmina width: 7.2; tegmina length/width: 5.5 ; tegmina width/pronotum length: 1.3 .

Diagnosis. A. ivoriana $\mathbf{n}$. sp. is a small sized $(\widehat{o} 25.3 \mathrm{~mm})$, very characteristic species, with translucent tegmina. The stridulatory vein is elevated above the wing plane and the cerci have a lateral long spine and two apical spinules.

Description. Male (Fig. 6). General habitus and colour pattern. Predominantly yellow-green, base of tegmina black, hidden by pronotum. Head and antennae. Eyes oval, fastigium of vertex sulcate. Antennal segments reddish with small brown rings. Head and legs yellow with brownish dots and stripes, face yellow. Thorax and legs. Fore coxa unarmed. Tympana on fore tibia open on outer and closed on inner side. Pronotum green, anterior margin slightly concave, posterior margin rounded. Tegmina oval, green with a dark spot at the base, 5.5 times longer than broad. The stridulatory area of the left tegmen is almost straight and elevated above the wing plane, the stridulatory file is straight and consists of ca. 85-90 evenly spaced teeth (Fig. 52). Fore femora with 4 inner ventral spines, fore tibiae with 8 inner and outer ventral spines, and 6 dorsal outer spines. Mid femora with 3 outer ventral spines, mid tibiae with 14 outer and inner ventral spines, 12 spines on outer and inner dorsal margins. Hind femora with 6 outer and 7 inner ventral spines, hind tibiae slightly curved, with 20 outer and inner ventral spines. Abdomen. Male cerci with expanded apex with an inner broad-based stout spine and two outer spinules. Subapically with a long spine with sclerotized tip so that cerci almost look branched (Fig. 73a). Subgenital plate short and narrow, the apex is straight. Styli present (Fig. 73b).

Female. Unknown.

Etymology. Named after the country Ivory Coast.

Affinities. It is related to A. (Arantia) angustipennis, from which it may be separated by the different shape of the cerci.

Distribution. Known only from the type locality (National Park of Taï, Ivory Coast).

Arantia (Arantia) fatidica (Stål, 1873) (Figs. 7, 74a, b)

http://lsid.speciesfile.org/urn:lsid:Orthoptera.speciesfile.org:TaxonName:464827

Stål (1873). Ofv. K. Vetensk. Akad. Forh., 30 (4): 43.

Type locality: SIERRA LEONE. Depository: NHRS, Stockholm; kind of type: holotype male.

Material examined. CAMEROON (3 ㅇ) (MNCN). TOGO. Bismarckburg 29.IX-31.X.1890, R. Büttner (1ð)).

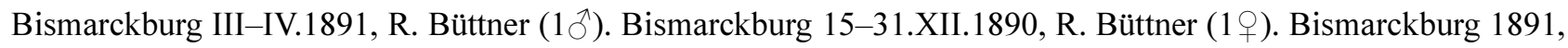
R. Büttner (1 ). Bismarckburg 30.VI-3.VII.1893, L. Conradt (1 + ) (MfN). GUINEA. Mt. Nimba, Yalanzon, M. Lamotte (1ㅇ). Mt. Nimba, Nion, M. Lamotte (1ㅇ). Mt. Nimba (1000 m), M. Lamotte (1ठ). Between Kéouleuta \& N'Zo 25.V.1991, C. Girard (1 + ) (MNHN).

Tegmina width: 9.1-11; tegmina length/width: 3.5-3.8; tegmina width/pronotum length: 1.8 (Heller et al. 2014).

Characters. A. fatidica is a species of small size (body length $\widehat{\jmath} 20-25 \mathrm{~mm}, q 29 \mathrm{~mm}$ ) (Fig. 7). Stål (1873) described the male from Sierra Leone, and later Karsch (1893) described the female from Togo; it has been recorded by Karsch $(1889,1890,1893)$ from Sierra Leone, Barombi Station (Cameroon) and Togo, by Griffini (1908) from Mukonje Farm (Cameroon), and by Chopard (1954) from Mt. Nimba (Ivory Coast and Guinea). This species has a shiny black spot at the base of the tegmina. Fore femora have 3-4 ventral spines, mid femora 2-4 ventral spines and hind femora with a double row of 6-7 yellow ventral spines with a black tip. Male cerci are short and slightly curved; at about middle of the cerci an inner stout, slightly flattened and pointed spine with a black tip is typical; the apex of the cerci is bifid, pointed and apically hairy (Figs 74a, 74b). Styli are present. Ovipositor is short without lateral protuberances. 
Distribution. Species with a probably wide distribution in West and Central Africa (records from Sierra Leone, Guinea, Ivory Coast, Togo, Cameroon).

Arantia (Arantia) dentata Saussure, 1899 (Fig. 76)

http://sid.speciesfile.org/urn:lsid:Orthoptera.speciesfile.org:TaxonName:464811

Saussure (1899). Abh. Senckenb. Natforsch. Ges., 21: 615.

Type locality: MAURITIUS. Depository: MHNG, Geneva. Kind of type: holotype male.

Tegmina width: 10; tegmina width/pronotum length: 1.3 (Heller et al. 2014).

Characters. $A$. dentata is a species of medium size (body length $\widehat{\delta} 35 \mathrm{~mm}$ ). Only two male specimens are known, but one of them comes from Cameroon (Saussure 1899; John Hollier, pers. comm.) and thus very likely belongs to A. orthocnemis. It is characterized by narrow and translucent tegmina with a black spot at their base. Further characters are a rounded margin of the pronotal lobes. The male cerci are rather stout and have an inner spine, as $A$. orthocnemis (compare Figs 76 and 77).

Remarks. A. dentata is morphologically very similar to $A$. orthocnemis. However, the localities of both taxa (A. dentata known from Mauritius in the Indian Ocean, A. orthocnemis occurring in Central and West Africa) are far apart geographically and therefore we decided not to synonymize these two species.

Distribution. Known only from the island Mauritius in the Indian Ocean.

Arantia (Arantia) orthocnemis Karsch, 1890 (Figs. 8, 77)

http://lsid.speciesfile.org/urn:lsid:Orthoptera.speciesfile.org:TaxonName:464832

Karsch (1890). Entom. Nachricht., 16 (23): 357.

Type locality: CAMEROON. Barombi Station. Depository: MfN, Berlin. Kind of type: syntypes male and female.

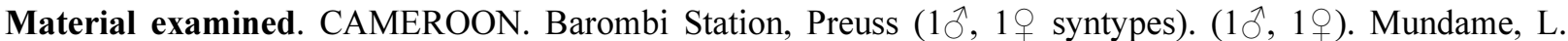

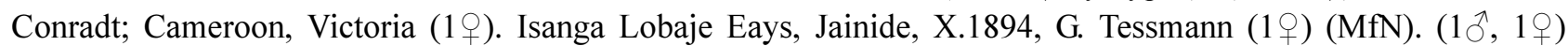

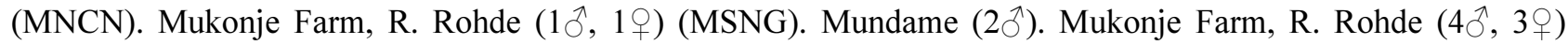
(RBINS). DEMOCRATIC REPUBLIC CONGO. Congo, Urw.-Mawambi 1910, Grauer (2ð) (NMW).

Tegmina width: 9.8-11; tegmina length/width: 4.6; tegmina width/pronotum length: 1.5 (Heller et al. 2014).

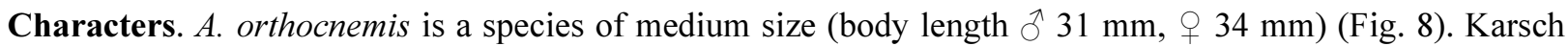
(1890) described both sexes from Barombi Station (Cameroon). Sjöstedt (1902) recorded it from Itoki (Cameroon), Bolívar (1906) from Fernando Póo (Equatorial Guinea), Griffini (1908) from Mukonje Farm (Cameroon) and Bruner (1920) from Lolodorf (Cameroon). It has narrow tegmina with reddish or ivory to white coloured spots, and with basal black markings. Tarsi in most specimens are black. Fore femora with 5-8 inner ventral spines (1 specimen from Mundame has 5 spines on the left femur, while the right is unarmed), mid femora are unarmed, hind femora with 6 outer and 8 inner ventral spines. Male specimens are easily distinguished from other Arantia species comparing the male cerci. The bases are swollen and a sclerotized ridge stretches from the base to the apex at the inner side. Basally at the inner side of the cerci a process is present, armed with an almost circular sclerotized ridge (Fig. 77). Styli well developed. The ovipositor has two lateral protuberances. The subgenital plate of the female is short and slightly pointed.

Affinities. Karsch (1889) and Griffini (1908) pointed out its affinity with A. hydatinoptera. A. orthocnemis has morphologically completely different male cerci while in $A$. hydatinoptera the male cerci are apically compressed and the tips incurved and a basal process is lacking as well as the inner sclerotized ridge. A. hydatinoptera is probably more closely related to $A$. leptocnemis. A. orthocnemis has almost identical male cerci as $A$. dentata (see above).

Distribution. Widespread in Central and Western Africa (Cameroon, Democratic Republic Congo, Equatorial Guinea). 


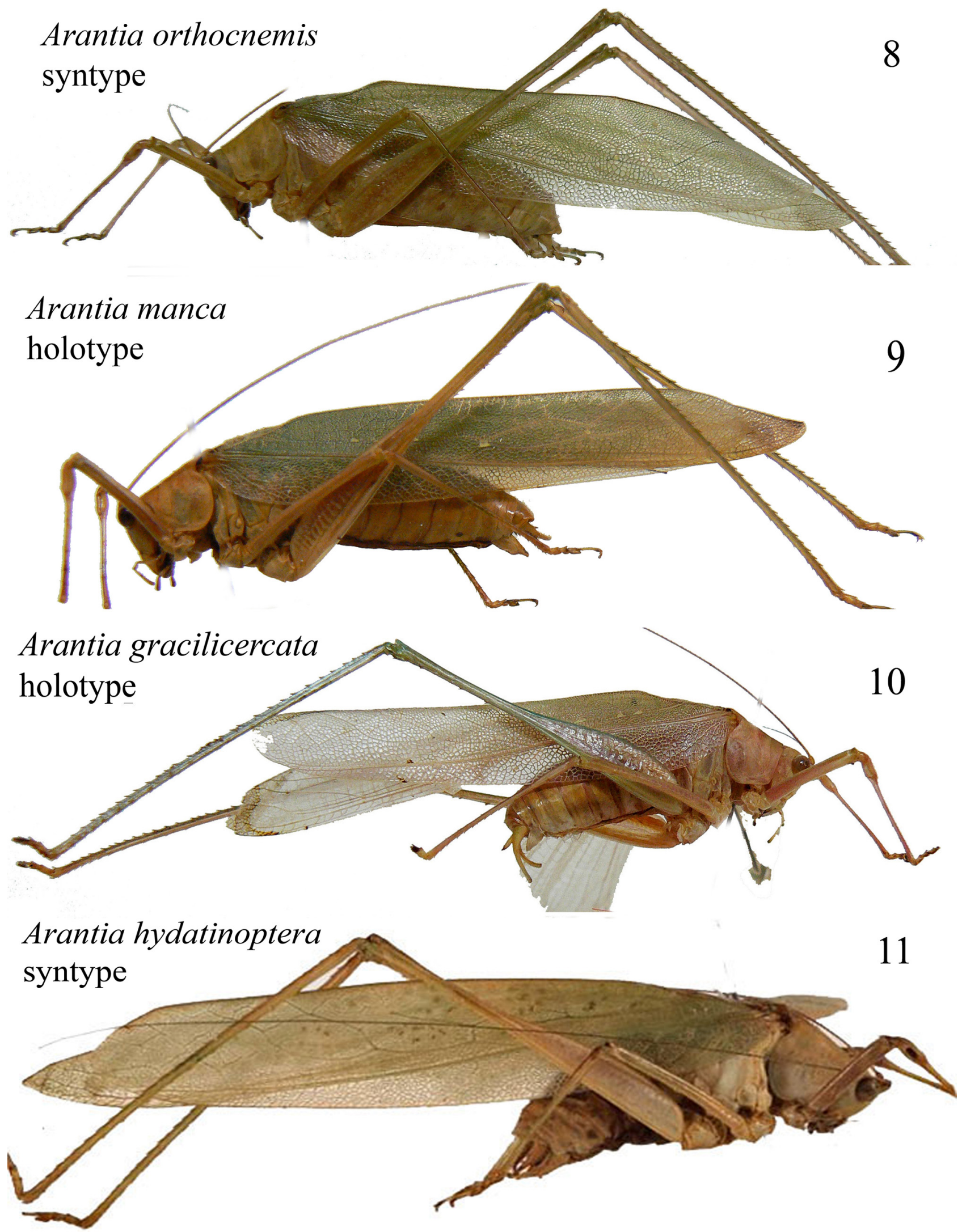

FIGURES 8-11. Habitus of Arantia (Arantia) orthocnemis (syntype) (8), A. (Arantia) manca (holotype) (9), A. (Arantia) gracilicercata (holotype) (10) and $A$. (Arantia) hydatinoptera (syntype) (11). 
Arantia (Arantia) manca Bolívar, 1906 (Figs. 9, 78a, b)

http://sid.speciesfile.org/urn:lsid:Orthoptera.speciesfile.org:TaxonName:464831

Bolívar (1906). Mem. Soc. espan. Hist. nat., 1: 332.

Type locality: CAMEROON. Depository: MNCN, Madrid. Kind of type: lectotype male.

Material examined. CAMEROON. L. Conradt ( $\delta$ lectotype) (MNCN). DEMOCRATIC REPUBLIC CONGO. Kisantu $\left(2 \jmath^{\Uparrow}\right)$. ANGOLA. Kabinda (1 $\left.\widehat{\delta}^{\Uparrow}\right)$ (RBINS).

Tegmina width: 7; tegmina width/pronotum length: 1.2 (Heller et al. 2014).

Characters. A. manca is a small sized species described on one male only. This species has narrow tegmina with a black spot at the base (Fig. 9). Hind tibiae are straight. Styli on the male subgenital plate are absent. Male cerci are short and in-curved and have an inner basal back-curved spine; from the spine to the upper cerci apex a brown chitinous ridge is present (Figs 78a, 78b).

Distribution. Bolívar (1906) wrote in the introduction of his paper that he was going to include not only specimens coming from Spanish Guinea, but also further specimens from the same geographic region (e.g. Cameroon). However, he did not mention any exact locality for Arantia manca. The specimen in the collection of MNCN, identified as Arantia manca by Bolívar, is labeled: Kamerun, L. Conradt, 1898-1899. This specimen was mentioned as holotype by Ragge (1968a), but according to the ICZN, must be considered as lectotype (Paris 1994). Known from Cameroon and recorded from Ghana by Naskrecki (2009), here newly reported from Angola and the Democratic Republic of Congo.

Arantia (Arantia) gracilicercata Heller, 2014 (Figs. 10, 79a, b)

http://lsid.speciesfile.org/urn:Isid:Orthoptera.speciesfile.org:TaxonName:464819

Heller et al. (2014). Zootaxa, 3785: 355-358.

Type locality: DEMOCRATIC REPUBLIC CONGO. Centre de Recherche en Sciences Naturelles in Irangi, ca. $100 \mathrm{~km}$ (north) west of Bukavu. Depository: MfN, Berlin. Kind of type: holotype male.

Material examined. DEMOCRATIC REPUBLIC CONGO. Centre de Recherche en Sciences Naturelles in Irangi, ca. $100 \mathrm{~km}$ (north) west of Bukavu (ô holotype) (MfN).

Tegmina width: 7-10.5; tegmina length/width: 4.0-4.2; tegmina width/pronotum length: 1.3-1.7 (Heller et al. 2014).

Characters. A gracilicercata is related to A. orthocnemis (compare Figs 9 and 10). Both species share a similar habitus and shape of the male cerci which are long and slender with an inner sclerotized ridge and an inner basal spine. However, in A. orthocnemis the male cerci are not as long and slender as in A. gracilicercata and the inner spine or process located at the inner base of the male cerci is differently shaped between both species (cf. also Heller et al. 2014) (Figs 79a, 79b).

Distribution. Known only from the type locality, Bukavu area in the border region of the Democratic Republic of the Congo with Rwanda, Central Africa.

Arantia (Arantia) hydatinoptera Karsch, 1889 (Figs. 11, 80)

http://lsid.speciesfile.org/urn:lsid:Orthoptera.speciesfile.org:TaxonName:464829

Karsch (1889). Berlin Ent. Z., 32: 433, 434, 436.

Type locality: NIGERIA. Benue. Depository: MZPW, Warsaw. Kind of type: syntypes male and female.

Material examined. EQUATORIAL GUINEA. Fernando Póo, Punta Frailes X-XI.1901, L. Fea $\left(1 \delta^{\lambda}, 1\right.$ ) $)$ (MSNG). CAMEROON. John-Albrechtshöhe III.1896, L. Conradt (1q). Lolodorf, L. Conradt (1+) (MfN). Staudinger (1 + ) (NMW).

Tegmina width: 8.9-10; tegmina length/width: 4.8; tegmina width/pronotum length: 1.4 (Heller et al. 2014).

Characters. A. hydatinoptera is of medium size (body length $\delta 30 \mathrm{~mm}$, ㅇ $35 \mathrm{~mm}$ ) (Fig. 11). Karsch (1889) 
described both sexes from Nigeria. Later, Griffini (1906) recorded it from Bioko (Fernando Póo, Equatorial Guinea). The anterior area of the pronotum is narrower than the posterior area. The tegmina are narrow with tiny small dark spots. Fore femora with 7-8 small inner ventral spines, mid femora are unarmed, hind femora with 3 inner and 4 outer small ventral spines. Male cerci are long, unarmed, apically in-curved and a little dorso-ventrally flattened, the apex is not sclerotized (Fig. 80). The ovipositor is short (4 mm) (Karsch 1889; Brunner von Wattenwyl 1891), the subgenital plate of the female is short and rounded, and has two lateral bulges at its base.

Distribution. Central and West Africa (records from Nigeria, Cameroon and Equatorial Guinea).

Arantia (Arantia) leptocnemis Karsch, 1890 (Figs. 12, 13, 81)

http://lsid.speciesfile.org/urn:Isid:Orthoptera.speciesfile.org:TaxonName:464830

Karsch (1890). Entom. Nachricht., 16 (23): 358.

Type locality: CAMEROON. Barombi Station. Depository: MfN, Berlin. Kind of type: holotype female.

Material examined. CAMEROON. Barombi Station (1 $\uparrow$ holotype). Barombi Station, Preuss $(1 \hat{)})(\mathrm{MfN})$. ANGOLA $(1 \overbrace{}^{\Uparrow})(\mathrm{MNCN})$.

Tegmina width: 7.7-9; tegmina length/width: 5.9; tegmina width/pronotum length: 1.3 (Heller et al. 2014).

Characters. A. leptocnemis is a medium sized species (body length $\widehat{\AA} 30 \mathrm{~mm}$, + $22.8 \mathrm{~mm}$ ). Karsch (1890) described the female and considered it related to A. orthocnemis. Later, Karsch (1891) described the male. Tegmina are narrow (Figs 12-13) and may have a black marking at their base. Fore femora have 4 spines, mid femora are unarmed (except for a small spine near the apex), hind femora have 5 outer and 3 inner small ventral spines. Male cerci are long, narrow and in-curved, the apex is sclerotized and rounded (Fig. 81). Styli are present. The subgenital plate of the female is short and rounded. The species is easily distinguished by its long and slender decussate male cerci.

Distribution. Central to Southwest Africa (Cameroon, Angola).

Arantia (Arantia) simplicinervis Karsch, 1889 (Figs. 14, 53, 82)

http://lsid.speciesfile.org/urn:lsid:Orthoptera.speciesfile.org:TaxonName:464833

Karsch (1889). Berlin Ent. Z., 32: 433, 434, 438.

Type locality: CAMEROON. Chinchoxo and Kuako (Kimpoko). Depository: MfN, Berlin. Kind of type: syntypes males.

Syn. Arantia (Arantia) simplicinervis curvata Griffini, 1908

Griffini (1908). Mem. Soc. entom. Belgique, Bruxelles, 15: 212.

Type locality: CAMEROON. Mukonje Farm. Depository: RBINS, Bruxelles. Kind of type: holotype female.

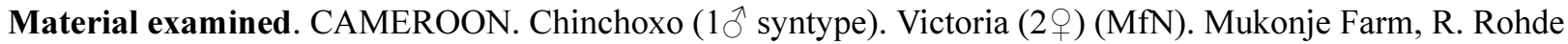
(1ㅇ holotype of ssp. curvata) (RBINS). TOGO. Bismarckburg 11-17.I.1893, L. Conradt (1 + ). ANGOLA. Dundo

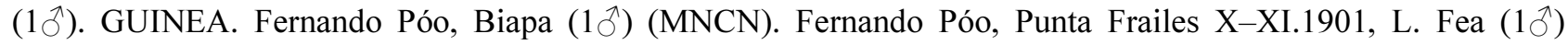

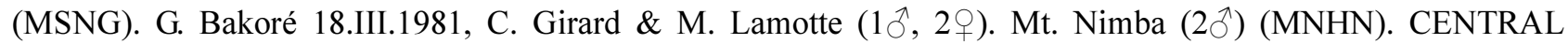
AFRICAN REPUBLIC. Dzanga-Ndoki National Park, Mboki 25.I.2012; Ndoki, Lake 1, 10-11.II.2012; 1112.II.2012; 13-14.II.2012; 22-23.II.2012; 24-25.II.2012; 28-29.II.2012 (light trap), P. Moretto (10ð) (BMCP). Dzanga-Ndoki National Park, Ndoki, Lake 1, 14.II.2012, 21-22.II.2012 (light trap) (4 ${ }^{\Uparrow}$ ) (PACT). IVORY COAST.

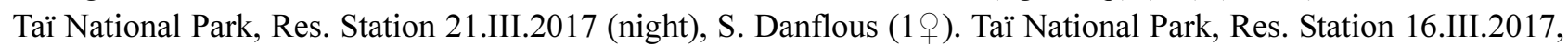
platform 40m (light trap), B. Massa (1 ${ }^{\Uparrow}$ ) (BMCP). Man, Mt. Tonkoui (1171m) 12-18.VII.2015 (light trap), M.

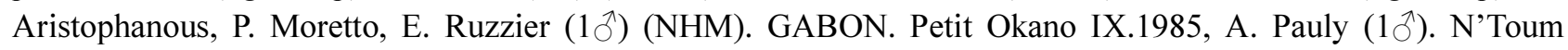
23.II.1982, 22.VII.1984, 28.VII.1984, V.1985, 18.V.1985, 15.VII.1985, 16.VIII.1985, 5.IX.1985, 9.IX.1985, 520.X.1985, 8.X.1985, A. Pauly (11ð̋,1ㅇ). M'Paga 12.IV.1986, A. Pauly (1ㅇ). Capo Santa Clara 29.IX.1985, A. Pauly (1ㅇ). ZAIRE. Bamania VII-VIII.1980, R. Kiss (1 $\left.0^{\lambda}\right)$ (RBINS). 

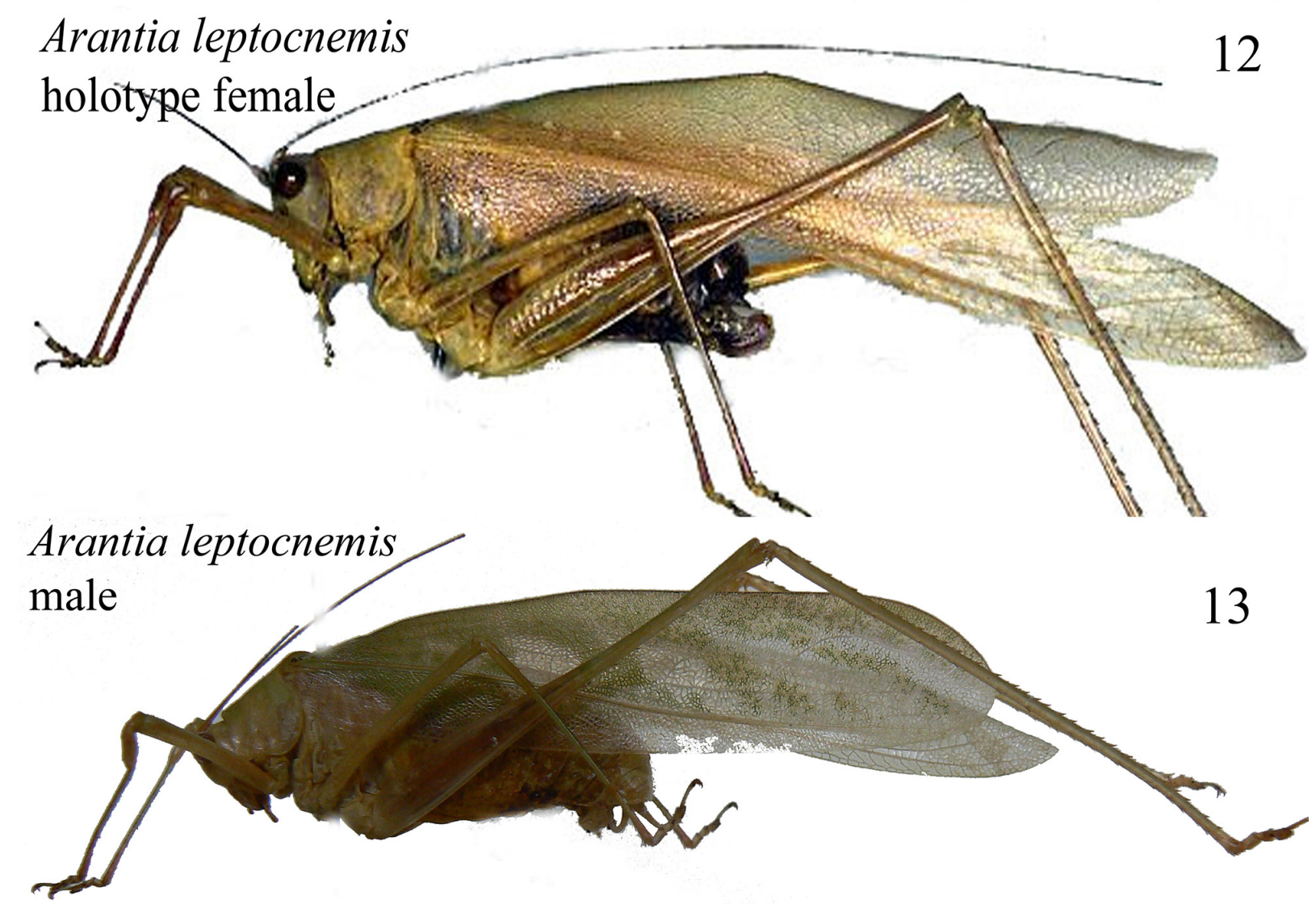

Arantia simplicinervis

14

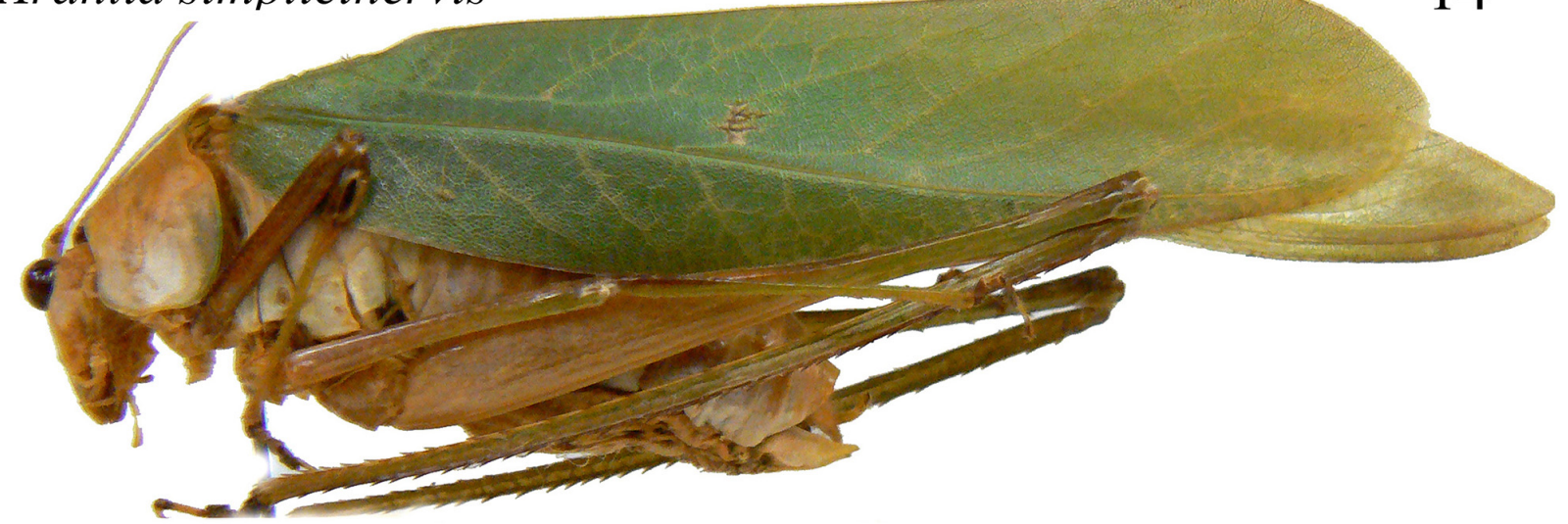

15

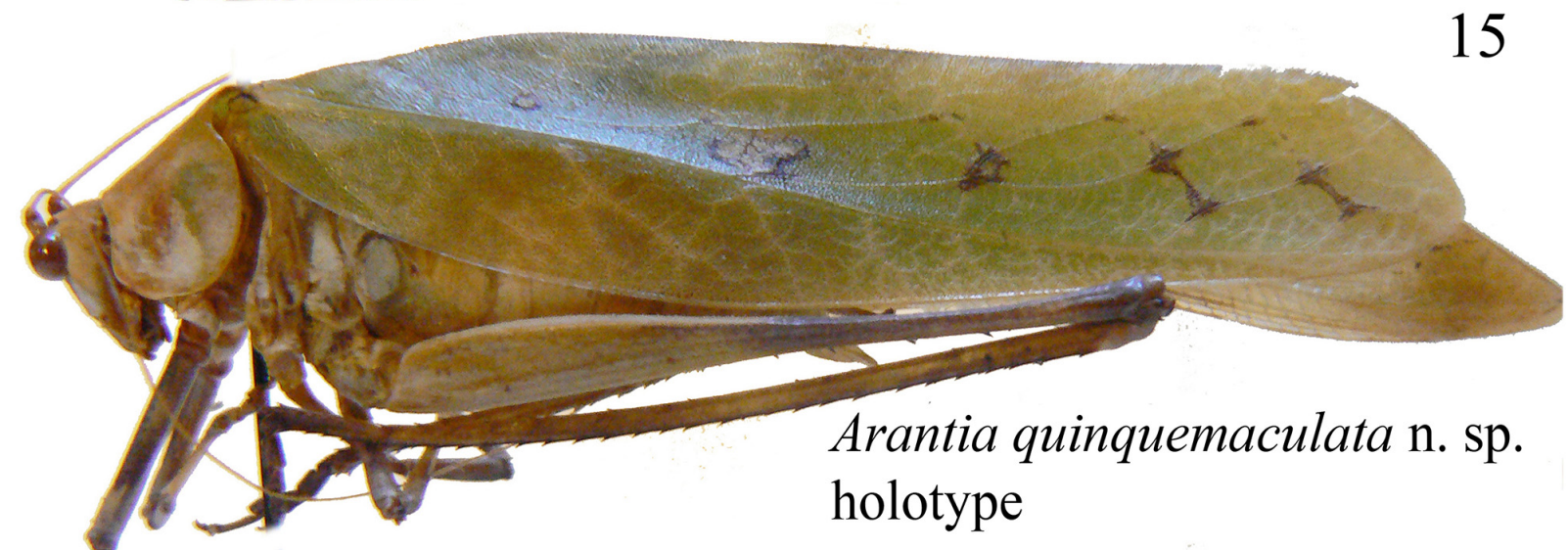

FIGURES 12-15. Habitus of Arantia (Arantia) leptocnemis (12: holotype female, 13: male), A. (Arantia) simplicinervis (14) and A. (Arantia) quinquemaculata n. sp. (holotype) (15). 
Measurements of males. Body length: $29.8 \pm 2.5$; pronotum length: $6.6 \pm 0.2$; pronotum height: $6.4 \pm 0.2$; hind femur: $28.1 \pm 1.1$; hind tibiae: $33.2 \pm 1.5$; tegmina: $44.2 \pm 1.6$; tegmina width: $9.0 \pm 0.3$; tegmina length/width: 4.9-5.0; tegmina width/pronotum length: 1.3-1.5.

Characters. A. simplicinervis is a medium-sized species (body length of $28-31 \mathrm{~mm}$, $q$ 36-39 mm). Karsch (1889) described both sexes from Chinchoxo and Kuako (Kimpoko, Cameroon). Later, Griffini (1906) recorded it from Fernando Póo (Equatorial Guinea). It is characterized by whitish-yellowish paranota and more or less rectangular tegmina with thick veinlets (Fig. 14). The metanotum is slightly dark and also the tympana of fore tibiae may be dark. The types and other specimens have two dark spots on the lateral sides of the pronotum. A small black spot is present on the base of the tegmina, more or less hidden by the pronotum. Some specimens have an additional second small black spot in that area. Fore femora are armed with 3-7 spines, mid femora have 4-7 outer spines, hind femora 4-7 inner and 0-7 outer ventral small black-tipped spines [according to Karsch (1889) outer ventral margin of hind femora is unarmed, but in some specimens spines are present]. The stridulatory file is short and consists of 48-50 teeth (Fig. 53). Male cerci are long, comparatively slender, in-curved at their tips and slightly flattened, apically with or without a black swelling and with 2 black small dents (Fig. 82) (Karsch 1889; Brunner von Wattenwyl 1891). Styli are absent. The ovipositor is shorter than the pronotum.

Remarks. Arantia simplicinervis curvata was described as a variety of A. simplicinervis by Griffini (1908) on one female from Mukonje Farm (Cameroon). According to Griffini (1908) dimensions of this taxon lie within those of A. simplicinervis (Tegmina width: 10.0; width tegmina/length pronotum: 1.5), with the exception of the larger size (39 mm), more curved apical hind tibiae, spines of hind femora green with dark apex (present also in $A$. simplicinervis), the metazona of the pronotum being brown, with a concavity at the posterior margin, and a very short ovipositor $(3.7 \mathrm{~mm})$. Sjöstedt (1912) reported it as variety of $A$. simplicinervis from Buea (Cameroon). Because of the absence of true differences, $A$. simplicinervis curvata has to be considered a synonym of $A$. simplicinervis.

Distribution. Widely distributed in West, Central and south-west Africa (records from Guinea, Togo, Ivory Coast, Cameroon, Central African Republic, Angola).

\section{Arantia (Arantia) quinquemaculata n. sp. (Figs. 15, 54, 83a, b)}

http://lsid.speciesfile.org/urn:Isid:Orthoptera.speciesfile.org:TaxonName:500641

Material examined and depository. CENTRAL AFRICAN REPUBLIC. Dzanga-Ndoki National Park, Lake 1,

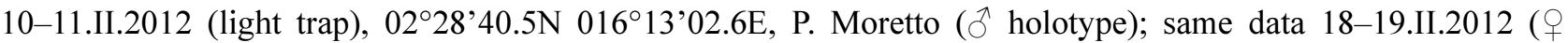

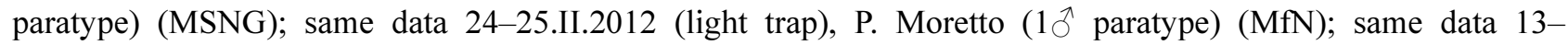
14.II.2012; 15-16.II.2012; 20-23.II.2012; 24-25.II.2012 (light trap), P. Moretto (9ð^, 19 paratypes) (BMCP). Dzanga-Ndoki National Park, Ndoki, Camp 1, 29.I.2005, 10.II.2005 (light trap), P. Annoyer (2へ̂ paratype).

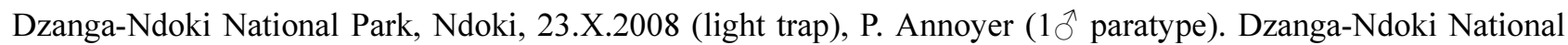
Park, Ndoki, Lake 1, 29.XI.2010 (light trap), P. Annoyer (1 ڤ̂ paratype). Dzanga-Ndoki National Park, Ndoki, Lake 1, 21-22.II.2012 (light trap), P. Annoyer (2仓 paratypes). Dzanga-Ndoki National Park, Ndoki, Lake 2, 10.II.2012 (light trap), P. Annoyer (1 $\widehat{\jmath}$ paratype) (PACT). TOGO. Fazao 4.VIII.2013 (light trap), P. Moretto (1 $\widehat{\jmath}$ paratype) (BMCP, 10 paratype in CHB). IVORY COAST. Taï Nat. Park, Res. Station 19-22.III.2017 (light trap), B. Massa (5ð paratypes). Taï National Park, Res. Station 16.III.2017, platform 40m (light trap), B. Massa (2ð paratypes). Taï Nat. Park, Res. Station 4.IV.2017 (light trap), P. Moretto (3ô paratypes) (BMCP). Taï Nat. Park, Res. Station 510.VII.2015 (light trap), M. Aristophanous, P. Moretto, E. Ruzzier (2ð paratypes) (NHM). Tabou 21.XII.1979, A.

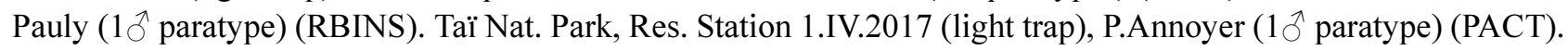
GABON. N'Toum 16.IX.1985, A. Pauly (1 ○̂ paratype) (RBINS).

Measurements. Males. Body length: $30.4 \pm 1.8$ (27.6-33.5); pronotum length: $7.2 \pm 0.4$ (6.6-7.7); pronotum height: $6.9 \pm 0.4$ (6.4-7.5); hind femur: $25.4 \pm 1.0$ (24.0-27.1); hind tibiae: $30.0 \pm 1.0$ (28.9-31.5); tegmina: $41.7 \pm 0.7$ (40.5-42.8); tegmina width: $9.5 \pm 0.2$ (9.1-9.8); width tegmina/length pronotum: $1.2-1.4$. Females. Body length: $32.7 \pm 0.2$ (32.6-32.9); pronotum length: 7.1 \pm 0.1 (7.0-7.2); pronotum height: $6.9 \pm 0.1$ (6.8-7.0); hind femur: $26.6 \pm 1.0$ (25.9-27.3); hind tibiae: $29.9 \pm 0.8$ (29.3-30.5); tegmina: 43.6; tegmina width: $10.1 \pm 0.1$ (10.1-10.2); ovipositor: $4.95 \pm 0.1$ (4.9-5.0); tegmina width/pronotum length: 1.4.

Diagnosis. A medium sized species characterized by at least 5 dull brown markings in at least 3 hexagons on the yellow-green tegmina. 
Description. Male. General habitus and colour pattern. Medium-sized with a characteristic colour pattern of 5-7 spots on the tegmina. First two antennal segments are yellow with a black spot, the remaining antennomeres are yellow. Head and legs are yellow with blackish areas (fore femora, tympana of fore tibiae, second half of mid and hind femora). Face yellow. Pronotum green, lateral lobes with a whitish area, metazona darker than prozona. Tegmina slightly oval, yellow-green with black markings at the very base, and 5-7 brown dull markings distributed along its length (Fig. 15). Head and antennae. Eyes oval, fastigium of vertex sulcate. Thorax and legs. Tympana of fore tibiae open on outer, closed on inner side. Prozona of pronotum clearly narrower than metazona. Anterior margin of pronotum slightly concave, posterior margin rounded. Lower margin of pronotal lobes without the concavity present in other species of the genus. A small black spot is present on the base of the tegmina, more or less hidden by the pronotum. Tegmina are 4.0-4.4 times longer than wide. The stridulatory area of the left tegmen is short. The stridulatory file consists of 28-30 teeth, the inner 4 more spaced than the outer ones (Fig. 54). Fore coxae unarmed. Fore femora with 5 inner ventral spines, fore tibiae with 6 inner and outer ventral spines, and 3 dorsally. Mid femora with 6-7 outer ventral spines, mid tibiae with 9-10 outer and inner ventral spines, 2-3 spines on outer and inner dorsal margins. Hind femora with 5 inner ventral black spines and $0-1$ on outer ventral margin. Hind tibiae little curved, with 17-18 spines on outer and 10-11 on inner ventral margin. Abdomen. Cerci are long and in-curved, with an apical hairy sclerotized black tip, ending with two small dents (Fig. 83a). The subgenital plate is triangular, long and narrow, the apex is concave and styli are absent (Fig. 83b).

Female. Similar to male. Ovipositor is short and gently up-curved with small teeth only at the lower apical valve. The subgenital plate is triangular with a straight apex. Cerci are in- and up-curved.

Etymology. This species is characterized by at least five (from Latin: quinque) brown markings (in latin: macula) on the tegmina; quinquemaculata is a feminine adjective.

Affinities. A. quinquemaculata is related to A. hydatinoptera and A. simplicinervis, morphologically very similar to $A$. simplicinervis. Characterized by its brown markings on tegmina and the stridulatory file. In addition, its hind femora are comparatively shorter than those of $A$. simplicinervis.

Distribution. Central African Republic, Ivory Coast, Gabon and Togo, probably also occurring in suitable habitats between these localities.

\section{Subgenus Euarantia Heller, 2014}

Arantia (Euarantia) fasciata (Walker, 1869) (Figs. 16, 17, 18, 55, 56, 85a, b)

http://lsid.speciesfile.org/urn:lsid:Orthoptera.speciesfile.org:TaxonName:464789

Walker (1869). Catalogue of the Specimens of Dermaptera Saltatoria in the Collection of the British Museum, 2: 378.

Type locality: GAMBIA. Depository: BMNH, London. Kind of type: holotype female.

Syn. Arantia (Euarantia) atrolineata Brunner von Wattenwyl, 1891

Brunner von Wattenwyl (1891). Verh. der Zoologisch-Botanischen Gesellsch, Wien 41: 63, 69.

Type locality: WEST TROPICAL AFRICA. "Slave Coast". Depository: ETHZ, Zurich. Kind of type: holotype female.

Syn. Arantia (Euarantia) spinulosa Brunner von Wattenwyl, 1878

Brunner von Wattenwyl (1878). Monographie der Phaneropteriden 137.

Type locality: SOUTH AFRICA. KwaZulu-Natal, Durban. Depository: NMW, Vienna. Kind of type: holotype female.

Material examined. GAMBIA. ( + holotype). GUINEA. Beyla, BM1967-33 (NHM). TANZANIA. Mt Kilimanjaro, Plantation belt 1430 m, Kidia XI.1997, I.1998, XII.2000, III.2008, IX.2013; plantation belt 1330 m, III.2007, IX.2010, I.2014, cultivated Savanna 890 m, VI.2013 (CHB). E. Usambara Mountains, Amani, 1000 m, I.1976 (ZMUC). E. Usambara, Amani 17-20.VI.1998, L. Bartolozzi \& A. Sforzi (1 $\overbrace{}^{\Uparrow})$ (MZUF). SOUTH AFRICA

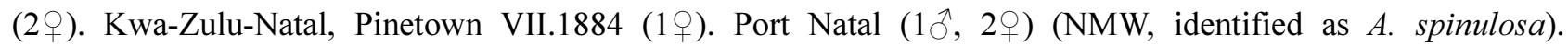
ZIMBABWE. Salisbury, VIII.1815 (1 ). MALAWI. Blantyre, Nyasaland 1922 (1 $\delta^{\Uparrow}$ ) (ISAM, identified as $A$. spinulosa). ? Cap Drenge (1ㅇ) (MfN). IVORY COAST. Lamto $13 . I I .1969$ (light) (1ठ) (MNHN). SOMALIA. Giohar 10-13.IX.1968 (1§). Afgoi II-III.1978, A. Simonetta (1 †). KENYA. Masai Mara National Park (1600m) 11.VI.1994, L. Bartolozzi (1 $\overbrace{}^{\Uparrow}$ ). Malindi 10.XI-6.XII.1989 (1 1 ) (MZUF). DEMOCRATIC REPUBLIC CONGO. Lusingan18.VII-8.VIII.1947 (1 +). Kilwezi, Lufira 16-21.VIII.1948 (1 +). Katanga (1 9 ) (RBINS).

Measurements of South African specimens. Males ( $\mathrm{N}=6$ ). Body length: 29.0-32.8 (mean: 30.5); pronotum length: 7.0-7.8 (mean: 7.4); pronotum height: 8.3-9.9 (mean: 9.2); hind femur: 32.7-37.8 (mean: 34.8); tegmina 
length: 54.9-63.3 (mean: 57.6); tegmina width: 15.0-17.1 (mean: 16.1); length/tegmina width: 3.58; width tegmina/length pronotum: 2.18 .

Measurements of female holotype. Body length: 34; pronotum length: 8.5 ; pronotum height: 9.1 ; hind femur: 35.2; hind tibiae: 41.1; tegmina: 63.2; tegmina width: 19.4; tegmina length/width: 3.26 ; tegmina width/pronotum length: 2.28; ovipositor: 5.5 .
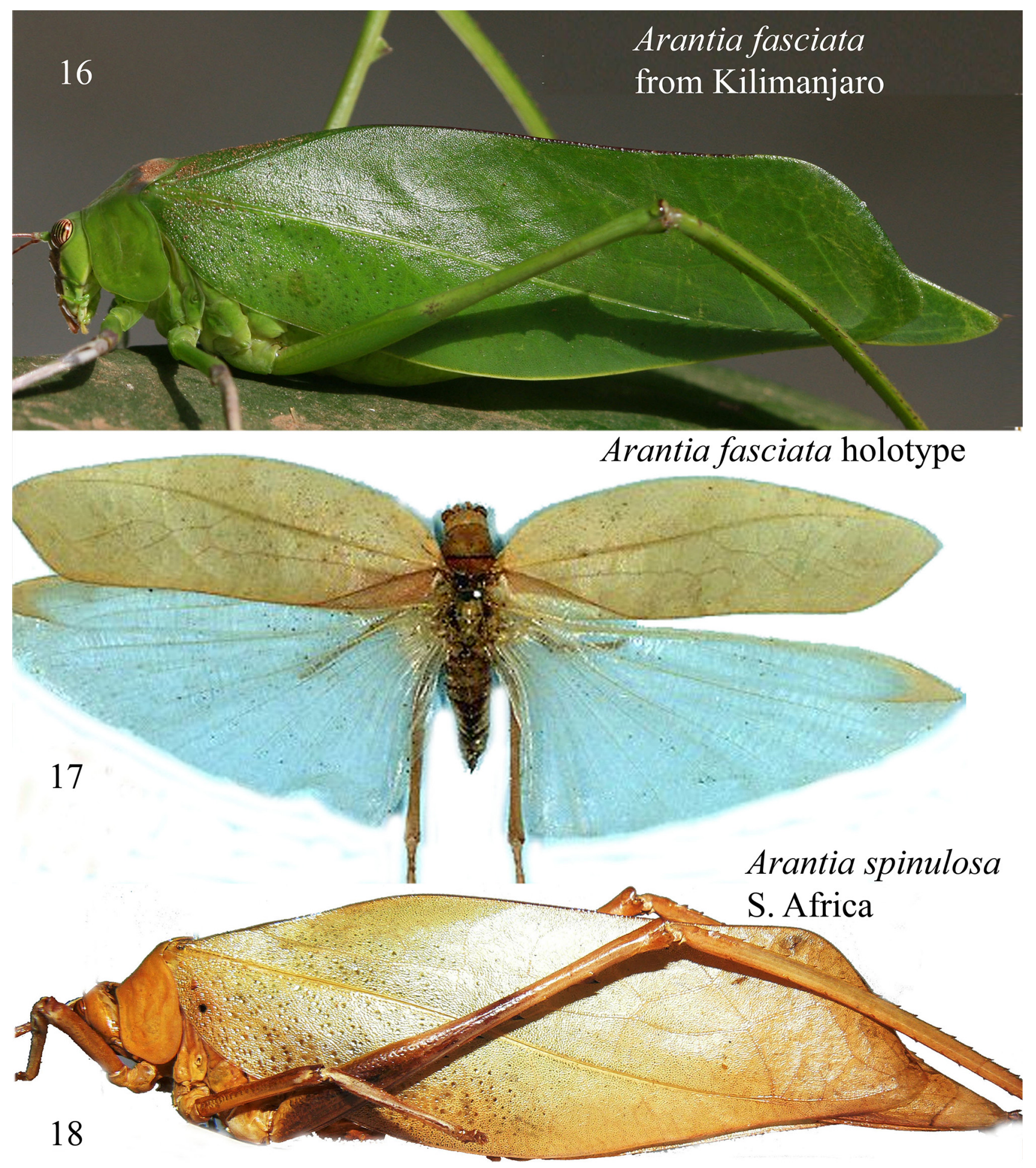

FIGURES 16-18. Arantia (Euarantia) fasciata from Kilimanjaro (16), A. (Euarantia) fasciata (holotype) (17) and A. (Euarantia) spinulosa from South Africa (18). 
Measurements of East African specimens (Tanzania). Males ( $\mathrm{N}=6)$. Body length: 29.2-32.7 (mean: 30.5); pronotum length: 7.5-8.2 (mean: 7.85); pronotum height: 8.5-9.4 (mean: 8.8); hind femur: 32.1-33.7 (mean: 33.23); tegmina length: 55.0-58.7 (mean: 56.38); tegmina width: 14.0-16.5 (mean: 15.3); length/tegmina width: 3.7; width tegmina/length pronotum: 2.0. Females $(\mathrm{N}=6)$. Body length: 31.6-39.7 (mean: 35.72); pronotum length: 8.1-9.3 (mean: 8.48); pronotum height: 9.5-10.6 (mean: 10); hind femur: 35.9-40 (mean: 37.4); tegmina length: 62-70 (mean: 65) tegmina width: 17.5-21.2 (mean: 19.1); ovipositor: 5.4-6.6 (mean: 6.1); tegmina length/width: 3.4; tegmina width/pronotum length: 2.25 .

Characters. A. fasciata is a species of large size (Figs 16-18). Only the female is described at present. It is characterized by closed tympana on both sides of the fore tibiae. Part of the face is white, often lateral brownreddish stripes are present. Very characteristic is a broad fascia transverse on the metazona of the pronotum being dark anteriorly and white posteriorly. The tegmina are wide with clear impressed dots in the costal area. The anterior margin of the pronotum is nearly straight, the posterior margin broadly rounded. The female ovipositor has numerous small tubercles especially on the posterior end of the valves and is covered densely with short hairs. Kirby (1906) synonymized A. atrolineata with A. fasciata and Hemp (2013a) synonymized A. spinulosa with $A$. fasciata.

Description of the male (based on East African specimens). General habitus and colour pattern. Large species with broad wings, predominantly green with a white and dark stripe on the posterior part of the pronotum. Head and antennae. Eyes oval, striped. Antennae long and thin, about 6-7 cm long. Fastigium of vertex forming a ridge with shallow sulcus above with rounded margin between antennae. Fastigium of frons conical; both fastigia separated by deep gap. Thorax and legs. Anterior margin of pronotum almost straight. Disc of pronotum almost plane with shallowly impressed sulcus on metazona. Posterior margin of pronotum slightly down-curved, broadly rounded. Broad based, short, blunt knob (reduced spine?) on fore coxa. Tympana of fore tibiae on both sides closed or closed on outer side and on inner side triangular shaped or longish oval. Fore femur unarmed or with few tiny, sometimes black tipped spines. Mid femora unarmed. Hind femora with two rows of small evenly spaced spines, black tipped with broad base. Distally 1-2 spines can be larger to very large in some specimens with flange-like bases. All femora with two pairs of spurs at apex. Fore and mid tibiae with two ventral rows of few small spines, a pair of spurs at the apex. Hind tibiae with four rows of spines, dorsal rows of spines very dense, especially distally; three spurs at each side at apex. The stridulatory file is curved and consists of ca. 100 evenly spaced teeth (Figs 5556). Abdomen. Cerci slightly curved, decussate, long with a stouter base and more slender anterior part, tips clubshaped with a serrated sclerotized ridge (Figs 85a, 85b). Subgenital plate longer than wide, with median ridge and tiny styli.

Diagnosis. General habitus and colour pattern as in female A. fasciata, but with a smaller body size. Specimens collected in East Africa and seen in various collections differ considerably in body size. Most specimens have dark green tegmina without any pattern. However, in savanna habitats on the southern slopes of Mt. Kilimanjaro few specimens were collected with a large body size and with a vivid pattern of brown patches and fasciae on the tegmina which looked very different from the other uniformly coloured specimens. Comparing the genitalia and the stridulatory files showed that also these specimens belonged to A. fasciata. A similar situation seems to be the case in A. regina (see below) where specimens also vary considerably in body size.

Distribution. Widespread in Africa, from Somalia to South Africa and Gambia further west.

Notes on habitat and ecology. Information on habitat and ecology are available only for East African populations (see Hemp 2005; 2013a, b). A. fasciata is a night-active canopy dweller. Its song of a few loud syllables can be heard from the canopy of trees during evening hours. In East Africa it is found in savanna habitats but is also common in submontane elevations on mountains. It also occurs in anthropogenic-influenced habitats such as banana-coffee plantations and here inhabits single high trees. Nymphs are often found on broad-leaved bushes and trees of medium height. A. fasciata is fully alate often covering great distances when disturbed. However, the species seems to rely greatly on its camouflage only moving when being shaken directly from the branches.

Remarks. A. fasciata is distributed over a large area of Africa south of the Sahara. Specimens studied from West, East and South Africa show a certain degree of morphological variation suggesting that at least different populations are present. Thus there are differences in the shape of the fastigium verticis, the shape of the tympana on the fore legs (West African species with completely closed tympana on both sides while in specimens from East Africa the inner side is more open, being tri-angular shaped and more open on the posterior side). Also the shape of 
the subgenital plate varies slightly. Further in West African species the face is smoother with parallel furrows below the eyes running to the labrum, while in East African specimens the facial area below the eyes is strongly wrinkled. However, the morphological variation is so gradual that no clear differences can be put down to define species. Unfortunately no male specimens from West Africa are stored in any museum we have visited and since females are generally morphologically very similar in Arantia ssp. it cannot be excluded that West and Central African populations differ from East and South African populations on species level. More collecting hopefully will eventually clarify the status of the Arantia fasciata species-complex and molecular analyses and studies on song should be undertaken to illuminate speciation patterns.

\section{Arantia (Euarantia) ugandana Rehn, 1914}

http://lsid.speciesfile.org/urn:Isid:Orthoptera.speciesfile.org:TaxonName:464818

Rehn (1914). Wiss. Ergebn. dtsch. Zent. Afr. Exped. 1907-1908, 5: 176.

Type locality: UGANDA. Depository: according to OSF it should be preserved at Senckenberg German Entomological Institute, Müncheberg, but it is not present in their catalogues (M. Ohl, pers. comm.). Kind of type: holotype female.

Tegmina width: 14; tegmina width/pronotum length: 2.3 (Heller et al. 2014).

It is a small sized species (body length $\circ 26.5 \mathrm{~mm}$, tegmina $67.5 \mathrm{~mm}$ ). Rehn (1914) described only the female from Uganda.

Characters. According to Rehn (1914) it is related to A. spinulosa, lacking one of the outer spines ventrally on the hind femora. It is clearly smaller in size, the margin of the tegmina lacks any concavity, lateral lobes of pronotum are a bit concave, lower margin sinuous.

Remarks. As mentioned in the introduction, the status of $A$. ugandana is unclear since the holotype is missing. Specimens identified as A. ugandana in the Natural History Museum, London, belong to the $A$. fasciata complex. Therefore we here synonymize $A$. ugandana with $A$. fasciata.

Arantia (Euarantia) rectifolia Brunner von Wattenwyl, 1878 (Figs. 19, 21, 22, 57, 88a, b)

http://lsid.speciesfile.org/urn:lsid:Orthoptera.speciesfile.org:TaxonName:464806

Brunner von Wattenwyl (1878). Monographie der Phaneropteriden, 137.

Type locality: EQUATORIAL GUINEA. Fernando Póo. Depository: NMW, Vienna. Kind of type: holotype male.

Syn. Arantia (Euarantia) accrana Karsch, 1889

Karsch, 1889. Berlin Ent. Z., 32: 433, 436.

Type locality: GHANA. Accra. Depository: MfN, Berlin. Kind of type: holotype female.

Material examined. EQUATORIAL GUINEA. Fernando Póo ( $\delta$ holotype) (NMW). TOGO. Kpalimé, Ft of Missahohe 29-30.VII.2013 (light trap), P. Moretto (1ð). Fazao 3-4.VIII.2013 (light trap), P. Moretto (3ð). BURKINA FASO. Pama VIII.2005, P. Moretto (3 ${ }^{\lambda}$ ). IVORY COAST. Boudoukou Zamou VII.2004, P. Moretto $\left(3 \delta^{\lambda}\right.$ ). Cornal VIII.1998, P. Moretto (1 $\left.\delta^{\lambda}\right)$. Khorogo, Koko village 20.VII.2013, P. Moretto (3ð). Man, Mt. Tonkoui (1200m) 14-15.VII.2014 (light trap), P. Moretto (3ð); same locality 28.VI-1.VII.2014 (light trap), P. Moretto (3 ${ }^{\lambda}$, 1 ) ); same locality 13-15.VII.2014 (light trap), P. Moretto (1§); 18-20.VI.2015 (light trap), F. Moretto (2§); same locality 24-28.VII.2015 (light trap), P. Moretto (1今); same locality 4.VI.2016 (light trap), P. Moretto (1ठ). Khorogo, Koko (347m) 31.VII.2014, dry forest (light trap), P. Moretto $\left(3{ }^{\Uparrow}\right)$. Comoe, Kolomabira (347m) 20.VII.2013, P. Moretto (1§). Comoe, Kolomabira (228m) 8.VI.2015 (light trap), P. Moretto (2ð); same locality

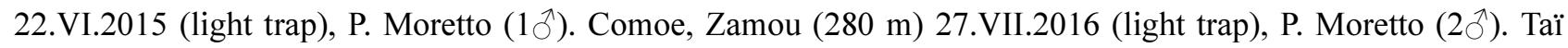
Nat. Park, Res. Station 18-21.III.2017 (light trap), B. Massa (11 đ). Taï National Park, Res. Station 16.III.2017, platform 40m (light trap), B. Massa (1 $\overbrace{}^{\Uparrow})$. Taï Nat. Park, Res. Station 2-4.IV.2017 (light trap), P. Moretto (5 $\overbrace{}^{\lambda}, 2$ ) (BMCP). Taï Nat. Park, Res. Station 25.III.2017 (light trap at platform 40m), P. Annoyer (1ठ) (PACT). Taï Nat. Park, Res. Station 5-10.VII.2015 (light trap), M. Aristophanous, P. Moretto, E. Ruzzier (1 $\left.{ }^{\Uparrow}\right)$ (NHM). CENTRAL AFRICAN REPUBLIC. Dzanga-Ndoki National Park, Lac 2, 25.I.2012, 10-11.II.2012, 15-16.II.2012, 28- 
29.II.2012, 24-25.II.2012 (6ð) (BMCP). Kaniana 15.II.1939, H.J. Brédo (1ð) Elisabethville (=Lubumbashi) 25.IV.1939, H.J. Brédo (1§ึ). GABON. N'Toum II.1983, 2.VII.1984, IV.1985, 15.VII.1985, 29.VII.1985, 15.VIII.1985, 15.IX.1985, 30.IX.1986, A. Pauly (7ðे, 1ㅇ). DEMOCRATIC REPUBLIK CONGO. 23-27.II.1948, G.F. de Witte (1へ). Kaziba. N Kivu, Rwankwi 31.V.1961, Y.V. Leroy (1へ). CAMEROON. Akono I-II.1969 (1ð) (RBINS). KENYA Kakamega Forest Reserve, Buyango Hill 27.IX.2005, Holstein \& Bartsch (1 $\left.{ }^{\Im}\right)$ (CHB).

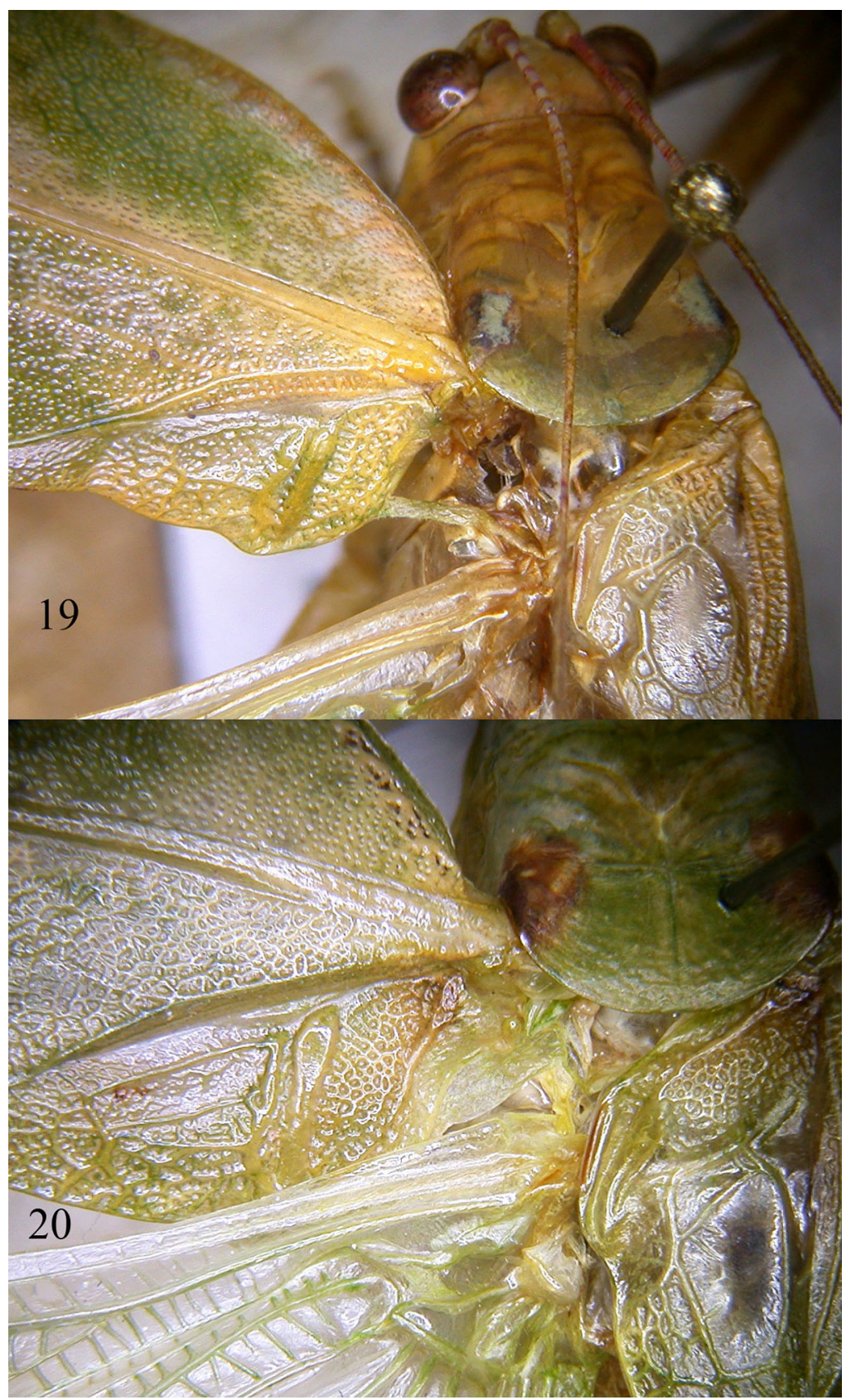

FIGURES 19-20. Dorsal view of stridulatory area of Arantia (Euarantia) rectifolia (19) and A. (Euarantia) tanzanica $\mathbf{n} . \mathbf{s p .}$ (holotype) (20).

Further material examined. A. accrana: GHANA. Accra, Ungar ( $\odot$ holotype). TOGO. Misahöhe 515.IV.1894, Baumann (2ð) (MfN).

Measurements. Males. Body length: 26.8-30.0 (mean: 27.0); pronotum length: 5.9-6.5 (mean: 6.2); pronotum height: 6.7-7.1 (mean: 6.9); hind femur: 25.5-28.5 (mean: 27.0); hind tibia: 27.1-30.1 (mean: 28.5); tegmina length: 45.0-49.0 (mean: 47.5); tegmina width: 12.0-13.8 (mean: 12.8); length/tegmina width: 3.5-3.7; width tegmina/length pronotum: $2.0-2.1$.

Measurements of the female holotype $\boldsymbol{A}$. accrana. Body length: $24 \mathrm{~mm}$; pronotum length: $7 \mathrm{~mm}$; tegmina: $53 \mathrm{~mm}$; tegmina width: 12.8; hind femur length: $28 \mathrm{~mm}$; ovipositor: $5 \mathrm{~mm}$ (Karsch 1889). 
Characters. A. rectifolia is a species of medium size [body length $026-30 \mathrm{~mm}$; $927-32 \mathrm{~mm}$; the size of the q $(47 \mathrm{~mm})$ reported by Griffini (1908) is uncertain, because doubtfully identified]. Brunner von Wattenwyl (1878) described the male and considered it similar to A. fatidica. Later, both sexes were recorded by Karsch (1889), Brunner von Wattenwyl (1891) and Bruner (1920) from Lolodorf (Cameroon) and the Democratic Republic Congo. Ragge \& Roy (1965) reported the species from Senegal, Ragge (1968b) from the Ivory Coast, and doubtfully Griffini (1908) from Mukonje Farm (Cameroon). Ebner (1943) recorded it again from Fernando Póo (Equatorial Guinea). The width of tegmina of the holotype is $12.8 \mathrm{~mm}$, intermediate between Arantia and Euarantia, in other specimens examined it ranged between 12.0 to $13.8 \mathrm{~mm}$. Hind tibiae are not as curved as it was given by Heller et al. (2014) for Euarantia.

Typical is an ivory-coloured coating mixed with some dark traces on the fore tibiae in the area of the tympana. The dorsal sides of the tympana are conchate while the ventral sides are oval and open. The tegmina are not very broad, with sometimes only faintly visible 4-5 ivory (in living specimens) or more tawny to orange spots (in preserved specimens, see Figs 19, 21, 22). The stridulatory file is short, curved and consists of 80-85 teeth (Fig. 57). The fore femora are unarmed or armed with 1-2 small spines ventrally. The hind femora are armed with 3-5 inner and 4-7 outer ventral black-tipped or black small spines. Male cerci are long and slightly sinuous and have a black, chitinous and rounded apex (Figs 88a, 88b). Subgenital plate with tiny styli, in many specimens absent.

Only the female of A. accrana was described by Karsch (1889) although 2 males are also present in the Berlin collection which Karsch himself identified as belonging to A. accrana in 1894 (examined; see Fig. 22). The comparison of material of the male holotype of $A$. rectifolia with the male identified by Karsch as $A$. accrana showed no differences between the two taxa. Also the female holotype of $A$. accrana was compared with females caught together with male $A$. rectifolia. No differences in size and shape of the ovipositor and subgenital plate could be detected. Brunner von Wattenwyl (1891) separated the taxa on base of the ventral spination of the fore femora (absent in accrana, present in rectifolia) and the presence of ivory spots on the anterior margin of the tegmina. The ivory spots are expressed mostly in males and also the spination varies between specimens checked from being tiny to absent. At that time only the female of $A$. accrana was described and stored in Berlin and the key of Brunner of Wattenwyl was based on Karsch's description. For these reasons here A. accrana is considered synonymous with $A$. rectifolia.

Remarks. A. rectifolia shows some variation in the morphology of the stridulatory area. Probably A. rectifolia is a complex of closely related species. Only studies on songs and molecular analysis will help to clarify the status of this taxon.

Distribution. Probably widely distributed throughout West and Central Africa (records from Cameroon, Equatorial Guinea, Central African Republic, Democratic Republic Congo, Senegal, Togo, Burkina Faso, Ivory Coast).

Arantia (Euarantia) tanzanica n. sp. (Figs. 20, 58, 85b)

http://lsid.speciesfile.org/urn:Isid:Orthoptera.speciesfile.org:TaxonName:500642

Material examined and depository. TANZANIA. Tabora, Puge Simbo Forest Reserve, submontane forest, February 2016 ( $\delta$ holotype) (MfN). Central Tanzania, East Chenene Forest Reserve, $80 \mathrm{~km}$ north of Dodoma, Miombo woodlands, March 2015 ( 0 paratype) (CHB).

Measurements. Male $(\mathrm{N}=2)$. Body length: 28.1-32.0; pronotum length: 7.2-7.3; pronotum height: 7.2-7.3; hind femur: 28.2; hind tibia: 28.4-31.2; tegmina length: 53.5-53.6; tegmina width: 13.5-13.6; length/tegmina width: 4.0; width tegmina/length pronotum: 1.9.

Diagnosis. A. tanzanica $\mathbf{n}$. sp. is larger than A. rectifolia, has broader wings, and a different stridulatory area on the left tegmen (compare Figs 19 and 20). The stridulatory file is much longer in A. tanzanica $\mathbf{n}$. sp. consisting of 90-110 teeth, being large in the middle and more widely spaced and smaller and more densely set at both sides while $A$. rectifolia has a comparatively short stridulatory file with more regular densely set $80-85$ small teeth (compare Figs 57 and 58). The fastigium verticis also differs between both species: A. rectifolia has a fastigium that is narrow triangular with a deep sulcus while in A. tanzanica $\mathbf{n}$. sp. the fastigium verticis has posteriorly a broad base then narrowing suddenly midway and is more shallowly sulcate. Also the spination of the legs is different between both species. Otherwise both species are morphologically very similar. 

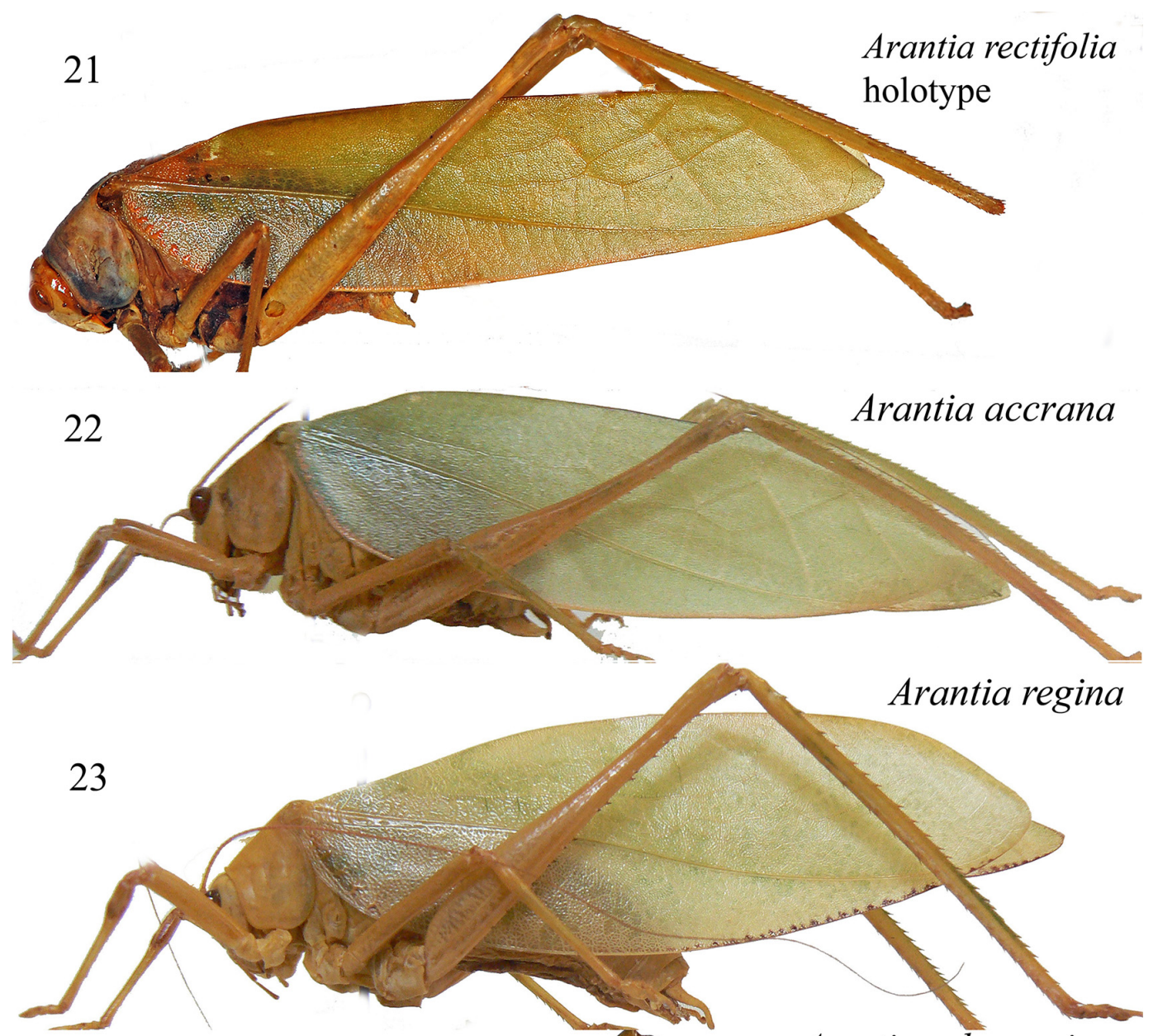

Arantia gabunensis

holotype
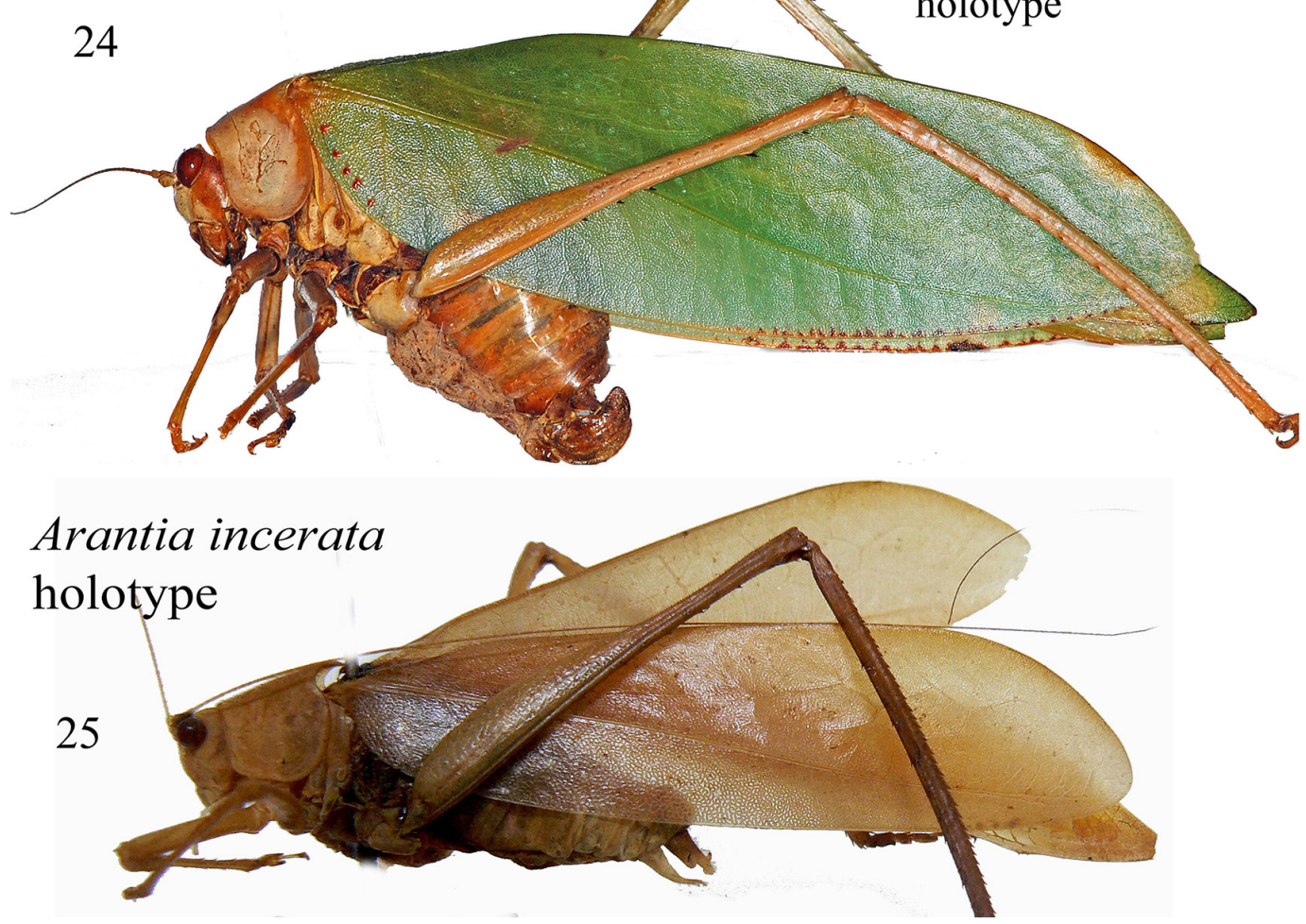

FIGURES 21-25. Habitus of Arantia (Euarantia) rectifolia (holotype) (21), A. (Euarantia) accrana (= A. rectifolia) (22), A. (Euarantia) regina (23), A. (Euarantia) gabunensis (holotype) (= A. regina) (24), and A. (Euarantia) incerata (holotype) (25). 
Description. Male. General habitus and colour pattern. Large to medium sized species with broad wings, predominantly green with pair of dark patches lateral on posterior part of pronotum. Head and antennae. Eyes oval-roundish, dark. Antennae long and thin, tawny. Fastigium of vertex forming a ridge with a broad base suddenly narrowing anteriorly; sulcate; fastigium of frons conical; both fastigia separated by deep gap. Thorax and legs. Fore coxa without spine. Tympana of fore tibiae open on inner side, conchate on outer side, whole area slightly inflated. Fore femora on inner side with two ventral black spines, mid femora unarmed, hind femora with 4 inner and 8 outer black-tipped spines. Fore tibiae with 1 dorsal spine on apical part of inflated part anterior of tympana and 2 spinules more proximally. 2 pair of spurs; ventrally with double row of irregular set of $1-4$ blacktipped spines. Mid tibiae with ventral row of 7-8 irregular set pairs of spines and 2 pairs of spurs. Hind tibiae tetragonal with 4 rows of numerous and irregularly set spines; dorsal 1 pair of spurs, ventral 2 pairs. Anterior margin of pronotum broadly rounded. Disc of pronotum slightly depressed on posterior part. Posterior margin of pronotum slightly incurved. Tegmina broad with evenly rounded posterior margin. At costal area pattern of ivorycoloured net of veins on dark ground. Stridulatory file on underside of left tegmen long, sinuous (Fig. 58); teeth in the middle larger and more widely spaced than at both ends. Abdomen. Cerci long and slender with club, sinuous at apical part and decussate. Club hairy with inner part black. Subgenital plate longer than wide and tiny dot-like styli.

Female. Similar to male but a bit larger. Only obtained specimen could not be preserved.

Etymology. After the country of Tanzania.

Habitat and song. Canopy dweller of Miombo woodlands in Tanzania. Its song is similar to A. fasciata, consisting of single chirps produced during night hours from the forest canopy.

Distribution. At present only known from the East Chenene Forest ( $80 \mathrm{~km}$ north of Dodoma) and Puge Simbo Forest (Tabora) Reserves of Central Tanzania. Probably more widespread in suitable habitats (Miombo woodlands).

Arantia (Euarantia) regina Karsch, 1889 (Figs. 23, 24, 59, 86, 87)

http://lsid.speciesfile.org/urn:lsid:Orthoptera.speciesfile.org:TaxonName:464837

Karsch (1889). Berlin Ent. Z., 32: 433, 434.

Type locality: GABON. Sibange Farm. Depository: MfN, Berlin. Kind of type: holotype female.

Syn. Arantia (Euarantia) gabunensis Brunner von Wattenwyl, 1891

Brunner von Wattenwyl (1891). Verh. der Zoologisch-Botanischen Gesellsch. Wien, 41: 64.

Type locality: GABON. Depository: NMW, Vienna. Kind of type: holotype female.

Material examined. GABON. Sibange Farm 15.IX-20.X.1884, D.R. Büttner ( $q$ holotype of $A$. regina). + , holotype of $A^{3}$. gabunensis (coll. Brunner, NMW). Boué V.2001, P. Moretto (1§). N'Toum 28.XI.1984, 7.VI.1985,

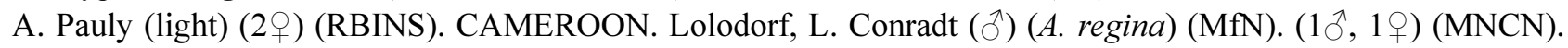

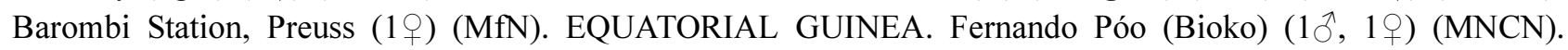
Mukonje Farm, R. Rohde (1 9 ) (RBINS). TOGO. Misahöhe X.1894, Baumann (1 $\left.{ }^{\Uparrow}\right)$. BURKINA FASO. Folonzo XII.2012, G. Boano \& M. Pavia (2 9 ). IVORY COAST. Man, Mt. Tonkoui (1200m) 1-4.VII.2014 (light trap), P. Moretto (1へ); same locality 24-27.XI.2014 (light trap), P. Moretto (2ð); same locality 18-20.VI.2015 (light trap), P. Moretto $(4 \hat{\jmath}, 3 \uparrow)$; same locality 4.VI.2016 (light trap), P. Moretto $(1 \hat{\jmath}, 1$ + $)$. Khorogo, Koko $(347 \mathrm{~m})$ 21.VII.2013 (light trap), P. Moretto (4^). Comoe, Zamou 30.IV.2016 (light trap), P. Moretto (1 9 ). Taï Nat. Park, Res. Station 13-22.III.2017 (light trap), B. Massa $(5 \hat{\jmath}, 1$ ) $)$. Taï National Park, Res. Station 16.III.2017, platform 40m (light trap), B. Massa (1 $\left.\delta^{\Uparrow}\right)$. Taï Nat. Park, Res. Station VII-X.2016 (light trap), P. Moretto (7 $\delta^{\text {) }}$. Taï Nat. Park, Res. Station 4.IV.2017 (light trap), P. Moretto $(6 \hat{\jmath}, 3$ ) ; CENTRAL AFRICAN REPUBLIC. Dzanga-Ndoki National Park, 11-12.II.2012, 13-14.II.2012, 20-23.II.2012, 24-25.II.2012; border of Lac 1, 13-14.II.2012. Lac 3, 18-19.II.2012; Lac 2, 15-16.II.2012, platform on the canopy 10-11.II.2012. Mboki 14.I.2012 (light trap), P. Moretto $(9 \AA, 4$ ) (BMCP). DEMOCRATIC REPUBLIC CONGO. Hombo 22.XII.1970 (2ð), 31.XII.1970 (1ð). Motel de Bahraka 20.X.63, T. De Stefani (1 9 ) (MRT).

Measurements. Males. Body length: 29.9 \pm 2.8 ; pronotum length: 7.0 \pm 0.6 ; pronotum height: $7.5 \pm 0.8$; hind

3. This specimen has two labels, in one is written "Gaboun" (= Gabon), in the other "Liberia, ex Mus. Lubeck"; and because it agrees perfectly with the description of Brunner von Wattenwyl (1891) we consider the locality as Gabon. 
femur: 27.3 \pm 2.4 ; hind tibiae: $30.9 \pm 3.1$; tegmina: $49.5 \pm 4.1$. Females. Body length: $32.2 \pm 1.0$; pronotum length: $7.0 \pm 0.2$; pronotum height: $7.4 \pm 0.2$; hind femur: $27.9 \pm 0.8$; hind tibiae: $32.6 \pm 1.0$; tegmina: $49.4 \pm 1.6$; ovipositor: 5.2 \pm 0.5 ; tegmina width: $15-19.6$; tegmina width/pronotum length: $2.0-2.8$.

Characters. A. regina ( $939 \mathrm{~mm}$ ) (Fig. 23) was described on the female only (Karsch 1889). Giglio Tos (1907) recorded another female of this species from Boko (Democratic Republic Congo). It was described as having broad tegmina with a conspicuous blackish area at the anterior margin of the costal area of the tegmina. In addition the tegmina have 5 small yellowish spots near the base. The veinlets of the tegmina form a clear network of brown veins on green ground. Fore femora have 4 inner ventral spines, mid femora $0-1$ outer ventral spine and hind femora 9 outer and 8 inner ventral spines. Male cerci are sinuous and end with an apical sclerotized bulge. Styli are absent. Brunner von Wattenwyl (1891) stated that $A$. regina agrees fully in habitus and dimensions with $A$. gabunensis but the latter differs from $A$. regina in having spines on the fore femora and lacking ivory spots at the anterior margin of the tegmina (however, the holotype has ivory spots on tegmina!). One male, identified as $A$. regina by Karsch (MfN) lies well within the variability of $A$. gabunensis, where styli are very small and sometimes invisible. Even though more material should be examined, $A$. gabunensis is here considered synonymous with $A$. regina.

Remarks. Brunner von Wattenwyl (1891) described only the female of A. gabunensis (Fig. 24). It is also a species of medium-large size [body length $q 34 \mathrm{~mm}$; one $q$ of $44 \mathrm{~mm}$, doubtfully identified, has been cited by Karsch (1891) from Barombi Station, Cameroon]. The anterior margin of the pronotum is straight and two dark spots are present on the lateral keels of the pronotum; a black spot may be present at the base of the tegmina, and some yellow spots are present on anterior margin of the tegmina basally. Radius veinlets are straight. The stridulatory file is short and straight and consists of ca. 40 teeth (Fig. 59). Fore femora are armed with 2 small spines, mid femora unarmed, hind femora have 5 inner black spines ventrally (cf. also Brunner von Wattenwyl 1878). Cerci are sinuous and apically enlarged (Figs 86, 87). Styli are absent.

This taxon is by far one of the most widespread Arantia species in central-western Africa and shows a high variability of characters (in size, spination of legs, etc).

Distribution. Probably widely distributed throughout West and Central Africa (records from Gabon, Cameroon, Equatorial Guinea, Central African Republic, Democratic Republic Congo, Togo, Burkina Faso, Ivory Coast).

Arantia (Euarantia) incerata Karsch, 1893 (Figs. 25, 89a, b)

http://lsid.speciesfile.org/urn:lsid:Orthoptera.speciesfile.org:TaxonName:464793

Karsch (1893). Berlin Ent. Z., 38: 128.

Type locality: SIERRA LEONE. Depository: MfN, Berlin. Kind of type: holotype male.

Material examined. SIERRA LEONE. $\delta$ holotype, $2 \AA$. CAMEROON. Barombi Station $(1 \delta)$. Mukonje

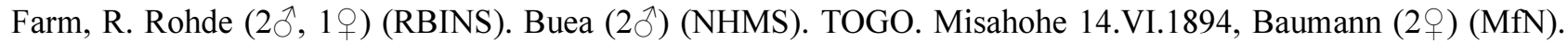
DEMOCRATIC REPUBLIC CONGO. Kinshasa 18-24.XII.1971, M. Spadone (1ð) (MZUF).

Tegmina width: 9.7-14; tegmina length/width: 3.2-4.1; tegmina width/pronotum length: 1.9 (Heller et al. 2014).

Characters. Species of medium size (body length $\widehat{\delta} 33 \mathrm{~mm}$ ) (Fig. 25). Easily distinguished from other Euarantia species by a large inner spine on the male cerci. A. incerata was erronously recorded by Karsch (1889) from Sierra Leone and Cameroon as A. fatidica because of the similarity of the male cerci. However, the male cerci of $A$. fatidica have a much smaller inner spine and the whole habitus is different. A. fatidica shows the typical habitus of the subgenus Arantia. Characteristic is the expanded furrow dorsally on the tibiae. Later Karsch (1893) described the specimens from West Africa as a separate species, A. incerata. Griffini (1908) examined both sexes from Mukonje Farm (Cameroon) and described the female. The posterior margin of the pronotum is brown, the basal area of tegmina black, the fore femora as long as the pronotum. Fore femora have 5-7 inner ventral spines, mid femora are unarmed or have 4-5 small outer spines, hind femora have 6-8 very small inner spines and 2-9 outer ventral species. The hind femora are comparatively short. The male cerci are stout and round at base, tapering towards the apex with a large sclerotized spine midway on the inner side. The apex of the male cerci are laterally 
flattened and inwardly curved (Figs 89a, 89b). Styli are present. The subgenital plate of the female is short and pointed. The ovipositor has two lateral protuberances.

Distribution. West Africa and Central Africa (records from Sierra Leone, Togo, Democratic Republic Congo and Cameroon).

Arantia (Euarantia) latifolia Karsch, 1890 (Figs. 26, 90)

http://lsid.speciesfile.org/urn:Isid:Orthoptera.speciesfile.org:TaxonName:464794

Karsch (1890). Entom. Nachricht., 16 (23): 356.

Type locality: CAMEROON. Barombi Station. Depository: MfN, Berlin. Kind of type: syntypes male and female.

Syn. Arantia (Euarantia) ovalipennis Chopard, 1954

Chopard (1954). Mem. Inst. franc. Afr. Noire, 40 (2): 38.

Type locality: GUINEA. Nimba, N'Zo. Depository: MNHN, Paris. Kind of type: holotype female.

Material examined. CAMEROON. Barombi Station, Preuss, $3 \hat{O}, 1 q$ syntypes of A. latifolia). Victoria, $1{ }^{\lambda}$. Lolodorf, L. Conradt, 1 $\sigma^{\lambda}, 1$. . Mundame, L. Conradt, 1 + . John-Albrechtshöhe 24.VI-13.VII.1896, L. Conradt, $1{ }^{\lambda}$

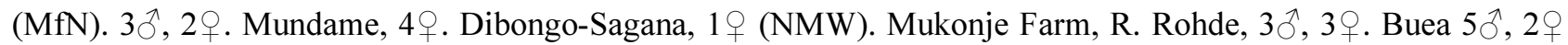
(NRMS). Dibongo 1 $\delta^{\lambda}, 1+$ (NRMS). GUINEA. Mt. Nimba, N'Zo (holotype $q$ of A. ovalipennis) (MNHN). EQUATORIAL GUINEA. Bioko, 1 ㅇ (MNCN). TOGO. Kpalimé, Ft of Missahohe 29-31.VII.2013 (light trap), P.

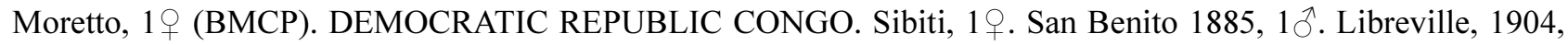
1 ㅇ (MNHN). Forest Banghi, 1 ( $($ RBINS).

Measurements. Body length: 34.0; pronotum length: 6.5; hind femur: 31.0; tegmina length: 42.30; tegmina width: 15.1-23.4; tegmina length/width: 2.0-2.8; tegmina width/pronotum length: 2.3 .

Characters. A. latifolia is a species of medium size (body length $\delta 32 \mathrm{~mm}$, $935 \mathrm{~mm}$ ) (Fig. 26). Karsch (1890) described both sexes, later Sjöstedt (1902) recorded one female from Itoki (Cameroon). Bolívar (1906) reported one female from Fernando Póo (Equatorial Guinea) and other specimens from Cameroon, and Griffini (1908) listed both sexes from Mukonje Farm (Cameroon). A. latifolia is very distinctive because of its very wide, and rounded leaf-like tegmina. Two black spots at the base of the tegmina or a black stripe are typical. Further the veins of the tegmina form several large hexagons in which a small black spot is positioned centrally in most specimens. The antennae are thin and white-black annulate, about 1.5 times of the body length. The stridulatory area of A. latifolia males is callous and very short. Fore femora with 5-6 inner ventral spines, mid femora with outer ventral $0-5$, and hind femora with 6-8 inner and 2-8 outer ventral dark-tipped spines. The male cerci are stout and hairy, and have almost the same size from base to apex; apically a sclerotized ridge is present (Fig. 90). Styli are absent. Lateral lobes of the ovipositor have a pointed protuberance, similar to those of $A$. marmorata and A. retinervis.

Distribution. Equatorial Guinea (Bioko = Fernando Póo), Cameroon, Togo, West and Central Africa.

Synonymic note. A. ovalipennis (Fig. 27) is here considered synonymous with A. latifolia. A. ovalipennis is known only from the holotype female (Chopard 1954), and it was not collected ever since. Both species have wide leaf-like tegmina, and $A$. latifolia covers a distribution including also Guinea, and is a widespread species in central and western Africa.

Arantia (Euarantia) marmorata Karsch, 1889 (Figs. 28, 60, 91)

http://lsid.speciesfile.org/urn:Isid:Orthoptera.speciesfile.org:TaxonName:464798

Karsch (1889). Berlin Ent. Z., 32: 433, 435.

Type locality: DEMOCRATIC REPUBLIC CONGO. Depository: MZPW, Warsaw. Kind of type: holotype female. Material examined: CENTRAL AFRICAN REPUBLIC. Dzanga-Ndoki National Park, Lac 1, 20-23.II.2012 (light trap), P. Moretto (đ); 14-15.II.2012 (light trap), P. Moretto (ठ̋) (BMCP).

Measurements. Males. Body length: 34-35.7; pronotum length: 7.0-7.3; pronotum height: 6.8-7.3; hind femur: 33.9-34.5; hind tibiae: 38.5-38.8; tegmina: 46-47.4; tegmina width: 16.9-17.5; tegmina width/pronotum length: 2.4. Female (according to Heller et al. 2014): tegmina width: 22; tegmina width/pronotum length: 2.8 . 

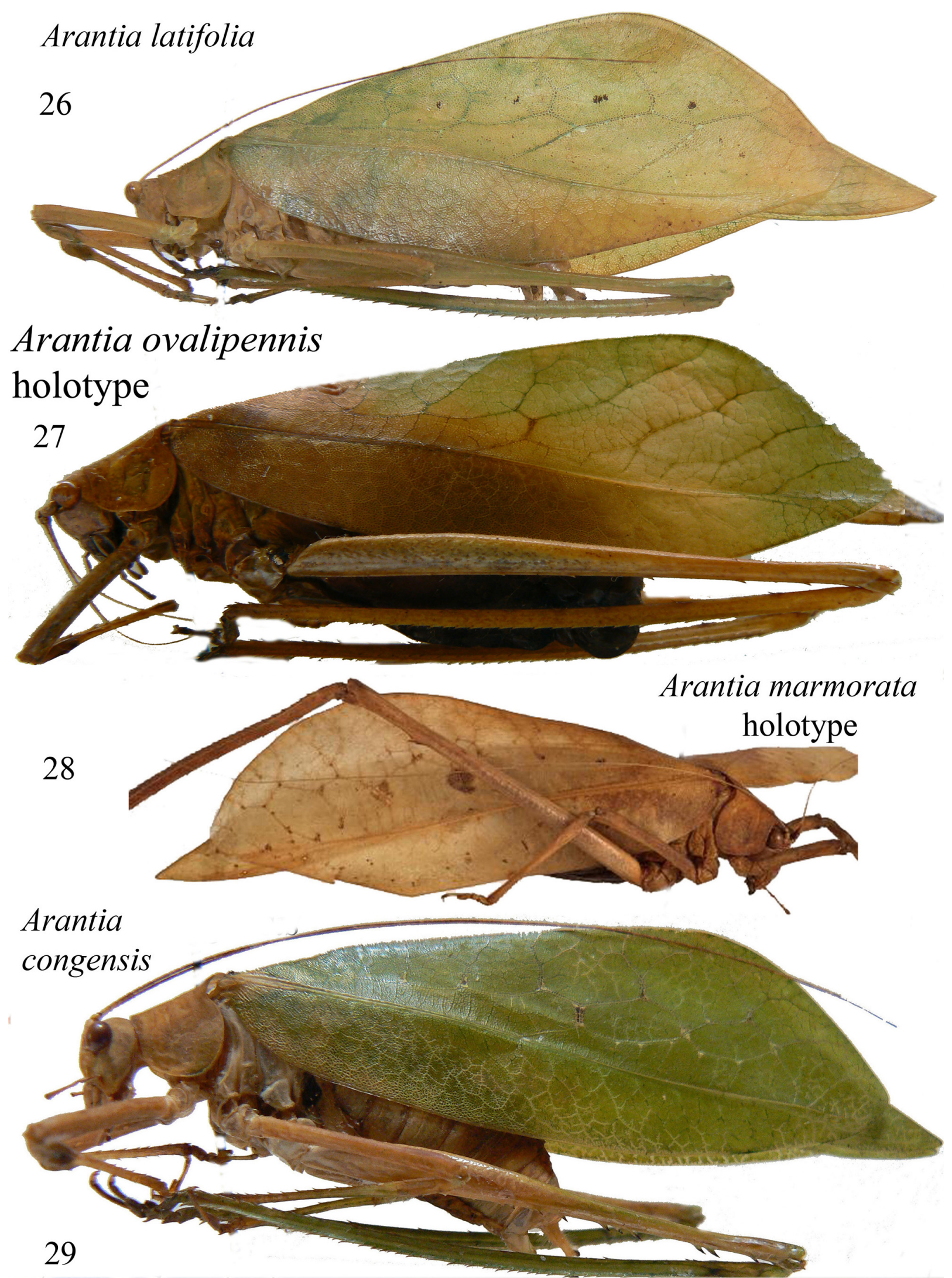

FIGURES 26-29. Habitus of Arantia (Euarantia) latifolia (26), A. (Euarantia) ovalipennis (holotype) (27), A. (Euarantia) marmorata (holotype) (28) and A. (Euarantia) congensis (29). 
Characters. A. marmorata is a medium-sized species (body length $\circ 33 \mathrm{~mm}$ ) (Fig. 28). Karsch (1889) described only the female. It is yellow-greenish, characterized by rather broad tegmina, with veinlets forming hexagons, and black spots on the base of tegmina, below the pronotum. Fore femora are armed with 3 inner ventral spines. A. marmorata has one broad-based spine on both sides on the hind femur (Karsch 1889). Lateral lobes of the ovipositor have a pointed protuberance.

Description of the male. Comparatively large with broad, leaf-like tegmina. General habitus and colour pattern. On tegmina many dark spots and maculae. Hind femora ventrally with two broad-based spines. First two antennal segments yellowish, others green, with black rings. Head and antennae. Eyes round, fastigium of vertex sulcate. Face with reddish tinge. Thorax and legs. Tympana of fore tibiae open on outer side, closed on inner side, dark. Pronotum green or yellow with green lines, metazona yellowish. Anterior margin of pronotum slightly concave, posterior margin rounded. Lower margin of pronotal lobes lacks concavity present usually in other species of the genus. Tegmina are 2.5-2.7 times longer than broad, oval, green with a dark stripe at the base and numerous scattered dark maculae. The stridulatory file on left tegmen is slightly curved and narrow, with 95-100 teeth (Fig. 60). Fore coxae unarmed. Fore femora with 4 inner ventral spines, fore tibiae with 5-6 inner and outer ventral spines, and 2-3 dorsal spines. Mid femora with 1-2 outer ventral spines near the joint of the tibia with the femur, mid tibiae with 11-12 outer ventral spines, 6-7 inner ventral spines, and 6-7 outer and inner dorsal spines. Hind femora with 7 outer and 5 inner ventral pines, the last two broad-based and black-tipped. Hind tibiae curved, with 16-18 outer spines and 12-13 inner ventral spines. Abdomen. Cerci are long, up- and in-curved, stout with a central narrowing, and a spoon-like expanded apex and a sclerotized apical spine (Fig. 91). Subgenital plate is triangular, tricarinate, with a straight apex and two small styli.

Remarks. Karsch (1890) separated A. marmorata from A. latifolia because of the slightly different shape of the posterior margins of the tegmina, the wide dark stripe at the base of tegmina and a different spination. However, differences between A. marmorata and A. latifolia consist in tegmina width (width tegmina/length pronotum in marmorata 2.8, in latifolia 2.3) and especially in the male cerci. Typical are the male cerci, which are spoon-like expanded at the tips, lacking a subapical process present e.g. in A. congensis. It also is morphologically related to A. congensis and A. melanota.

Distribution. Central Africa (Democratic Republic of the Congo, Central African Republic).

Arantia (Euarantia) congensis Griffini, 1908 (Figs. 29, 61, 92)

http://lsid.speciesfile.org/urn:lsid:Orthoptera.speciesfile.org:TaxonName:464785

Griffini (1908). Mem. Soc. entom. Belgique, Bruxelles, 15: 214.

Type locality: DEMOCRATIC REPUBLIC CONGO. Bussira and Mange. Depository: MNS, Brussells. Kind of type: syntypes male and female.

Material examined. CENTRAL AFRICAN REPUBLIC. Dzanga-Ndoki National Park, Lac 1, 24-25.II.2012

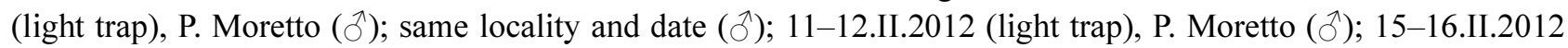
(light trap), P. Moretto (2ð); 14-15.II.2012 (light trap), P. Moretto (ð) (BMCP). DEMOCRATIC REPUBLIC

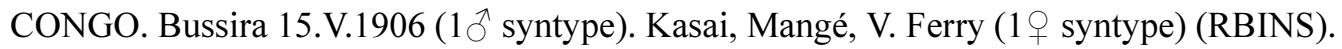

Measurements. Males. Body length: $32.2 \pm 2.7$; pronotum length: $6.7 \pm 0.2$; pronotum height: $6.3 \pm 0.2$; hind femur: $32.3 \pm 0.9$; hind tibiae: $37.3 \pm 0.7$; tegmina: $47.1 \pm 1.3$; tegmina width: $16-19$; tegmina width/pronotum length: 2.4-2.7 (present data). Female. Body length: 31; pronotum length: 7.2; tegmina: 51.5; tegmina width: 18; ovipositor: 4.4 (Griffini 1908).

Characters. A. congensis is a species of medium size (body length ${ }_{0} 29.5-36.1 \mathrm{~mm}, ~ q+31 \mathrm{~mm}$ ) (Fig. 29). Griffini (1908) described it from the Democratic Republic Congo as subspecies of A. melanota. According to Griffini (1908) it is similar to A. melanota but is characterized by longer fore femora (11 $\mathrm{mm}$ in $A$. congensis vs. $10.7 \mathrm{~mm}$ in $A$. melanota), broader tegmina, and different cerci. It has a narrow pronotum, and clearly longer and more slender legs than any other species of the genus Arantia. In addition, it has broad-based spines ventrally on the hind femora. The anterior margin of the pronotum is slightly concave, the posterior margin rounded. The lower margins of the pronotal lobes lack the concavity usually present in other species of the genus. Tegmina are 2.8-3.3 times longer than broad, about a dozen of hexagons formed by the veinlets centrally on the tegmen. The 
stridulatory file of the left tegmen is slightly curved, with 95-100 teeth (Fig. 61). A small spine is present at the posterior end of tergites $2^{\text {th }}-8^{\text {th }}$. Fore coxae unarmed. Fore femora with 3-5 inner ventral spines, fore tibiae with 78 inner and outer ventral spines, and 4-5 dorsally. Mid femora unarmed, mid tibiae dorsally and ventrally with 1112 outer and inner ventral spines and 6-7 outer and inner dorsal spines. Hind femora with 6-8 outer and 4-5 inner ventral spines, the last 4 spines broad-based and black-tipped. Hind tibiae curved, with 12-14 outer and 9-11 inner ventral spines. Tibiae and femora are long and slender. Very characteristic are the male cerci; the bases are spoonlike expanded at the tips, with a subapical process (Fig. 92). The subgenital plate is triangular, tricarinate, the apex is concave with two tips, similar to styli, that are obliterated.

The female has been re-described by Heller et al. (2014). It is characterized by unusually large and broadbased spines (especially the last two) on both edges ventrally on the hind femur. The ovipositor has two lateral protuberances.

Colour. Probably predominantly green in life, preserved insects with yellowish to tawny areas. Antennal segments reddish with small black rings. Tympana dark or only dark at their apex. Tegmina oval, green with a dark stripe at the base and some yellow spots on the vertical veinlets (Fig. 29).

Distribution. Central Africa (records from Democratic Republic Congo, Central African Republic).

\section{Arantia (Euarantia) melanota Sjöstedt, 1902 (Figs. 30, 62, 93a, b)}

http://lsid.speciesfile.org/urn:lsid:Orthoptera.speciesfile.org:TaxonName:464802

Sjöstedt (1902). Bihang Kungl. Svenska Vet. Akad. Handl., 27 (3): 6.

Type locality: CAMEROON. Bonge. Depository: NHRS, Stockholm. Kind of type: holotype male.

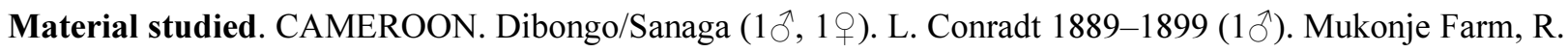
Rohde (1 9 ) (RBINS). ANGOLA (1 $\overbrace{}^{\Uparrow})(\mathrm{MNCN})$. CENTRAL AFRICAN REPUBLIC. Dzanga-Ndoki National Park, Lac 1, 24-25.II.2012 (light trap), P. Moretto (ठ) (BMCP).

Measurements. Male. Body length: 32.8; pronotum length: 7.4; pronotum height: 6.6; hind femur: 34.5; hind tibiae: 40.9; length of tegmina: 50.1; length of hind wings: 53.0; tegmina width: 15.3-15.8; tegmina width/ pronotum length: $2.0-2.1$.

Characters. A. melanota is a species of large size (body length $\bigcirc 32-40 \mathrm{~mm}$, $q 44 \mathrm{~mm}$ ). Sjöstedt (1902) described the male. Griffini (1908) described the female from Mukonje Farm (Cameroon). It is characteristic for its dark tympana, whitish metanotum bordered by a dark stripe and a black line on the posterior part of the pronotum in the area where the metazona is curved. Eyes round and prominent, first antennal segment covered with fine hairs. Fastigium of vertex sulcate. Anterior margin of pronotum straight, posterior margin rounded. Lower margin of pronotal lobes round. Tegmina are 3.4 times longer than broad. Veinlets of tegmina form some hexagons; at their angles some small yellow and black spots are present. The stridulatory file of the left tegmen is arcuate, composed of ca. 60-65 teeth (Fig. 62). Fore coxae unarmed. Conspicuous is a black area around the tympana of the fore tibiae. Fore femora with 5 inner ventral spines, fore tibiae with 8 inner and 4 outer ventral spines, and 5 dorsally. Mid femora unarmed. Mid tibiae with four rows of spines, 11 outer and 9 inner ventral spines, 6 outer and 8 inner dorsal spines. Hind femora with 5 black spines ventrally. Hind tibiae strongly curved, with 14 inner and outer ventral spines. Cerci in-curved, apex claw-like with sclerotized tips, densely covered by hairs (Figs 93a, 93b). The subgenital plate is more or less trapezoidal and short, with enlarged and closely spaced appendices. Styli are absent. Ovipositor has two lateral protuberances.

Affinities. The tegmina are comparatively broad, with several hexagons formed by the veins. Typical is also a black area at the immediate base of the tegmina. Characteristic are the male cerci with a claw-like apex. Large black spines are present ventrally on the hind femora. From its habitus with the broad leaf-like tegmina similar to A. latifolia. However, the latter has different male cerci that are undivided and wear a sclerotized ridge at the tips. Similar male cerci are present in $A$. retinervis also sharing a similar habitus with $A$. melanota. In the latter species the male cerci are divided into two approximately equally long sclerotized tips, one of them stout and broad-based the other tip more slender. Conspicuous in A. melanota are the black marked areas of the tympana on the fore tibiae which are green in $A$. retinervis. Further $A$. retinervis has a uniformly green pronotum while $A$. melanota has a thin black transverse line on the metazona of the pronotum.

Distribution. Angola, Cameroon and Central African Republic. 


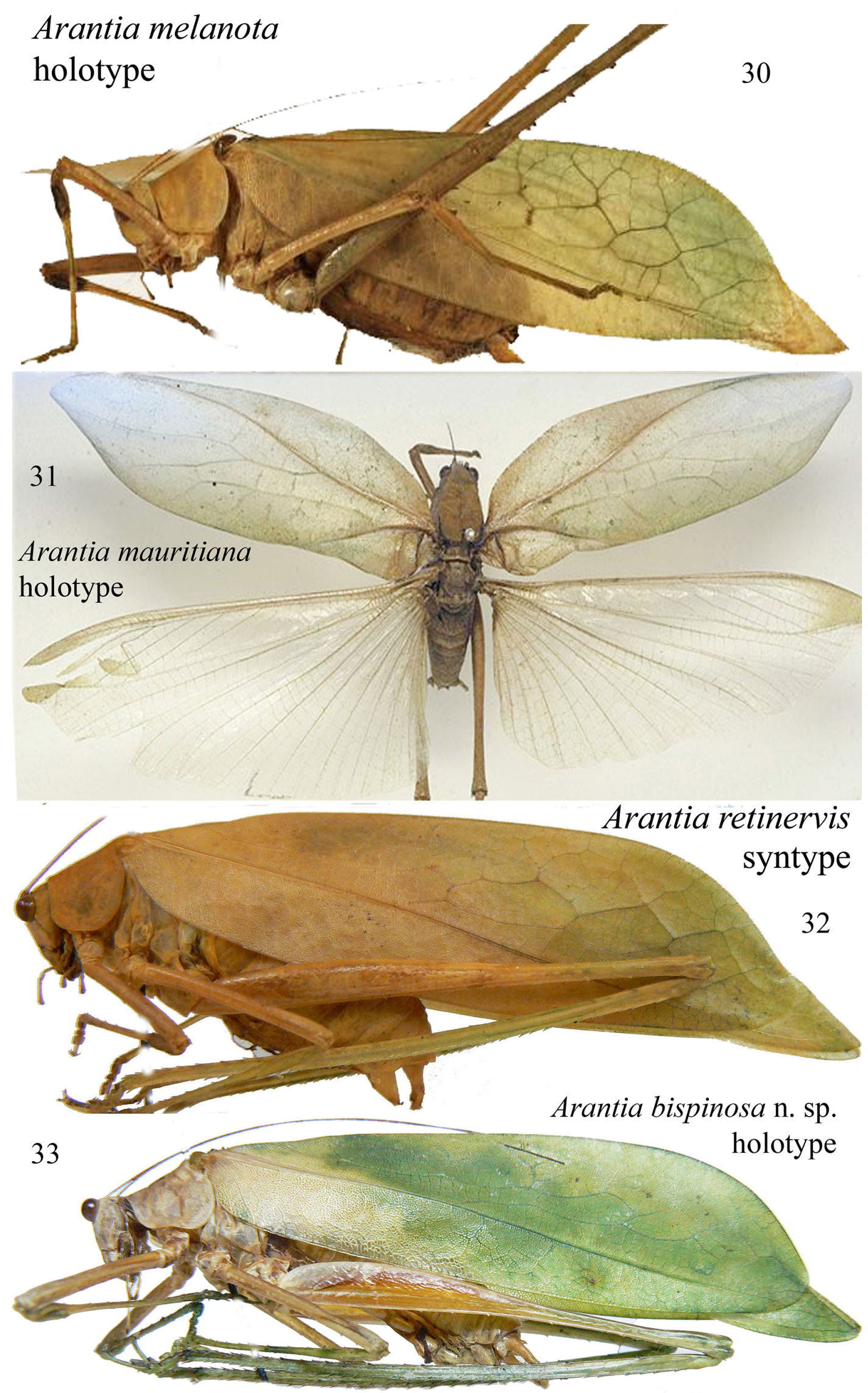

FIGURES 30-33. Habitus of Arantia (Euarantia) melanota (holotype) (30), A. (Euarantia) mauritiana (holotype) (31), A. (Euarantia) retinervis (syntype) (32) and $A$. (Euarantia) bispinosa n. sp. (holotype) (33). 
Arantia (Euarantia) mauritiana Saussure, 1899 (Figs. 31, 94)

http://sid.speciesfile.org/urn:lsid:Orthoptera.speciesfile.org:TaxonName:464800

Saussure (1899). Abh. Senckenb. Natforsch. Ges., 21: 615.

Type locality: MAURITIUS. Depository: MHNG, Geneva. Kind of type: holotype male.

Tegmina width: 19; tegmina width/pronotum length: 2.2 (Heller et al. 2014).

Characters. Species of medium size (body length $\widehat{3} 31 \mathrm{~mm}$ ). Saussure (1899) described the male from Mauritius. Conspicuous is the black wrinkled and up-lifted posterior margin of the pronotum (Fig. 31). Also part of the lateral lobes are black. The male cerci are straight. The apical part of the cerci is laterally flattened, the tip incurved wearing a single sclerotized spine (Fig. 94).

Distribution. Known only from the island Mauritius in the Indian Ocean.

\section{Arantia (Euarantia) retinervis Karsch, 1889}

http://lsid.speciesfile.org/urn:Isid:Orthoptera.speciesfile.org:TaxonName:464814

Karsch (1889). Berlin Ent. Z., 32: 433, 437. (Figs. 32, 63, 95a, b)

Type locality: CAMEROON. Chinchoxo, Barombi and SIERRA LEONE. Depository: MfN, Berlin. Kind of type: syntypes males.

Material examined. CAMEROON. Chinchoxo ( $3 \hat{\jmath}$ syntypes). Barombi Station (2 $\hat{\jmath}$ syntypes). Barombi

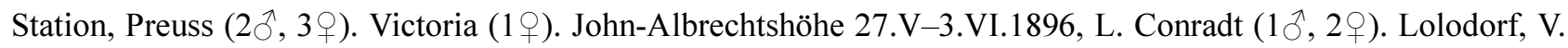

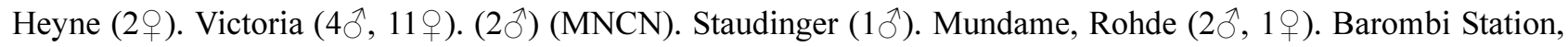

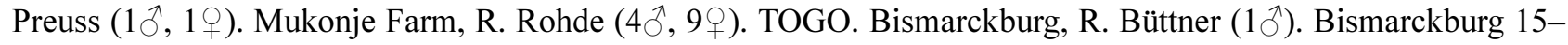

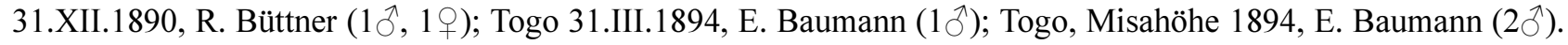
Misahöhe XII.1893, E. Baumann (2ㅇ). SIERRA LEONE Staudinger (1ð) (MfN). Dohrn (2ᄋ). GUINEA. Ebebeyin VII.1948, J. Mateu (1우). Rio Kongüe (Muni), Escalera (1へ̂). EQUATORIAL GUINEA. Fernando Póo,

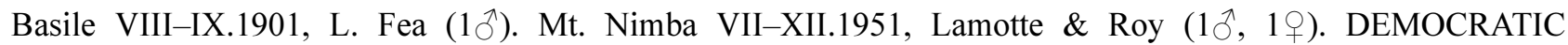
REPUBLIC CONGO. Fernand-Vaz X.1902 (1ㅇ). N’Jolé (= Ndjole) XI.1902 (1우) (MSNG). Sibiti XI.1963, A. Descarpentriès \& A. Villiers (1ठ) (MNHN). 27.III-5.IV.1975 (1 $\overbrace{}^{\Uparrow})$ (MZUF). CENTRAL AFRICAN REPUBLIC. Dzanga-Ndoki National Park, Ndoki, 26.I.2012; Lac 1, 20-23.II.2012; 13-14.II.2012; 15-16.II.2012 (light trap), P. Moretto (5`); Ivory Coast, Man, Mt. Tonkoui (1200m) 28.VI-1.VII.2014 (light trap), P. Moretto (1 $\left.{ }^{\Uparrow}\right)$. IVORY

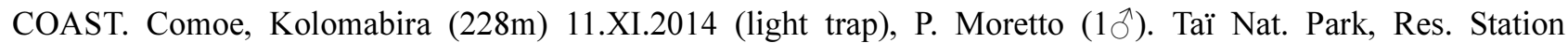
19.III.2017 (light trap), B. Massa (1ठ). Taï Nat. Park, Res. Station 4.IV.2017 (light trap), P. Moretto (4ð) (BMCP). Man, Mt. Tonkoui (1171m) 12-18.VII.2015 (light trap), M. Aristophanous, P. Moretto, E. Ruzzier (1 $\overbrace{}^{\Uparrow}$ ). Telo Village (415m) 10-13.XI.2015 (light trap), M. Aristophanous, P. Moretto, E. Ruzzier (2 $\oint^{\Uparrow}$ (NHM). Between Lambarene and the sea, E. Hang $1901\left(1{ }^{\top}\right)$. Lamto 15-30.X.1968, C. Girard (light) $(1 \overbrace{}^{\Uparrow}) .15 \mathrm{~km}$ before Lamto

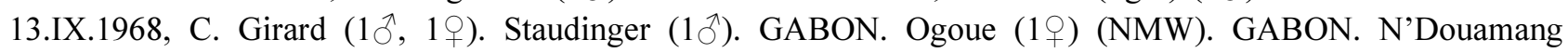

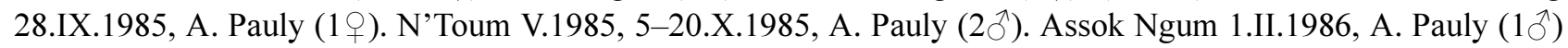
(RBINS).

Tegmina width: 13-16.20; tegmina length/width: 2.4-3.6; tegmina width/pronotum length: 1.9 (Heller et al. 2014).

Characters. A. retinervis is a species of medium size (body length: $\$ 30 \mathrm{~mm}$, $\rightarrow 35 \mathrm{~mm}$ ) (Fig. 32). Karsch (1889) described the male from Cameroon and Sierra Leone. Karsch $(1891,1893)$ recorded it from Togo, Bolívar (1906), Griffini (1906) and Ebner (1943) from Fernando Pòo (Equatorial Guinea), Sjöstedt (1929) from Democratic Republic Congo and Ragge (1968b) from the Ivory Coast. The anterior margin of the tegmina is slightly expanded. A small black spot is present at the base of the tegmina. The stridulatory file is arcuate and narrow and consists of ca. 60-65 teeth (Fig. 63). Veinlets of tegmina form some hexagons (Fig. 32) and may have small dark spots. Fore tibiae have a dark-reddish base and tympana are darkened. Fore femora have 4-7 inner ventral spines, mid femora unarmed or with 1-2 small spines, hind femora with 5 outer and 7 inner ventral small yellow spines. Male cerci are stout, long, slightly in-curved and show a bifid brown spatular and pointed apex (Figs. 95a, 95b). Male styli are absent. The ovipositor has two lateral pointed protuberances, the subgenital plate of the female is short and rounded. Probably green in life, preserved insect yellowish green. 
Distribution. Widely distribution throughout West and Central Africa (records from Sierra Leone, Guinea, Togo, Ivory Coast, Equatorial Guinea, Democratic Republic Congo, Central African Republic and Cameroon).

Arantia (Euarantia) bispinosa n. sp. (Figs. 33, 68, 84a, b)

http://sid.speciesfile.org/urn:lsid:Orthoptera.speciesfile.org:TaxonName:500643

Material examined and depository. IVORY COAST. Taï National Park, Res. Station 18.III.2017 (light trap), B. Massa ( $1 \overbrace{}^{\hat{\gamma}}$ holotype, $1 \hat{\jmath}$ paratype) (BMCP).

Measurements. Body length: 31.4-32.1; pronotum length: 6.4-6.6; pronotum height: 5.6-5.7; fore femur: 11.5-12.0; mid femur: 13.0-13.2; hind femur: 31.1-32.2; hind tibiae: 35.4-37.0; tegmina length: 42.8-44.6; length of hind wings: 46.8-48.5; tegmina width: 12.0-12.5; tegmina length/width: 3.6-3.9; tegmina width/pronotum length: 1.9 .

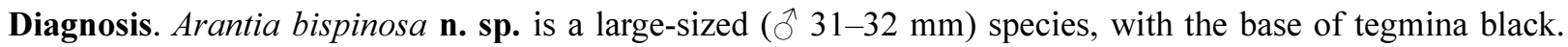
Very peculiar are two spines at the inner base of the cerci with a sclerotized ridge that stretches along the inner side of the cercus. It is also characterized by long femora (see measurements). We placed it within the subgenus Euarantia, but as in the case of A. rectifolia, the width of tegmina is intermediate between Arantia and Euarantia.

Description. Male (Fig. 33). General habitus and colour. Predominantly yellow-green, leaf-like. Antennal segments reddish. Pronotum yellow, legs yellow, except for hind tibiae that are green. Base of tegmina black. Head and antennae. Eyes oval-roundish, antennae long and very thin, $64.5 \mathrm{~mm}$. Thorax and legs. Fore coxa unarmed. Tympana on fore tibiae open on outer, closed on inner side. Anterior margin of pronotum straight, posterior margin rounded. Lower margin of pronotal lobes with a concavity. Tegmina oval, green with a dark stripe at the base, 3.6 times longer than broad. The stridulatory area of the left tegmen is almost straight, the stridulatory file is arcuate, narrow and consists of less than 40 teeth (Fig. 68). Fore femora with 6 inner ventral spines, fore tibiae with 7 inner ventral and 6 outer ventral spines. Mid femora with 2 outer ventral spines, mid tibiae dorsally with 5 outer and inner spines, 12 spines on outer and inner ventral margins. Hind femora with 5 outer and 4 inner ventral spines, hind tibiae slightly curved, with many ventral spines. Abdomen. Cerci are long and in-curved, with an acute small spine at the inner dorsal base, and an inner sclerotized ridge that stretches from the mid to the apex of the cerci; the ventral base of the cerci is circlic expanded with an apical brown chitinous margin (Figs 84a, 84b). Subgenital plate is triangular, the apex is straight and styli are present (Fig. 84a).

Female. Unknown.

Etymology. Named for the presence of two spines at the inner dorsal base of cerci.

Affinities. Cerci with a circlic expanded process at the base of the cerci together with a acute small spine dorsal at the base is unique so far for Arantia.

Distribution. Known only from the type locality, the Taï National Park (Ivory Coast).

Arantia (Euarantia) excelsior Karsch, 1889 (Figs. 34-37, 39-40, 64, 96-98)

http://lsid.speciesfile.org/urn:Isid:Orthoptera.speciesfile.org:TaxonName:464787

Karsch (1889). Berlin Ent. Z., 32: 434-435.

Type locality: SIERRA LEONE. Depository: MZPW, Warsaw. Kind of type: holotype male.

Syn. Arantia (Euarantia) mammisignum Karsch, 1896

Karsch (1896). Stett. Entomol. Z. 57: 332.

Type locality: CAMEROON. Lolodorf. Depository: MfN, Berlin. Kind of type: holotype female.

Syn. Arantia (Euarantia) tigrina Bolivar, 1906

Bolívar I. (1906), Mem. Soc. espan. Hist. nat. 1: 330.

Type locality: EQUATORIAL GUINEA. Bioko (Fernando Póo). Depository: MNCN, Madrid. Kind of type: holotype male.

Material examined. SIERRA LEONE. A. excelsior ( $\widehat{\partial}$ holotype images on OSF, Cigliano et al. 2017, MZPW, Warsaw). (1今̄, 1우) (MNCN). CAMEROON. Kiroi 1908, S. Lamey (1ㅇ) (MSNG). CENTRAL AFRICAN REPUBLIC. Dzanga-Ndoki National Park, Ndoki 26.I.2012; Border of Lac 1, 13-14.II.2012. Lac 1, 24-25.II.2012 (light trap), P. Moretto (5 ${ }^{\Uparrow}$ ). IVORY COAST. Taï Nat. Park, Res. Station 20-22.III.2017 (light trap), B. Massa 
(6今) (BMCP). Taï National Park, Res. Station 5-10.VII.2015 (light trap), M. Aristophanous, P. Moretto, E. Ruzzier (5 ${ }^{3}$ ). Man, Mt. Tonkoui (1171m) 12-18.VII.2015 (light trap), M. Aristophanous, P. Moretto, E. Ruzzier (7 ${ }^{3}$ ). Telo Village (415m) 10-13.XI.2015 (light trap), M. Aristophanous, P. Moretto, E. Ruzzier (1 9 ) (NHM). Taï Nat. Park, Res. Station 25.III.2017 (light trap on platform at 40m), P. Annoyer (2今). Taï Nat. Park, Res. Station 25.III.2017 (light trap), P. Annoyer (1 $\overbrace{}^{\jmath}$ ) (PACT). GABON. N'Toum 19.XI.1982, V.1985, 16.IX.1985, A. Pauly (3 $\overbrace{}^{\top})$ (RBINS). A. tigrina: EQUATORIAL GUINEA. Fernando Póo (Bioko) (ô holotype) (MNCN). CAMEROON. Dibongo, (q paratype) (MNCN). A. mammisignum: CAMEROON. Lolodorf ( $q$ holotype) (MfN).

Measurements. Body length: $33.8 \pm 1.3$; pronotum length: $8.3 \pm 0.3$; pronotum height: $9.3 \pm 0.2$; hind femur: 28.4 \pm 1.3 ; hind tibiae: $33.6 \pm 0.4$; tegmina: $57.5 \pm 1.4$ (우 holotype: 68.4 ); tegmina width: $15-21$; tegmina length/ width: 2.7-3.2 ( holotype: 3.2 ); tegmina width/pronotum length: 1.9-2.1.

Characters. Karsch (1896) described A. excelsior on a single male from Sierra Leone (Fig. 34). A few years later he described A. mammisignum on a single female from Cameroon (Fig. 37). The most conspicuous characters of A. mammisignum are the two shiny white patches on the posterior part of the pronotum, and black markings on the fore margin of the tegmina. Obviously because of the conspicuous two white patches on the posterior pronotum Karsch did not realize that the newly described female was conspecific with $A$. excelsior. However, also the male shows this conspicuous character of white patches on the posterior margin of the pronotum, as well as black markings on the tegmina (Figs 39-40). Now more specimens became available for study and it became obvious that A. mammisignum is conspecific with A. excelsior. Collections of MNCN hold a specimen from southern Cameroon (Dibongo) identified as A. tigrina, which is almost identical with the female of $A$. mammisignum including the colour pattern of the two large white patches on the posterior margin of the pronotum. The male holotype of A. tigrina (Fig. 36) has the same genitalic morphology as A. excelsior: the male cerci are stout at their base tapering to the apex, are sinuous midway and end in a dark coloured club (compare Figs 96, 97, 98). The male subgenital plate is very distinctive being elongate, almost rectangular and very narrow without styli but blunt short processes. Also the costal area of the tegmina has brown to black markings both in the $A$. excelsior and the $A$. tigrina types. In specimens studied the metazona of the pronotum is often brown with a whitish area at the posterior margin. Two large white patches may be present on the posterior pronotum (holotype A. mammisignum, female paratype A. tigrina), may cover the whole posterior down-curved part of the pronotum (holotype A. tigrina) or may be restricted to the immediate margin (holotype $A$. excelsior). Typical is also a strong deflection of the pronotal disc in the area of the metazona (Fig. 39). The face of the holotype in A. excelsior is reddish brown while it is ivory white in A. tigrina; the face of the female of A. tigrina in $\mathrm{MNCN}$ is uniformly brown. Therefore, colour variation is apparent in this species as has also observed e.g. in specimens of A. fasciata from East Africa, as well as differences in body size. Some specimens of $A$. excelsior have blackish stripes on the legs (including the tympana of the fore tibia). Thus, both A. tigrina and A. mammisignum are here synonymized with $A$. excelsior. The stridulatory file of $A$. excelsior is short and broad and consists of ca. 65 more evenly spaced teeth (Fig. 64). Further, some specimens (from Ivory Coast) have both inner and outer tympana closed on the fore tibia.

Affinities. A. excelsior is closely related to A. rectifolia and A. regina having a similar habitus of broad leaflike wings and similar male genitalia. A. rectifolia has tegmina less broad than $A$. excelsior and $A$. regina. In addition, in $A$. regina the male cerci are more slender and the club at the tips of the cerci is not as large as in $A$. excelsior. The female ovipositor is smaller in A. rectifolia. Also A. rectifolia lacks the brown-black patches at the anterior margin of the tegmina which seem typical for A. excelsior (Fig. 34). Another striking difference is seen on the metazona of the pronotum. In A. excelsior a conspicuous deflection is present while in A. rectifolia and in $A$. regina the posterior part of the metazona is only shallowly bent.

Distribution. Central and West Africa (records from Sierra Leone, Equatorial Guinea, Central African Republic and Cameroon).

Arantia (Euarantia) scurra Karsch, 1896 (Figs. 38, 41-42, 65, 99)

http://lsid.speciesfile.org/urn:Isid:Orthoptera.speciesfile.org:TaxonName:464815

Karsch (1896). Stett. Entomol. Z., 57: 331. 

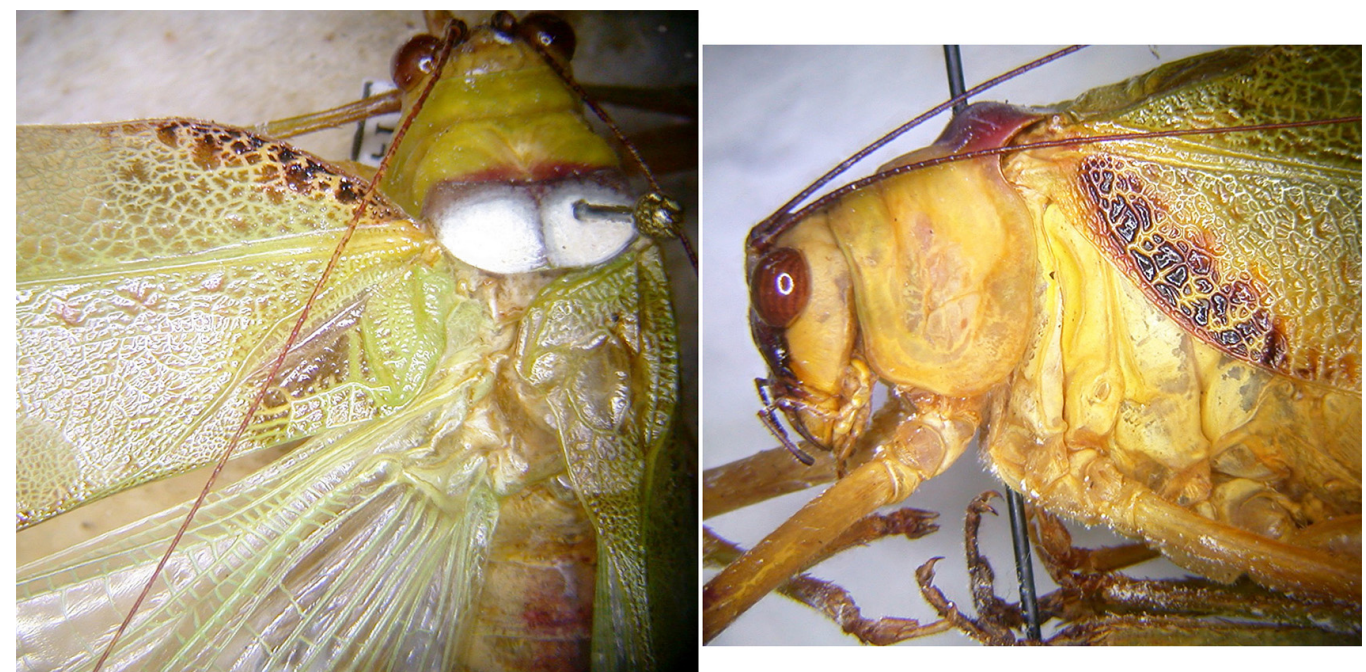

\section{9}

Arantia excelsior

40
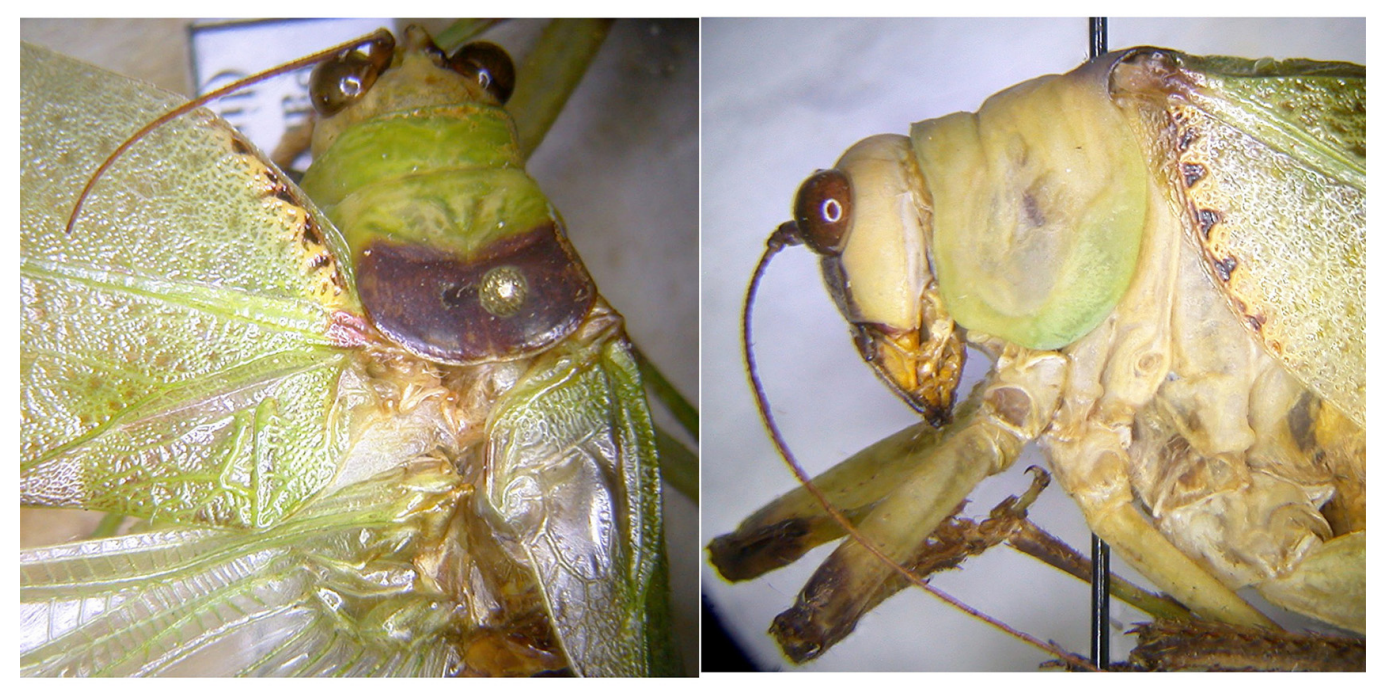

41

Arantia scurra

42
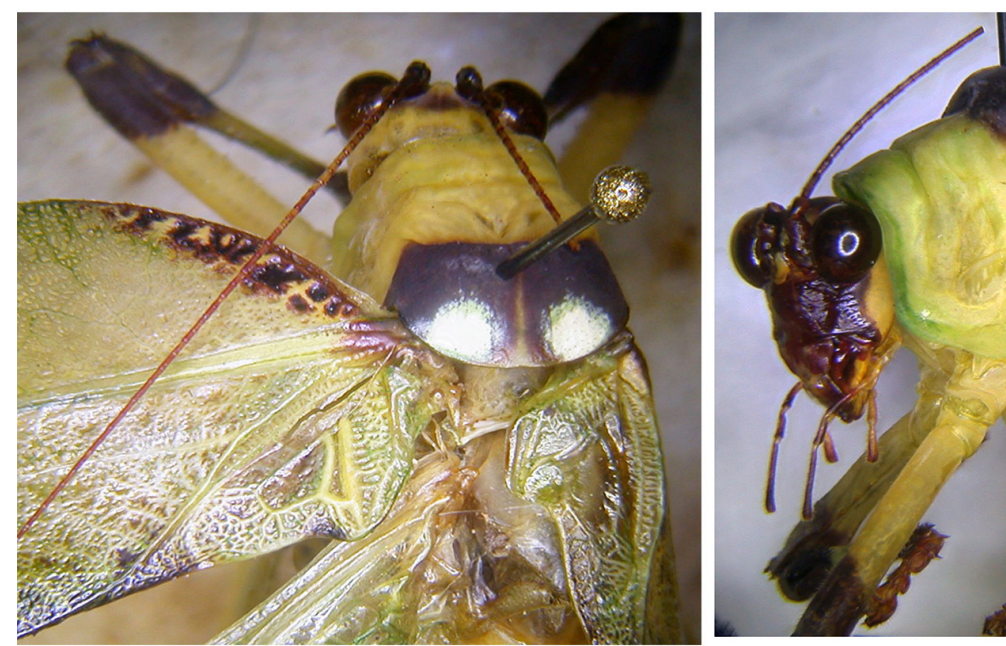

43

Arantia tibiaspinosa n. sp.

44

FIGURES 39-44. Dorsal view of the pronotum and stridulatory area of tegmina (left) and lateral view of head, pronotum and base of tegmina (right) of Arantia (Euarantia) excelsior (39, 40), A. (Euarantia) scurra (41, 42) and A. (Euarantia) tibiaspinosa n. sp. $(43,44)$. 
Type locality: CAMEROON. Lolodorf. Depository: MFN, Berlin. Kind of type: holotype male.

Material examined. CAMEROON. Lolodorf ( 0 holotype) (MfN). IVORY COAST. Taï National Park, Res. Station 20-23.III.2017 (light trap), B. Massa (5今)). Taï National Park, Res. Station 16.III.2017, platform 40m (light trap), B. Massa (1 $\overbrace{}^{\Uparrow}$ ). Taï National Park, Res. Station 4.IV.2017 (light trap), P. Moretto (4ð) (BMCP, CHB).

Measurements. Males $(\mathrm{N}=4)$. Body length: $31-32.7$; pronotum length: $7.8-8.1$; pronotum height: 8.0-8.7; hind femur: 26.1-28.0; hind tibiae: 29.8-32.8; tegmina: 50.2-52.9; tegmina width: 14.3-14.7; tegmina length/ width: 3.4-3.7; tegmina width/pronotum length: 1.8-1.9.

Characters. A. scurra has small to medium size (body length ${ }^{\lambda} 26.5-33 \mathrm{~mm}$ ). Karsch (1896) described it on one male, on the following characters: head, pronotum, legs and abdomen ochreous, antennal segments pale with dark rings and ochreous basal segment, face reddish-black, basal lobe of pronotum, apex of fore femora, base of fore tibiae and apex of hind femora reddish, hind tibiae with dark rings, fore and hind femora with black spines, tegmina more or less rectangular with some black spots on their base (Fig. 38). The face is also dark and the palps have a dark apex. Fore and mid femora unarmed, hind femora with 5 inner and 7 smaller ventral spines. Male cerci are in-curved, slightly sinuous, long and stout and have a black round and wrinkled apex, styli are small and black (Fig. 99).

Affinities. A. scurra belongs to a group of Arantia species with stout and sinuous male cerci ending in a club that is black, brownish or has the same colour as the cerci. A. rectifolia males have a small club on the tip of the cerci which has the same colour as the cerci or is slightly brownish, A. excelsior has strongly sinuous male cerci with a large club which is black. Also A. fasciata has stout sinuous male cerci with a well developed club that is slightly coloured. A. excelsior and A. scurra also share brown to black grooves at the anterior margin of the tegmina.

Remarks. A. scurra is morphologically closely related to $A$. excelsior. The only characters delimitating $A$. scurra from $A$. excelsior are the dark brown pronotum and the smaller size. The male cerci are very similar and $A$. scurra shares the darkened tympana and anterior dark parts of the fore femora with $A$. excelsior. The stridulatory file (Fig. 65) is very similar to that of $A$. excelsior. Also very apparent are the dark brown and black grooves on the anterior margin of the fore tegmina shared by both A. scurra and A. excelsior specimens. At present the male holotype of $A$. scurra was unique, no collection studied so far had further specimens which would have supported the status of this species. A. scurra is known from Cameroon and thus also overlaps in its locality with the known distribution of $A$. excelsior. Only more material will clarify whether $A$. scurra is conspecific with A. excelsior.

Distribution. Central Africa (records from Cameroon and the Central African Republic).

\section{Arantia (Euarantia) tibiaspinosa n. sp. (Figs. 43-44, 45a, 66, 100)}

http://lsid.speciesfile.org/urn:lsid:Orthoptera.speciesfile.org:TaxonName:500646

Material examined and depository. IVORY COAST. Taï National Park, Res. Station 20.III.2017 (light trap), B.

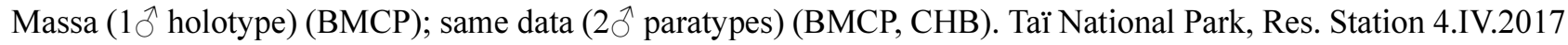
(light trap), P. Moretto (5 paratypes) (BMCP). 5-10.VII.2015 (light trap), M. Aristophanous, P. Moretto, E. Ruzzier (4 $ð$ paratypes) (NHM).

Measurements. Males (N=3). Body length: 30.2-32.5; pronotum length: 8.1-8.6; pronotum height: 9.1-10.0; hind femur: 27.5-28.6; hind tibia: 33.4-34.9; tegmina length: 48.6-54.2; tegmina width: 14.0-15.0; tegmina length/width: 3.4-3.6; width tegmina/length pronotum: 1.7-1.8.

Diagnosis. A. tibiaspinosa n. sp. is very similar in its colour pattern to A. excelsior and especially to $A$. scurra. All three species also share similar male genitalia, the apices of the cerci being club-shaped. With $A$. excelsior it shares the conspicuous white patches on the metazona of the pronotum and with A. scurra an almost identical colour pattern of tegmina and legs (compare Figs 39-40 with 41-42 and 43-44). The tegmina of both species have brown dots and patches where tegmina meet in the middle when folded and have dark brown stripes on the hind legs. The joints of the fore and mid legs are dark brown in both species. A. tibiaspinosa n. sp. may easily be distinguished by the enlarged and densely set spines of the basal hind tibiae, a character unique so far for Arantia.

Description. Male (Fig. 45a). General habitus and colour pattern. Large to medium sized species with broad wings. Posterior part of pronotum dark brown with two small white patches. Hind legs with pattern of dark stripes, also joints of fore and mid legs of same dark brown colour. Along midline where tegmina meet irregular black to 
brown set patches. On anterior margin of tegmina with ivory spots on dark ground. Head and antennae. Eyes ovalroundish, very dark. Antennae long and thin, brown. Fastigium of vertex forming a ridge with sulcus; fastigium of frons conical; both fastigia separated by deep gap. Fastigium of vertex and fastigium of frons green while face dark brown. Thorax and legs. Anterior margin of pronotum almost straight. Posterior part of pronotum strongly deflexed in metazona (Figs 43-44). Metazona of pronotum dark brown with small well defined white patches or white patches larger and diffuse. Tegmina broad with truncate margin. At costal area conspicuous pattern of ivory patches set in broad dark brown fascia. Stridulatory file on underside of left tegmen long, almost straight with teeth largest in middle part, with 55-60 teeth (Fig. 66); teeth in the middle larger and more widely spaced than at both ends. Fore coxa without spine. Tympana of fore tibiae open on inner side, conchate on outer side, whole area slightly inflated and marked dark brown in this area. Fore femora on inner side with 5 inner ventral spines and $2-4$ outer dorsal, mid femora with 2-3 inner ventral spines, hind femora with 6-9 black inner and outer ventral spines. Fore tibiae with 5 inner dorsal spines; 2 pair of spurs. Mid tibiae with ventral row of 7-8 irregular set pairs of spines, $1-$ 2 on both dorsal sides and 2 pairs of spurs. Hind tibiae tetragonal with 4 rows of numerous spines; with 3-5 enlarged, densely set spines basally and more than 25 spines on upper margins (Fig. 45b); dorsal 1 pair of spurs, ventral 2 pairs. Abdomen. Cerci long and slender with club with small apical spine, sinuous at apical part and decussate (Fig. 100). Club small, dark. Subgenital plate longer than wide and without styli.

Female. Unknown.

Etymology. Named for the conspicuous enlarged tibial spines.

Habitat and locality information. Canopy inhabitant of Taï National Park (Ivory Coast). This Park is located approximately $100 \mathrm{~km}$ from the Ivorian coast on the border with Liberia between the Cavally and Sassandra rivers. It covers an area of $3,300 \mathrm{~km}^{2}$ with a $200 \mathrm{~km}^{2}$ buffer zone. The park consists of $4,540 \mathrm{~km}^{2}$ of tropical evergreen forest, it is one of the last remaining portions of the vast primary Upper Guinean rainforest that once stretched across present-day Togo, Ghana, Ivory Coast, Liberia and Sierra Leone to Guinea-Bissau. It is the largest island of probably most pristine forest remaining in West Africa. It holds many endemic species of fauna and flora. The Taï Forest Reserve was created in 1926 and promoted to National Park status in 1972. It was recognised as a UNESCO Biosphere Reserve in 1978 and added to the list of Natural World Heritage Sites in 1982.

Distribution. West Africa, Ivory Coast. At present only known from the type locality.

\section{Arantia (Euarantia) griffinii n. sp. (Figs. 46, 67, 101)}

http://lsid.speciesfile.org/urn:lsid:Orthoptera.speciesfile.org:TaxonName:500647

Material examined and depository. CENTRAL AFRICAN REPUBLIC. Dzanga-Ndoki National Park, Lac 1, 24-25.II.2012 (light trap), 02²8’40.5N 016²1’02.6E, P. Moretto (ð̊ holotype) (BMCP).

Measurements. Body length: 30.6; pronotum length: 7.2; pronotum height: 6.6; hind femur: 35.5; hind tibiae: 40.1; tegmina length: 48.1 ; length of hind wings: 50.1 ; tegmina width: 15.5 ; tegmina length/width: 3.1 ; tegmina width/pronotum length: 2.1 .

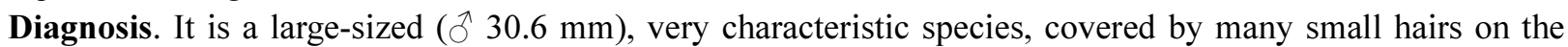
legs. The coloration is unusual for the genus (abdomen yellow with dorsal part red). Inner margins of the tympana inflated. Posterior margin of the pronotum is brownish, similar to A. scurra but not as dark. Very peculiar is the fastigium of vertex being almost heart-shaped leaving a large gap to the fastigium of the face.

Description. Male (Fig. 46). General habitus and colour. Predominantly green, leaf-like. Antennal segments reddish with small black rings. Head and legs yellow with reddish dots and stripes. Behind the eye yellow, face yellow, labium dark. Posterior part of pronotum brown, lateral lobes with a yellow area, metazona dark reddish. Head and antennae. Eyes oval, fastigium of vertex heart-shaped, forming two broad wings. Between fastigium of vertex and the face a large gap. Antennae long and very thin, $52.5 \mathrm{~mm}$. Thorax and legs. Fore coxa unarmed. Tibiae densely covered by short hairs. Tympana on fore tibiae open on outer, closed and inflated on inner side. Pronotum green, anterior margin slightly concave, posterior margin rounded. Lower margin of pronotal lobes without the concavity present in most other species of the genus. Tegmina oval, green with a thin dark stripe at the base, 3 times longer than broad. The stridulatory area of the left tegmen is almost straight, the stridulatory file is arcuate, narrow and consists of ca. 80-85 teeth (Fig. 67). Fore femora with 4 inner ventral spines, fore tibiae with 8 inner ventral and 5 outer ventral spines. Mid femora with 1 outer ventral spine near the tibia joint, mid tibiae ventrally with 14 
outer and 11 inner spines, 9 spines on outer and inner dorsal margins. Hind femora with 5 outer and 4 inner ventral spines, hind tibiae slightly curved, with 14 outer and 10 inner ventral spines. Abdomen. Cerci are long and incurved, apically slightly inflated with a larger and a very small dent (Fig. 101). Subgenital plate is triangular, long and narrow, the apex is straight and styli are absent.

Female. Unknown.

Etymology. A. griffinii n. sp. is dedicated to Achille Griffini (1870-1932), distinguished Italian entomologist, who studied many African collections of Orthoptera preserved in different world museums.

Affinities. It is related to $A$. melanota, but the tibiae of $A$. griffinii do not have blackish tympana and the male cerci have a smaller dent at the tip. In addition $A$. melanota has broad-based spines on the hind femora.

Distribution. Known only from the type locality, the Dzanga-Ndoki National Park in the in the south-west of the Central African Republic, Central Africa.

\section{Subgenus Arantia (Goetia) n. comb.}

Arantia (Goetia) dimidiata (Bolívar, 1906) n. comb. (Figs. 47-48, 70, 102-103)

http://lsid.speciesfile.org/urn:lsid:Orthoptera.speciesfile.org:TaxonName:500649

Bolívar (1906). Mem. Soc. espan. Hist. nat. 1: 335.

Type locality: EQUATORIAL GUINEA. Fernando Póo and CAMEROON. Depository: MNCN, Madrid. Kind of types: syntypes male and females.

Syn. Arantia gestri Griffini, 1906

Griffini (1906). Ann. Mus. Civ. Stor. Nat. Genova, 3 (2): 384.

Type locality: GABON. N'Jolè (=Ndjole). Depository: MSNG, Genoa. Kind of type: holotype male.

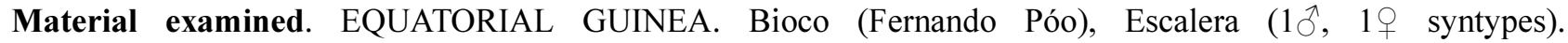
CAMEROON. L. Conradt ( 19 syntype) (MNCN). CENTRAL AFRICAN REPUBLIC. Dzanga-Ndoki National Park, Lake 1, (light trap) 10-11.II.2012 (1ð); 11-12.II.2012 (2ð); 20-23.II.2012 (3ð); 24-25.II.2012 (6ð). Ndoki, border of Lake 1 (light trap) 13-14.II.2012 (6 $\left.{ }^{\top}\right)$. Ndoki, Lake 1 (light trap) 2, 15-16.II.2012 (4ð). Ndoki, Lake 3 (light trap) 18-19.II.2012 (1ठ). Ndoki, Lake 1, platform on the canopy, 35m (light trap) 4-5.II.2012 (1ठ); 10-

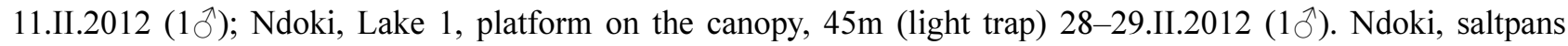
25.I.2012 (1§), P. Moretto (BMCP). A. gestri: GABON. Ndjolé XI-XII.1902, L. Fea (ð holotype) (MSNG). DEMOCRATIC REPUBLIC CONGO. Kasai, Mange, V. Ferry (1 9 ) (RBINS).

Measurements. Males. Body length: 27.0-32.0; pronotum length: 7.0-7.2; pronotum height: 5.2-6.1; hind femur: 26.0-29.0; hind tibiae: 31.0-34.0; length of tegmina: 45.0-47.0; tegmina width: 9.5-10.5 (A. gestri: 11.8); tegmina width/pronotum length: 1.3-1.4 (A. gestri: 1.7). Females. Body length: 25.0-27.0 (A. gestri: 27.4); pronotum length: 6.1-6.5 (A. gestri: 6.4 ); pronotum height: 5.8-6.0 (A. gestri: 5.8); hind femur: 28.5; hind tibiae: 27.5; length of tegmina: 44.0-47.0 (A. gestri: 49.8); tegmina width: 10.5-10.6 (A. gestri: 11.0); ovipositor: 3.8-4.2 (A. gestri: 3.0); tegmina width/pronotum length: 1.6-1.7 (A. gestri: 1.7).

Characters. A. dimidiata is easily distinguished from A. galbana by the absence of hexagonal areas in the tegmina and by black spines present on the legs of $A$. galbana (Karsch 1891; Bolívar 1906) (compare Figs 48 and 49). In addition, the cerci of $A$. dimidiata are long, in-curved, dorso-ventrally compressed and end with a small black spine, while those of $A$. galbana are sinuate and end with a round hairy bulge (compare Figs 102 and 104). Further, some specimens of $A$. dimidiata have a dark fascia on the posterior area of the pronotum, absent in $A$. galbana. The stridulatory file consists of ca. 55-60 teeth, the central situated teeth are broader and more spaced (Fig. 68). Griffini (1906) described the male of Arantia gestri from the Democratic Republic Congo (Fig. 47) and later (Griffini 1908) the female from Mange (Kassay, Congo). A peculiar character is the black velvet color of the hind margin of the pronotum. The fore coxae are armed with a very small spine (both in the male holotype and in the female), fore femora armed with 7-9 black-tipped small spines. The outer tympanum of the fore tibia is black. The mid femora are armed with 6 small ventral spines, and the hind femora with 6-8 ventral black-tipped spines. The anterior margin of the tegmina is straight with small black spots, and the stridulatory area of the left tegmen also has small black markings, as in A. dimidiata. Further, a concavity on the lower margins of the pronotal lobes is present also in $A$. dimidiata. Cerci of $A$. gestri are long, hairy, with an enlarged apex and a very small dark spine, identical to those of $A$. dimidiata (compare Figs 102 and 103). Styli are absent. The ovipositor of the female is short 
and the last tergite has two tumescent bumps. A. gestri and G. dimidiata were described in the same year, thus authors of their descriptions probably were unaware of the respective described taxa. However, G. dimidiata was described on $1^{\text {st }}$ August 1906, while $A$. gestri on $5^{\text {th }}$ August 1906 (cf. Poggi 2010). Thus, A. gestri Griffini, 1906 is a junior synonym of G. dimidiata Bolívar, 1906.

Distribution. Central and West Africa (Cameroon, Central African Republic, Equatorial Guinea, Gabon).

Arantia (Goetia) galbana (Karsch, 1891) n. comb. (Figs. 49, 69, 104)

http://lsid.speciesfile.org/urn:lsid:Orthoptera.speciesfile.org:TaxonName:500650

Karsch (1891). Berlin Ent. Z. 36 (1): 323.

Type locality: CAMEROON. Barombi Station. Depository: MfN, Berlin. Kind of type: holotype female.

Tegmina width: 13.8-16.0; tegmina length/width: 3.1-3.4; tegmina width/pronotum length: 2.4-2.6

Material examined. CAMEROON. Barombi Station ( $q$ holotype). Lolodorf (2 + ). 1897 (1 + ) (MfN). ( $)$ (MNCN). Buea VI-VII.2015 (ठ) (BMCP). Mukonje Farm, R. Rohde (1§) (RBINS). EQUATORIAL GUINEA. Ebomeku VII.1948, Mateu (ठ). Fernando Póo (ㅇ). Fernando Póo, Punta Frailes ( $($ ) (MSNG). CENTRAL AFRICAN REPUBLIC. Dzanga-Ndoki National Park, Lake 1 (light trap) 22.II.2012 (3 ${ }^{\Uparrow}$ ) (PACT).

Characters. Karsch (1891) described the female, Sjöstedt (1902) reported both sexes from Bonge (Cameroon), Griffini (1906, 1908) from Fernando Póo (Equatorial Guinea) and Mukonje Farm (Cameroon), Chopard (1954) and Ragge (1968b) from the Ivory Coast, and Naskrecki (2009) from Ghana. Typical are the hexagonal areas in the tegmina and black spines present on the hind femora (Karsch 1891; Bolívar 1906) (Fig. 49). A. galbana has 6 spines on the fore femora, 5 on the mid and 7-8 black spines on inner ventral margin of the hind femora (with a black spot at their base). No spines are present dorsally on the hind femora. The lower margin of the lateral lobes of the pronotum is undulated. The stridulatory file of the left tegmen is rather short and consists of ca. 60 teeth (Fig. 69). Cerci of A. galbana are sinuate and end with a round hairy bulge (Fig. 104). Styli are absent.

Distribution. West and Central Africa (records from Cameroon, Equatorial Guinea, Ghana and Ivory Coast).

Arantia (Goetia) purpurea (Massa, 2013) n. comb. (Figs. 50, 71, 105)

http://lsid.speciesfile.org/urn:Isid:Orthoptera.speciesfile.org:TaxonName:500651

Massa (2013). J. Orth. Res. 22 (2): 148.

Type locality: CENTRAL AFRICAN REPUBLIC. Dzanga-Ndoki National Park. Depository: BMCP, Palermo. Kind of types: holotype male and allotype female.

Material examined. CENTRAL AFRICAN REPUBLIC. Dzanga-Ndoki National Park, Ndoki, Lake 1, Light trap, 11-12.II.2012, P. Moretto ( $̋$ holotype, $q$ allotype) (BMCP). La Maboké, M’Baiki I.1966, M. Pavan (1ㅇ) (MSNP).

Measurements. Male. Body length: 30.5; pronotum length: 6.1; pronotum height: 7.0; hind femur: 28.0; tegmina: 49.6; tegmina width: 10.7. Female. Body length: 33.5; pronotum length: 6.0; pronotum height: 6.9; hind femur: 29.0; tegmina: 50.1; ovipositor: 5.5; tegmina width: 10.8 (Massa 2013). Tegmina length/width: 4.6; tegmina width/pronotum length: $1.7-1.8$.

Characters. Large species characterized by its purplish color (Fig. 50). Lower margin of lateral lobes of the pronotum with a small concavity. Anterior margin of pronotum straight, posterior margin rounded. Fore coxae armed, fore tibiae dorsally furrowed. Stridulatory area of left tegmen well-developed, elevated above the wing plane and accentuated by a swelling of the rib; the stridulatory file consists of 70-75 evenly spaced teeth (Fig. 71). Male cerci are long, sinuous, down- and in-curved, covered by sparse hairs, basally black and apically brown and slightly flattened, with round apices (Fig. 105). Subgenital plate has a straight concavity, delimited by two apical apices, without styli. Fore femora are armed, hind femora ventrally with 9 black spines, surrounded by a wide black spot. Ovipositor short, gently curved and toothed at the apex of ventral and dorsal valves. A. purpurea is distinguished at once by its purple colour and the presence of black spots ventrally on the femora (Massa 2013).

Distribution. Central Africa (Central African Republic). 
Arantia tibiaspinosa n. sp.

paratype

$45 \mathrm{a}$

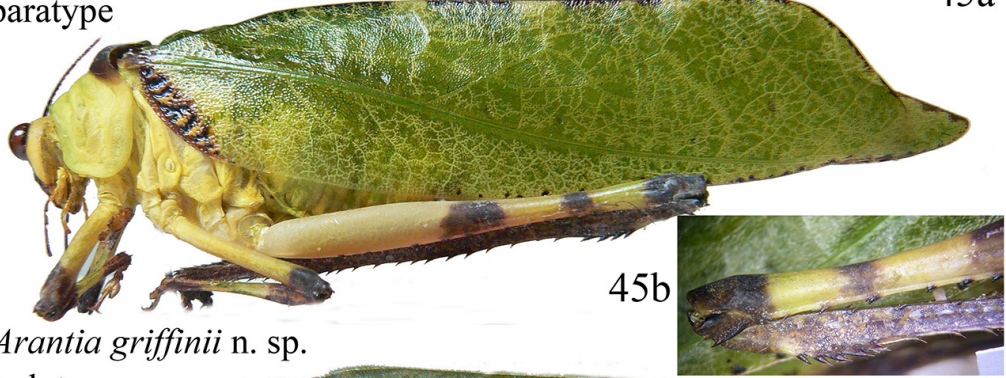

holotype
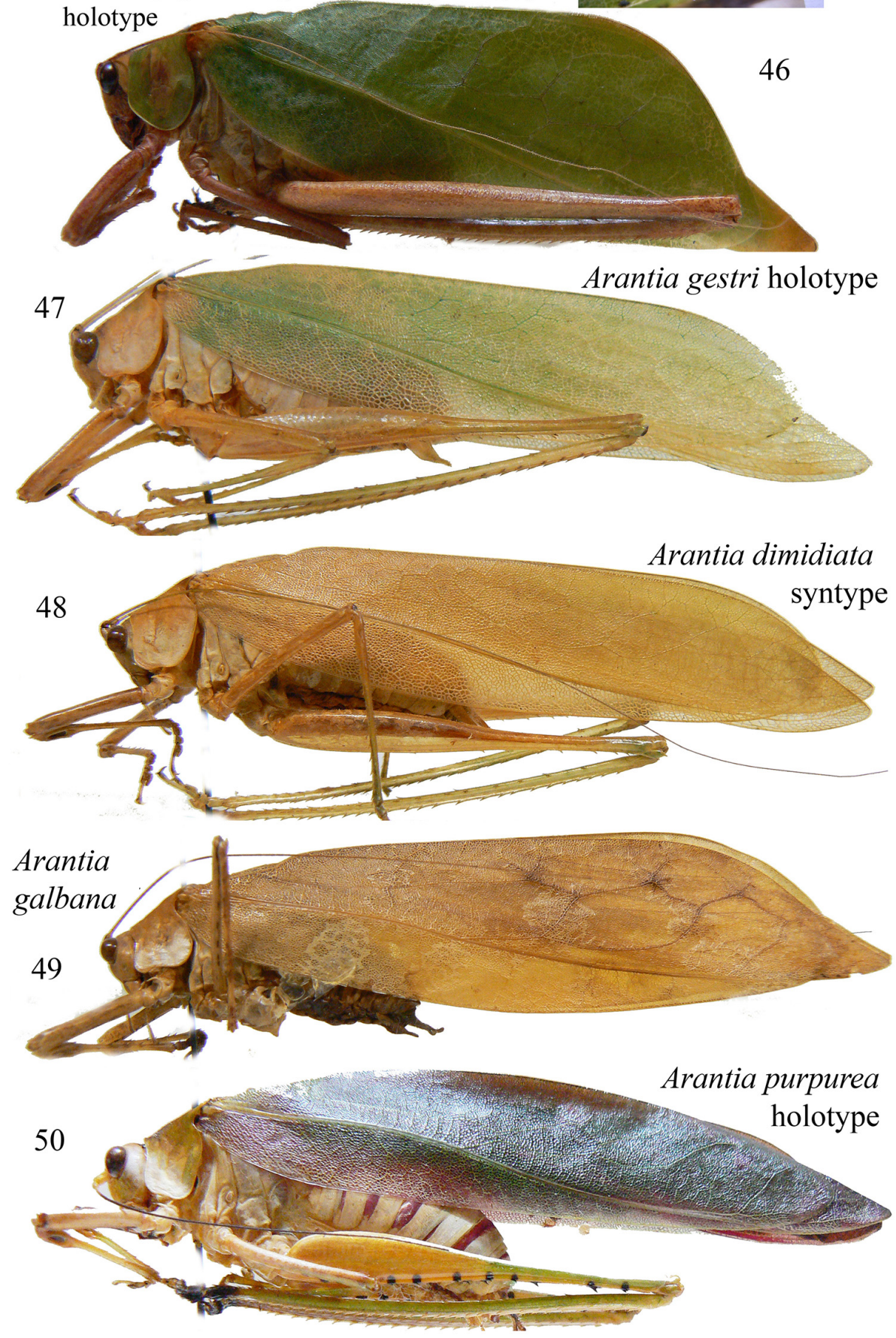

FIGURES 45-50. Habitus of Arantia (Euarantia) tibiaspinosa n. sp. (45a), inset expanded spiny base at joint with femur of hind tibia (45b), A. (Euarantia) griffinii n. sp. (46), Arantia (Goetia) gestri (holotype) (= A. dimidiata) (47), A. (Goetia) dimidiata (syntype) (48), A. (Goetia) galbana (49) and A. (Goetia) purpurea (holotype) (50). 


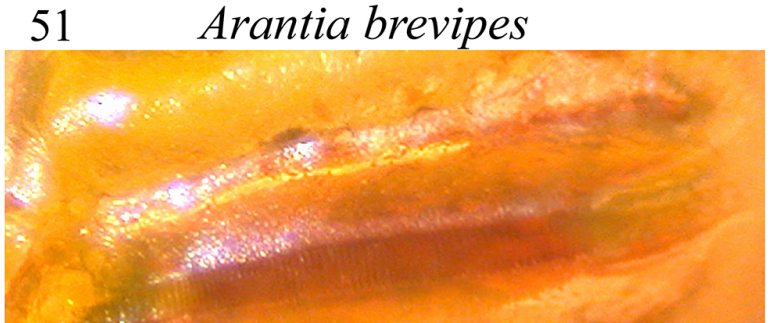

53 Arantia simplicinervis

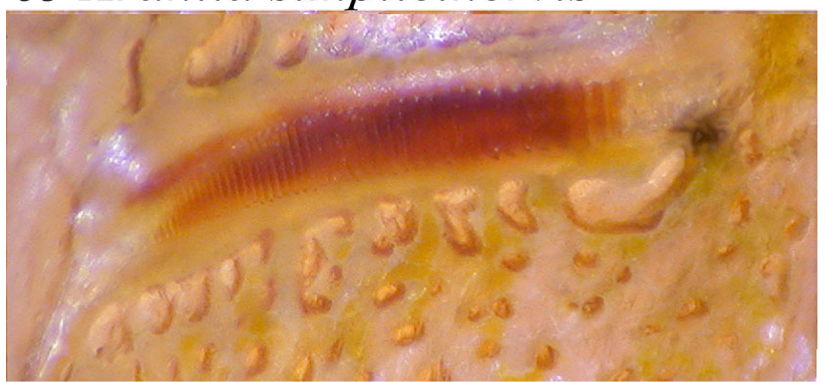

55 Arantia fasciata Mt. Kilimanjaro

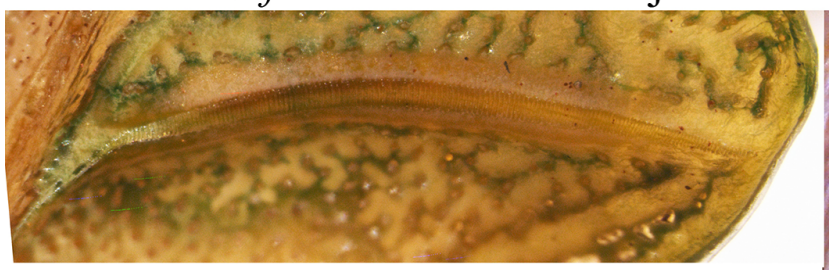

57 Arantia rectifolia

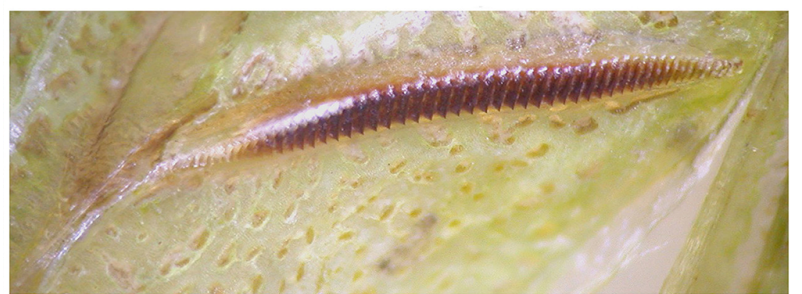

\section{Arantia regina}

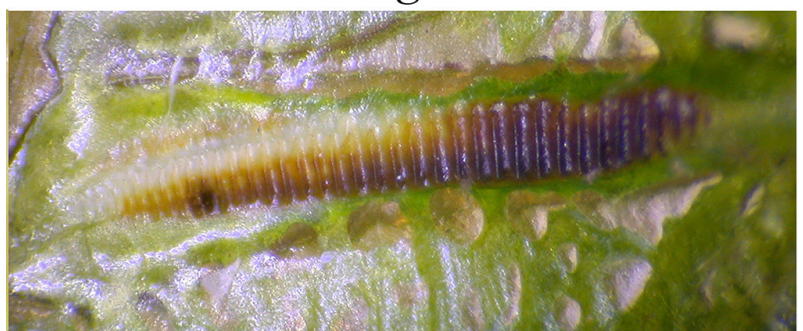

$61 \quad$ Arantia congensis

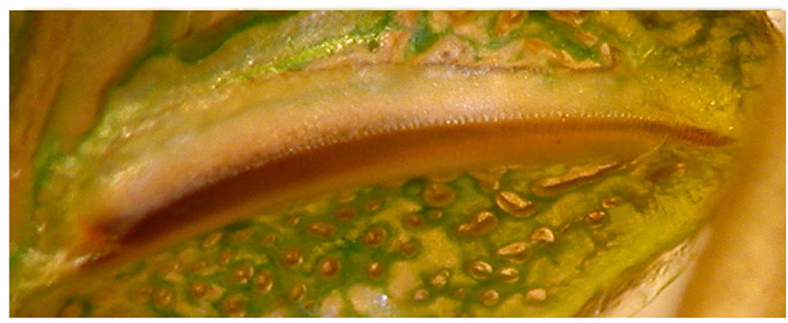

Arantia ivoriana n. sp.

52

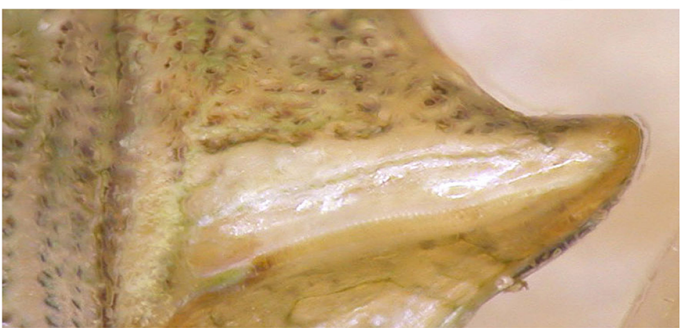

Arantia quinquemaculata n. sp. 54
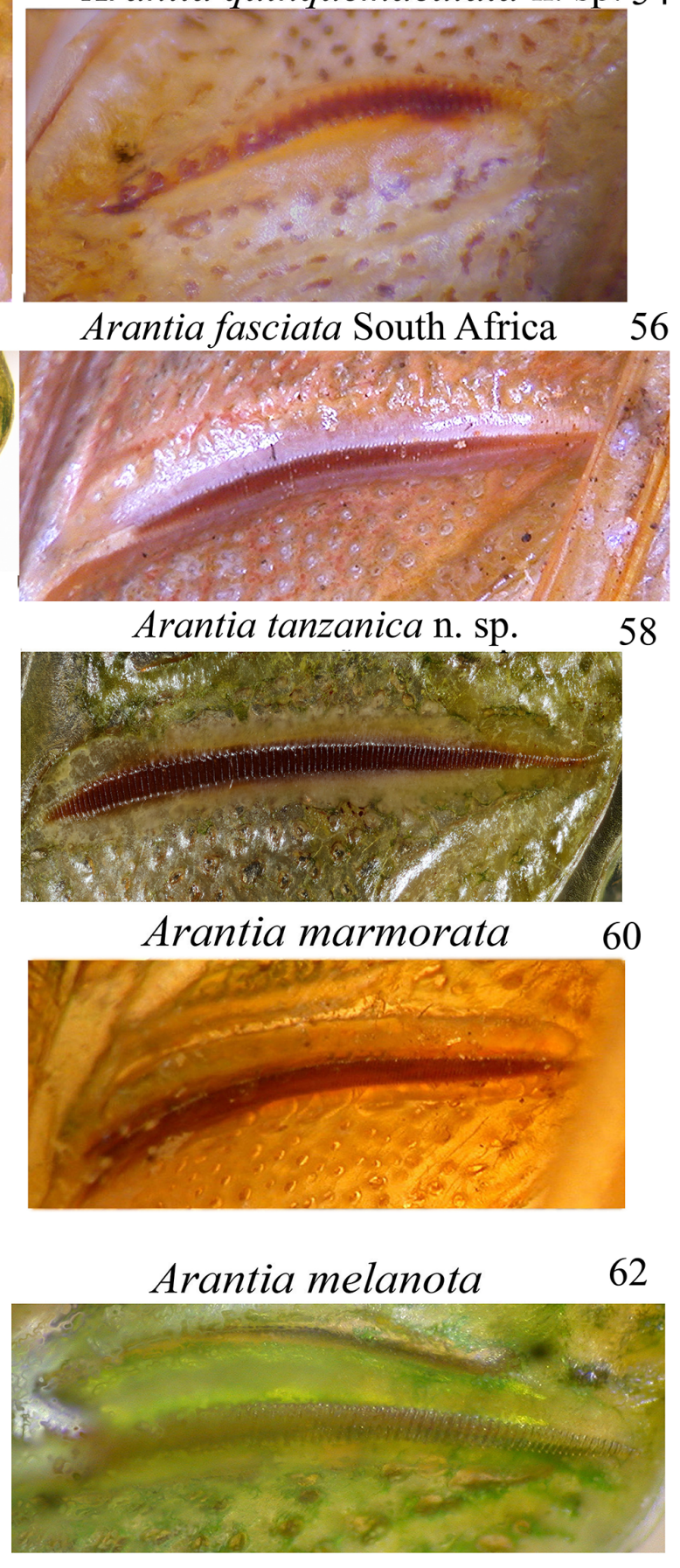

FIGURES 51-62. Stridulatory files of Arantia brevipes (51), Arantia ivoriana n. sp. (52), Arantia simplicinervis (53), Arantia quinquemaculata n. sp. (54), Arantia fasciata from Mt. Kilimanjaro (55), Arantia fasciata from South Africa (56), Arantia rectifolia (57), Arantia tanzanica n. sp. (58), Arantia regina (59), Arantia marmorata (60), Arantia congensis (61) and Arantia melanota (62). 

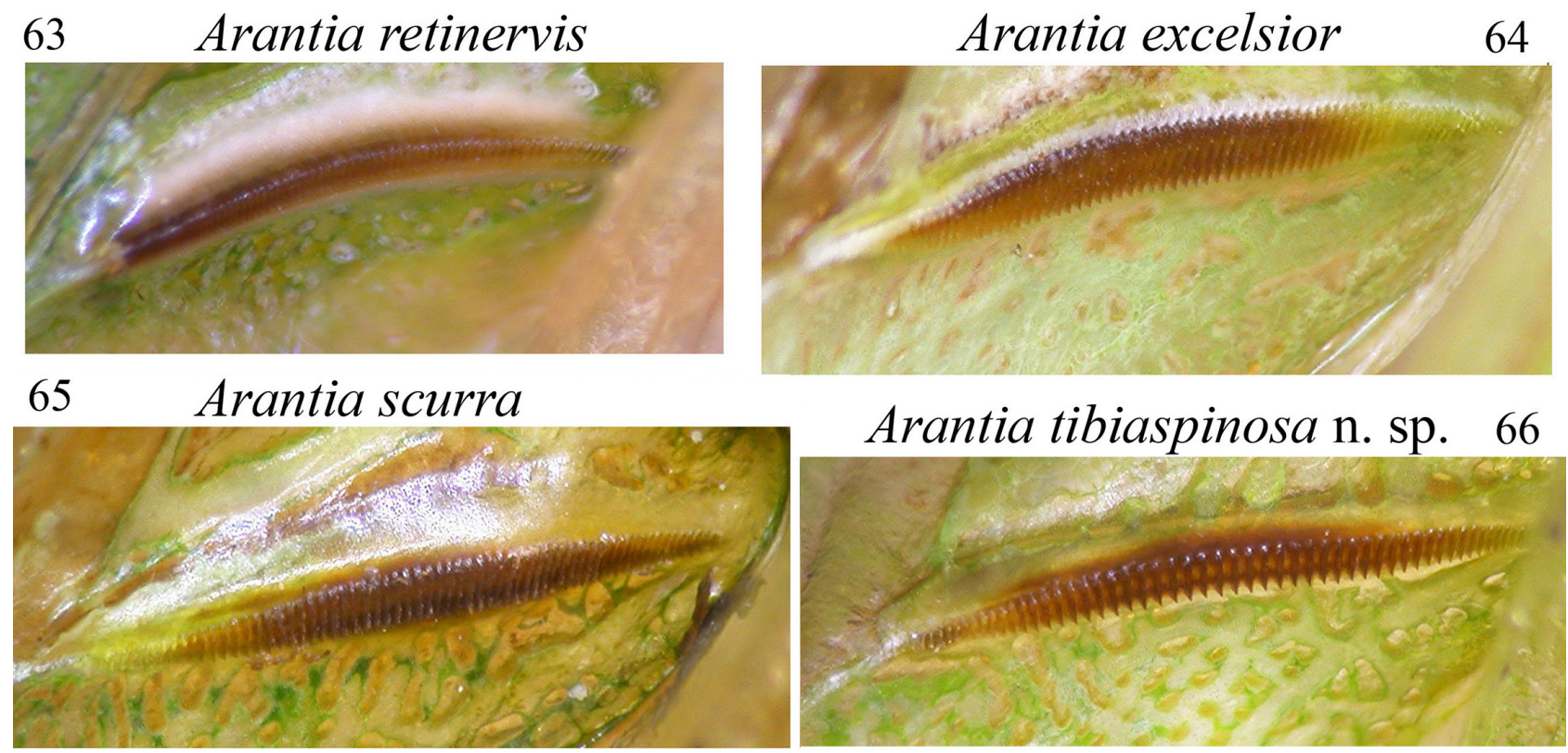

\section{Arantia tibiaspinosa n. sp. 66}

67 Arantia griffinii n. sp.
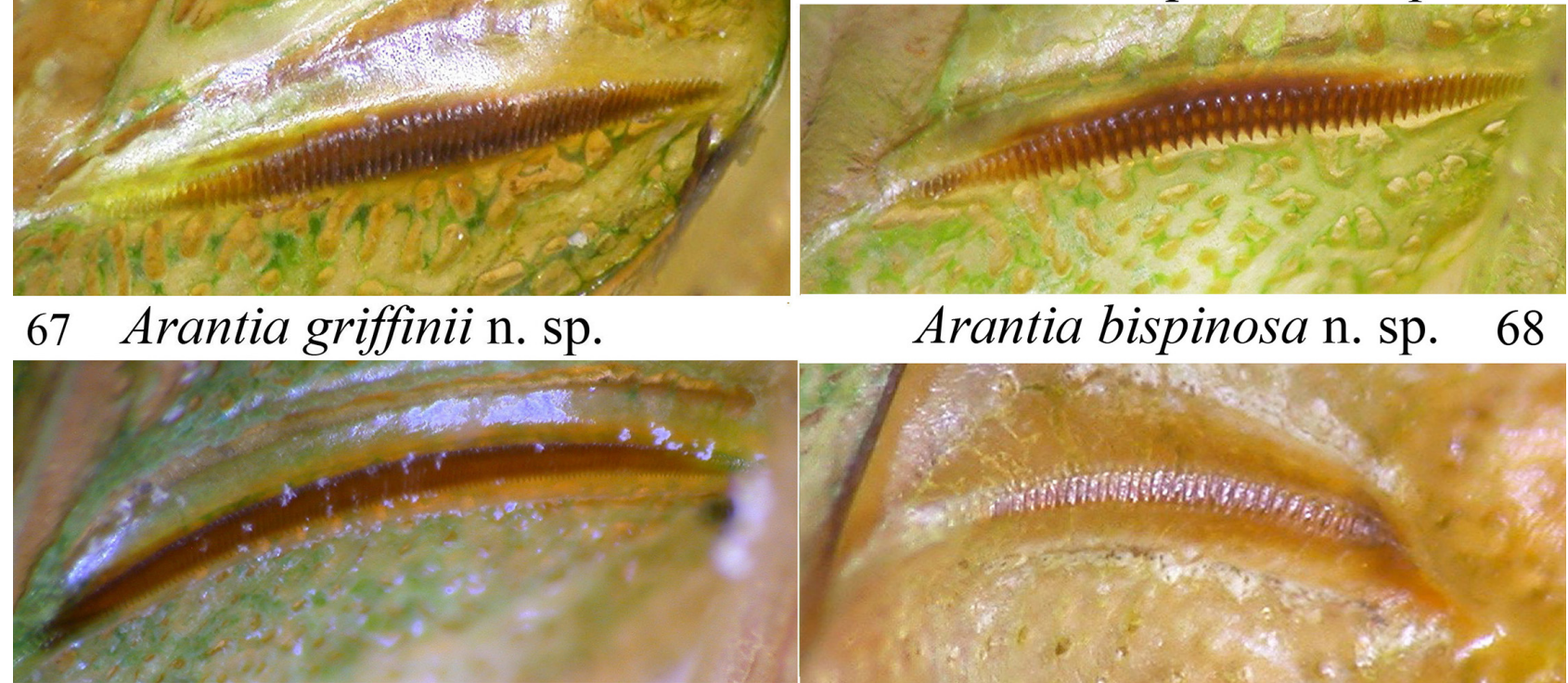

Arantia bispinosa n. sp. 68

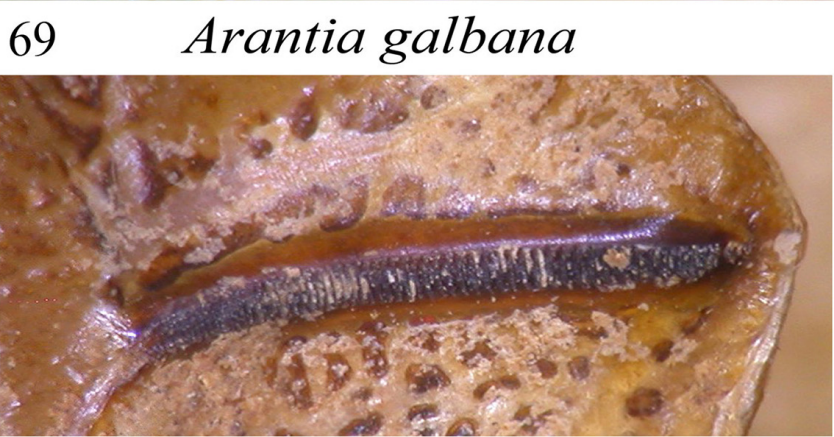

71 Arantia purpurea
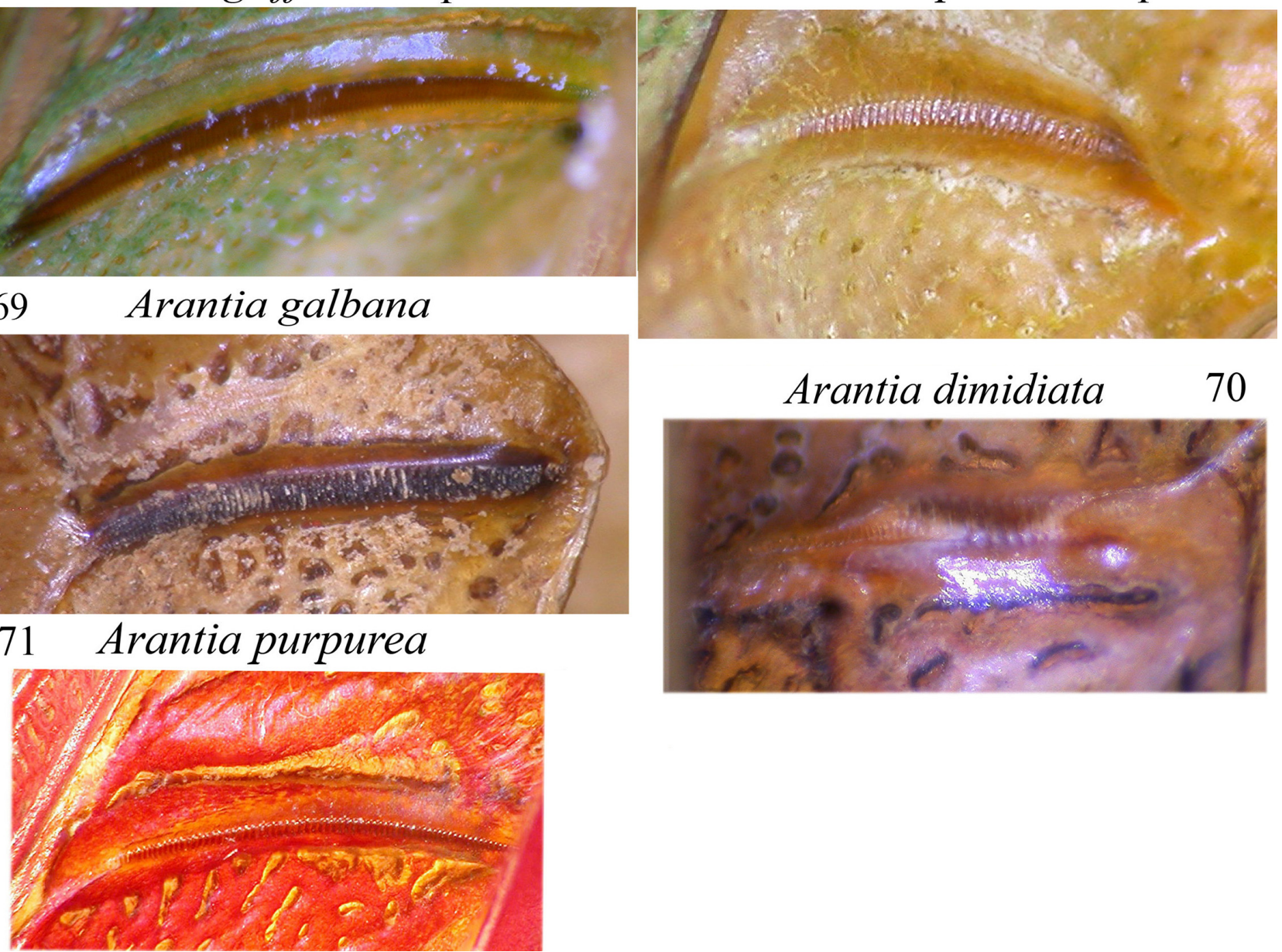

FIGURES 63-71. Stridulatory files of Arantia retinervis (63), Arantia excelsior (64), Arantia scurra (65), Arantia tibiaspinosa n. sp. (66), Arantia griffinii n. sp. (67), Arantia bispinosa n. sp. (68), Arantia galbana (69), Arantia dimidiata (70) and Arantia purpurea (71). 

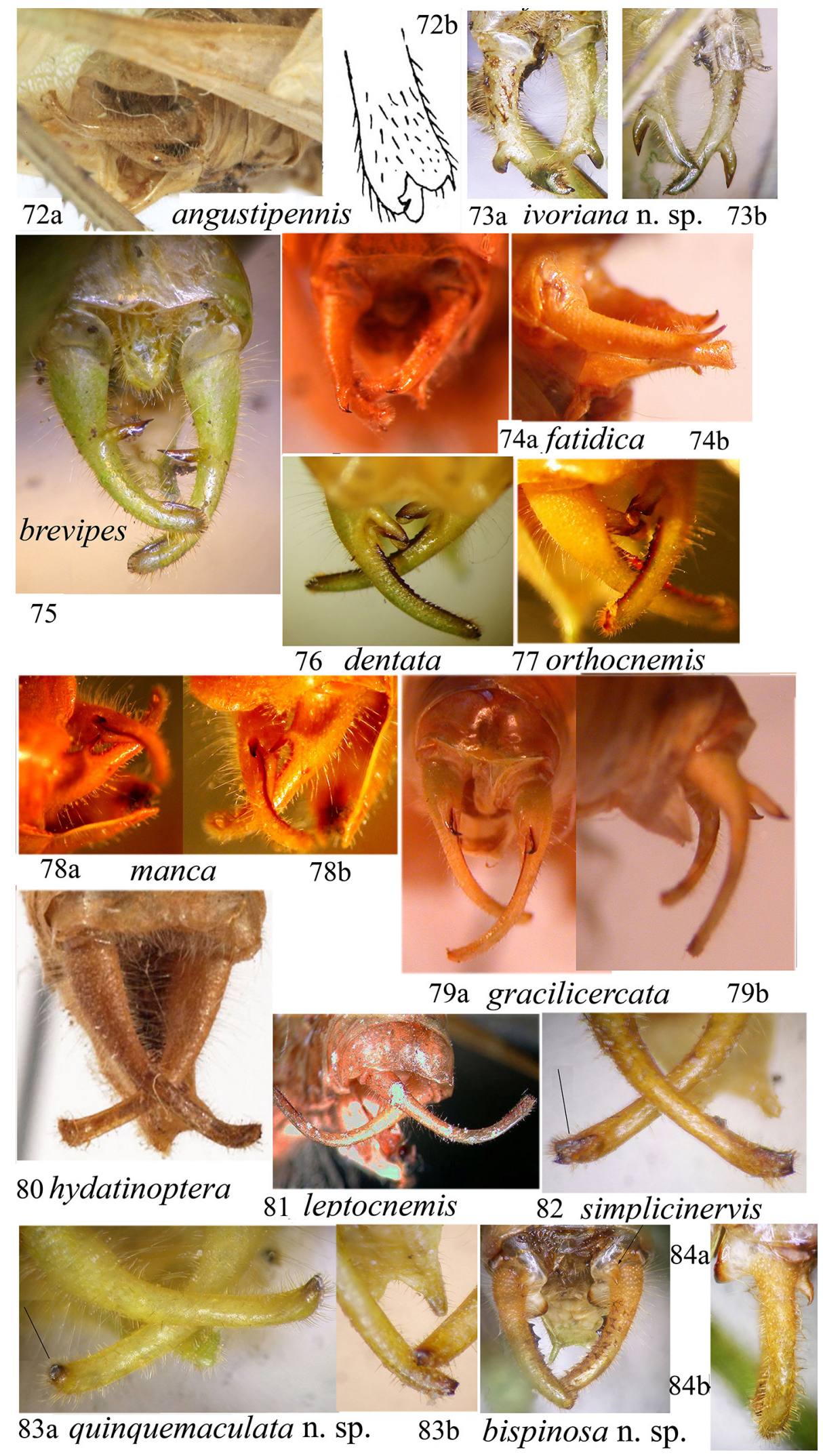

FIGURES 72-84. Cerci of Arantia angustipennis (72a) and original drawing of Chopard (1954) (72b), Arantia ivoriana $\mathbf{n} . \mathbf{s p . ~}$ (dorsal and ventral view) (73a, 73b), Arantia fatidica (dorsal and lateral view) (74a, 74b), Arantia brevipes (75), Arantia dentata (76), Arantia orthocnemis (77), Arantia manca (lateral and dorsal view) (78a, 78b), Arantia gracilicercata (dorsal and lateral view) (79a, 79b), Arantia hydatinoptera (80), Arantia leptocnemis (81), Arantia simplicinervis (82), Arantia quinquemaculata n. sp. (83a, 83b), and Arantia bispinosa n. sp. (dorsal view and lateral view of left cercus) (84a, 84b). 

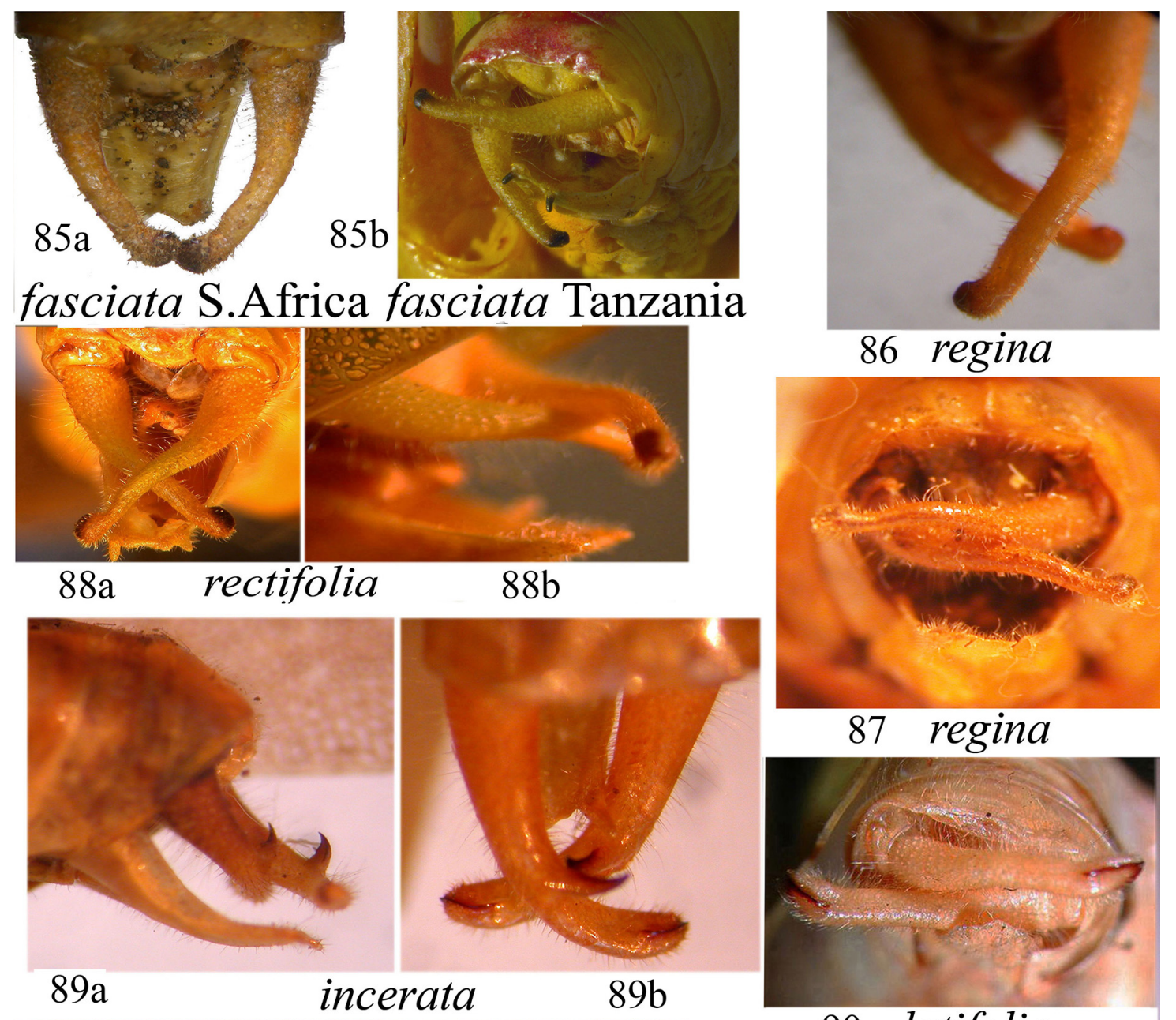

87 regina
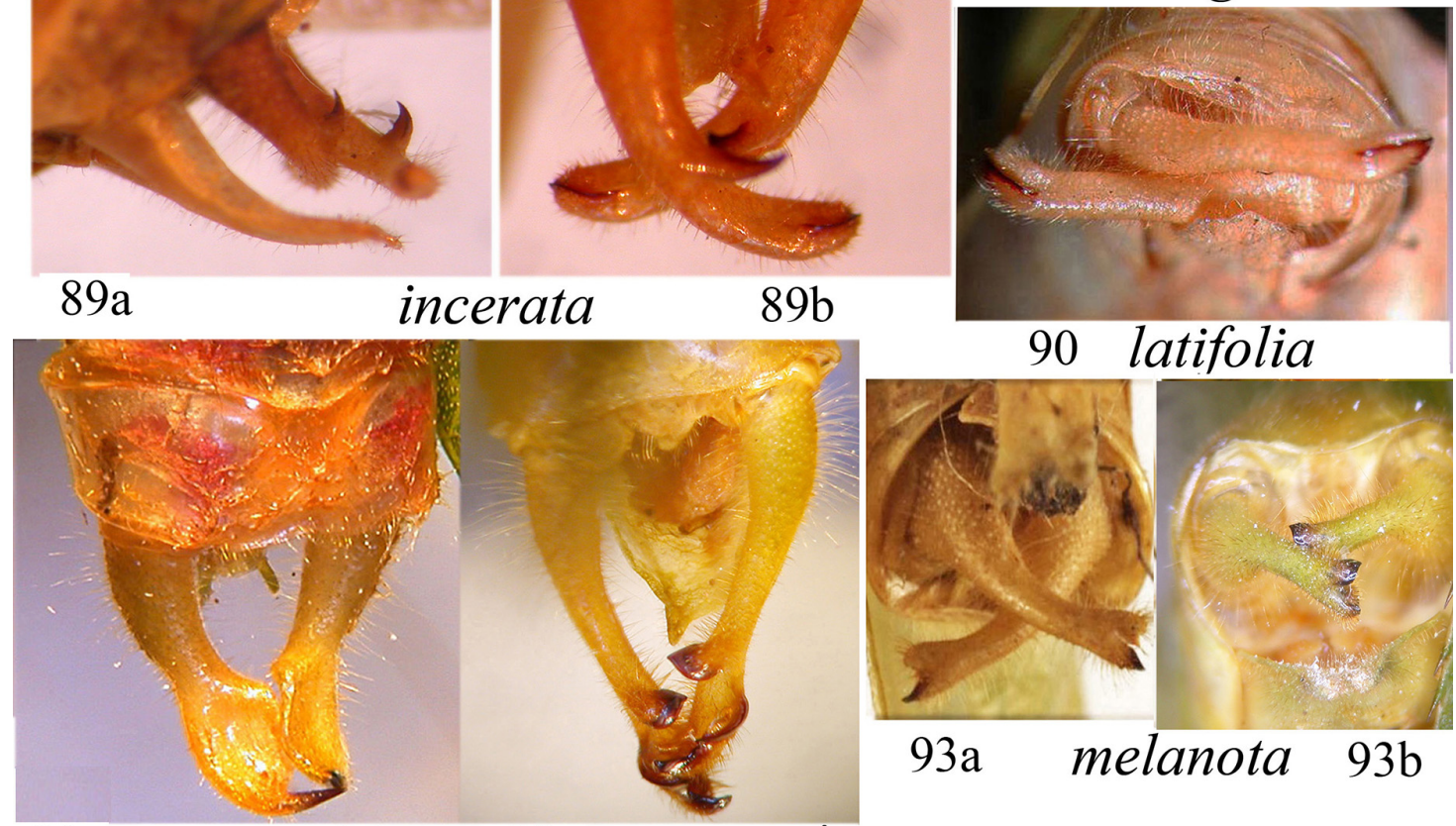

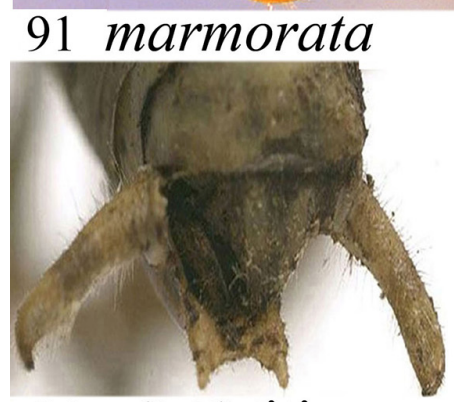

94 mauritiana
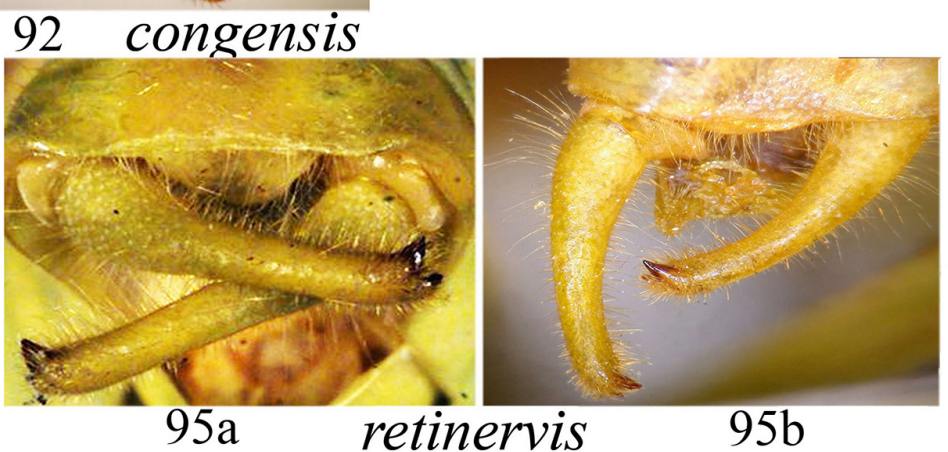

FIGURES 85-95. Cerci of Arantia fasciata from South Africa (85a) and Tanzania (85b), Arantia regina (86, 87), Arantia rectifolia (dorsal and lateral view) (88a, 88b), Arantia incerata (lateral and dorsal view) (89a, 89b), Arantia latifolia (90), Arantia marmorata (91), Arantia congensis (92), Arantia melanota (93a, 93b), Arantia mauritiana (94) and Arantia retinervis (95a, 95b). 

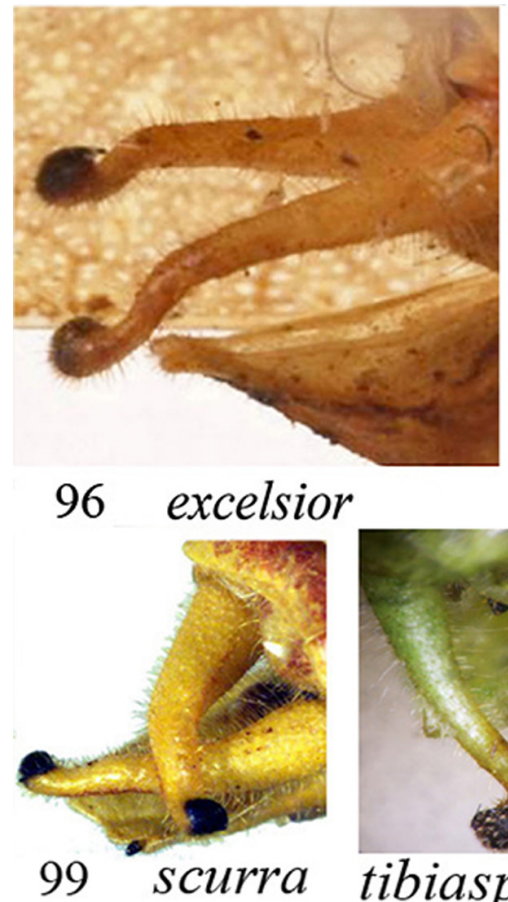

99 scurra

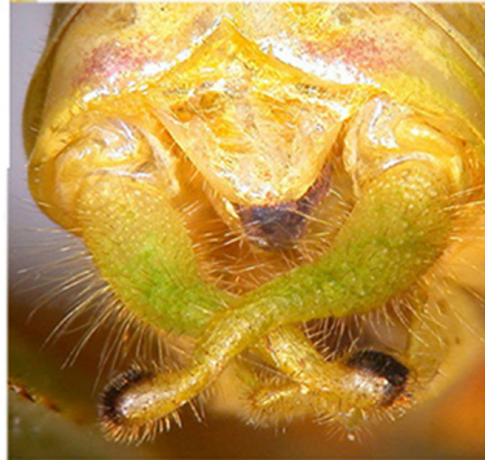

97 excelsior

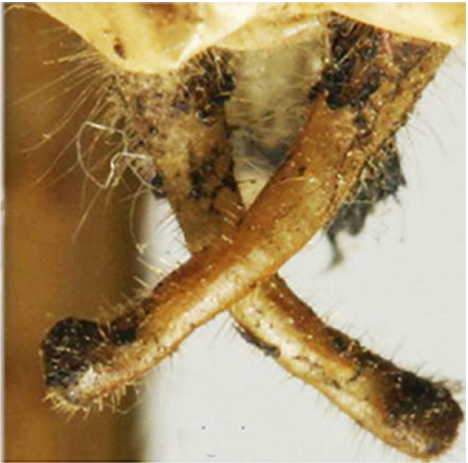

98 tigrina
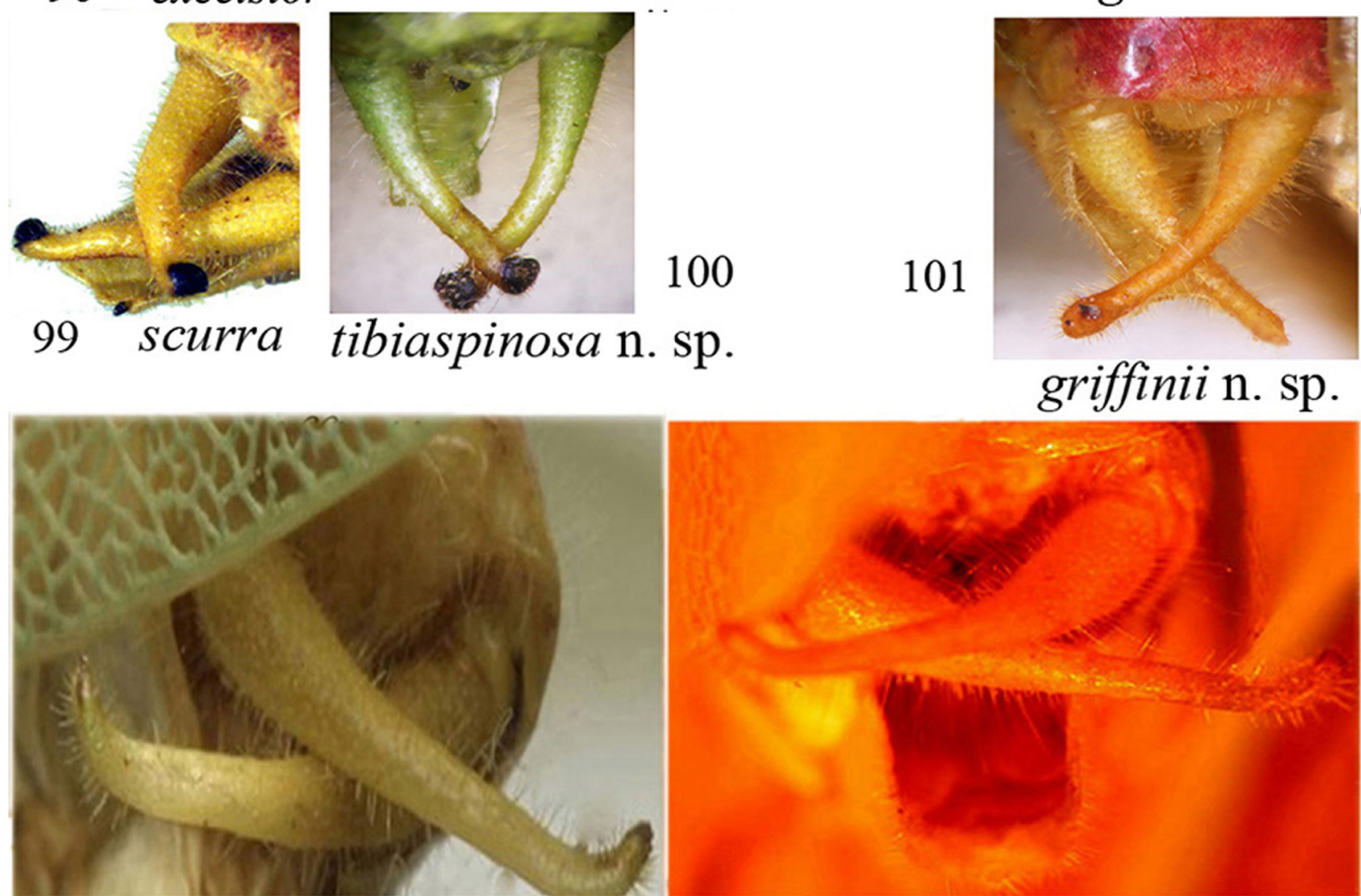

griffinii n. sp.

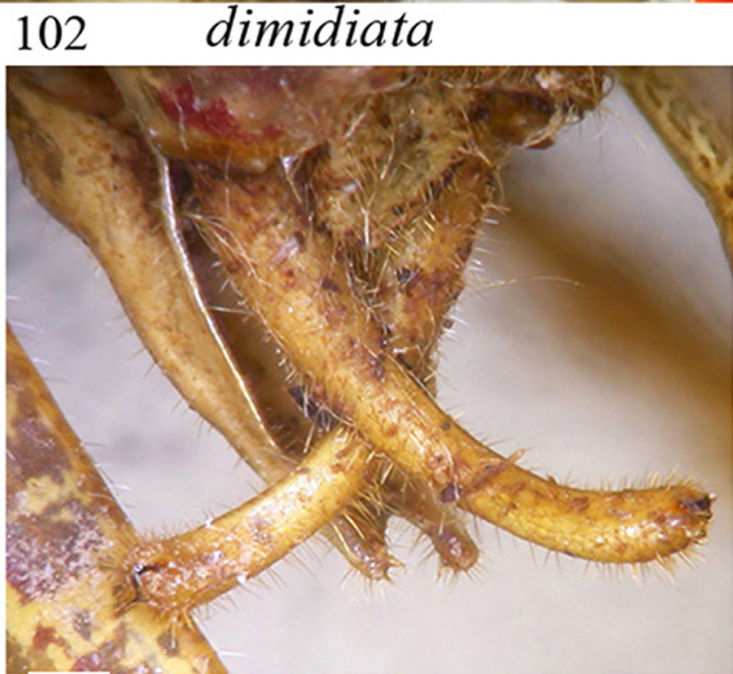

104

galbana

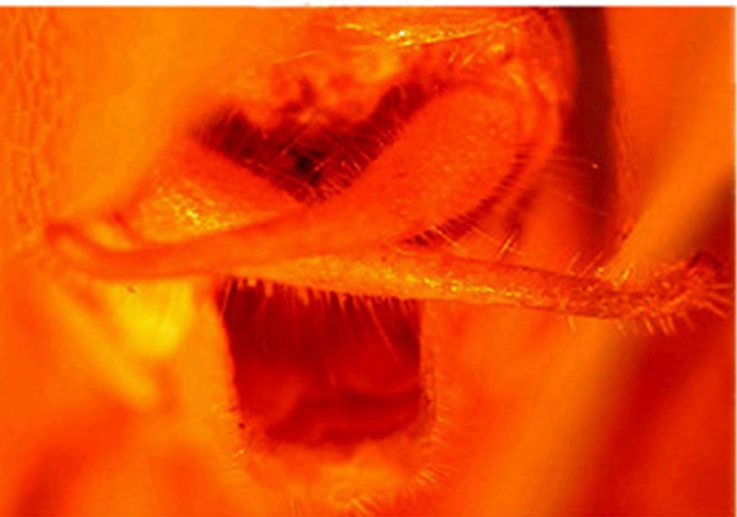

103

gestri

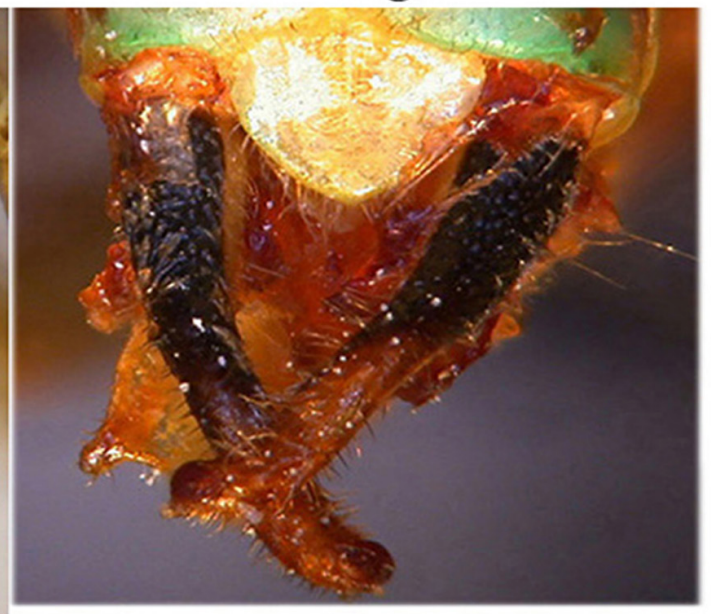

105 purpurea

FIGURES 96-105. Cerci of Arantia excelsior (96, 97), Arantia tigrina (= A. excelsior) (98), Arantia scurra (99), Arantia tibiaspinosa n. sp. (100), Arantia griffinii n. sp. (101), Arantia dimidiata (102), Arantia gestri (= A. dimidiata) (103), Arantia galbana (104) and Arantia purpurea (105). 


\section{Remarks on the genus Arantia}

The genus Arantia at present consists of 31 species, 12 in the subgenus Arantia, 16 in the subgenus Euarantia and 3 in the newly erected subgenus Goetia.

Most species of the subgenus Arantia seem very closely related to each other as suggested by a uniform habitus, being of slender built with almost translucent elongate and light green tegmina and a similar genital system of the males. A. leptocnemis and A. hydatinoptera males have slender elongate cerci while those of $A$. simplicinervis and $A$. quinquemaculata $\mathbf{n}$. sp. are comparatively stout. In A. leptocnemis the male cerci are more slender, also at their base and not flattened at their apical parts as in A. hydatinoptera. The bases of the male cerci are stout in A. hydatinoptera and the apical parts flattened and incurved. Also A. manca, A. orthocnemis and $A$. gracilicercata have long and slender male cerci but differ from the latter two species in having an inner cercal process or spine and an inner sclerotized ridge stretching from the base to the apex of the male cerci. Beside differences in body size (A. manca is smaller than the other two species of this group) these species may be distinguished by the different shape of the inner cercal process of the male cerci. This inner process is large with a conspicuous sclerotized ridge encircling the process in A. orthocnemis. In A. gracilicercata the inner cercal process is strongly developed with an inwardly curved tip but without a sclerotized ridge. In A. manca the inner cercal spine is tiny and thorn-like and of brown colour. Further in $A$. manca the male cerci are stouter than in the other Arantia species with an inner cercal process. A. fatidica is characterized by comparatively stout male cerci that wear sclerotized dents at their tips and an inner stout spine midway on the cerci. A. dentata, a species known from Mauritius only is morphologically very similar to A. orthocnemis. A syntype of A. dentata was studied in the collection of Geneva coming from Cameroon. However, this latter specimen for sure belongs to A. orthocnemis rather than $A$. dentata. Both localities lie so far apart from each other that it is not very likely that a species occurs both in the Indian Ocean on a remote island and in Central Africa. This shows that both species are morphologically so closely related that they had been synonymized if they occurred geographically more closely. Also of small size are the West African species A. brevipes and A. angustipennis, with stout male cerci and a sclerotized ridge at the apices. The male cerci of $A$. brevipes have an inner tooth midway on the cerci, similar to $A$. fatidica. However, the cercal tips are flattened in comparison to the male cerci of $A$. fatidica. Most species of the subgenus Arantia have elongate light green and almost translucent tegmina.

Sixteen species belong to the subgenus Euarantia. Study of types in different collections in Europe showed that several species are synonymous. Few species of Euarantia have strongly oval-shaped tegmina, the tegmina of other species of this subgenus are more elongate. Especially A. rectifolia, has very narrow tegmina, and is thus intermediate between the subgenera Arantia and Euarantia. Thus, we consider the choice of placing species within subgenera only an easy way to separate species into three main groups until more information e.g. on the molecular phylogeny gets available.

A. rectifolia is a widespread taxon with some morphological variation suggesting a species complex. At first specimens collected in Tanzania in Miombo woodlands were considered as belonging to A. rectifolia. Only the study on the stridulatory file and some size differences showed that it belonged to a new taxon, described here as $A$. tanzanica $\mathbf{n}$. sp.

Very striking is also that several Arantia species occur syntopically in forests in Central and West Africa. Thus, individuals of $A$. scurra were collected at the same time at light traps with A. tibiaspinosa $\mathbf{n}$. sp. At first they were considered being one species because of the very similar striking colour pattern of striped legs and dark joints of the knees and the dark brown coloured metanotum. Only closer studies of the individuals showed that two species were caught at the same time. A. scurra was at present only known from the male holotype coming from Cameroon. Thus the second population now recorded from the Ivory Coast suggests a larger distribution of this beautiful species. Also A. regina, A. rectifolia, A. brevipes, A. bispinosa n. sp. and A. ivoriana $\mathbf{n}$. sp. were trapped at the same locality during the same time of the year (March 2017, Tai Forest National Park).

In this study we place three species of the former Goetia under Arantia as a subgenus since Goetia only differs from species of the subgenus Arantia by the presence of a coxal spine. Since A. gestri was the only species in the genus Arantia with a coxal spine we transferred this species to the here newly erected subgenus Goetia and synonymized it with G. dimidiata. Both species were described at the same time by Bolívar and Griffini in 1906 (only 4 days apart) and both authors were not aware of the species description of the other.

Our study of Arantia shows that also fully alate and large species underwent rapid speciation in Africa. Arantia 
is one of the species richest genera of tropical African Phaneropterinae (beside Eurycorypha Stål, 1873 or Catoptropteryx Karsch, 1890). Still some species are known only from the types and nothing is known about the biology, habitat and song of most Arantia species. More studies on this genus will shed light on large scale speciation patterns of an African taxon.

\section{Acknowledgements}

B. Massa thanks Philippe Moretto and Philippe Annoyer, who kindly provided material collected during the 20092012 Sangha expeditions (www.insectesdumonde.org); Philippe Annoyer, President of the Association Insectes du Monde, Matias Loubes, President of the Association Tout-là-haut, Jean-Louis Fijalkowski, responsible of logistics during the preparation of the expedition Sangha 2012, and Bongola Dieubénit Omonoma, responsible of logistics for the captures of insects within the forest during the expedition Sangha 2012. We thank also His Excellency JeanPierre Vidon, Ambassador of France in Bangui, His Excellency François Naoueyama, Minister of Environment and Ecology, His Excellency Emmanuel Bizot, Minister for Forestry, Hunting and Fishing, His Excellency the Minister for Education, Literacy, Higher Education and Research, His Excellency Karim Mekassoua, Minister of State Sangha-M'Baere; Gustave Doungoube, Environment Project Manager and Bob Konzi-Sarambo, ecology Project Manager, National Focal Point of Conservation on Biological Diversity at the Ministry of the Environment and the Ecology, for their support and assistance in obtaining necessary permits; the University of Bangui, Faculty of Science, Central African Republic, for the active participation in the Sangha mission, through Prof. Georgette Florence Koyt Deballé, Rector, Prof. Dr. Joachim Rouauld, Vice Rector, Prof. Dr. Jean-Laurent Syssa-Magalé, Dean of the Faculty of Science, University of Bangui, member of the Sangha Scientific Committee, for all resources provided to efficiently run the project; Serge Florent Bolevane Ouantinam, Department Head of Life Sciences, and Olga Yongo, for documents and granted facilitations; Jean-Bernard Yarissem, Chief Director of the WWF program in Central African Republic, Sylvain Dongolo, Angelique Todd, WWF chief scientist at Bayanga for authorizations in the Dzanga-N'Doki National Park; sampling in the canopy was made possible by the association "Tout Là-Haut" represented by Mr. Erwan Le Couillard, Matias Loubes, David Siegwalt and Yoan Ramos. We also would like to mention Mr. Jean-Louis Fijalkowski for his logistical help in Bangui, porters and guides who, from Bayanga, accompanied the expedition, the Central African population, partners and all persons who directly or indirectly supported the Sangha project team, Biodiversité en Terre Pygmée.

Without support of the Synthesys Project, which is financed by European Community Research Infrastructure Action under the FP7 "Capacities" Programme, this study would not have been possible. Synthesys enabled us to visit the collections at the Museo Nacional de Ciencias Naturales of Madrid (CSIC) (2013: B. Massa; 2014: C. Hemp), the Natural History Museum London (C. Hemp), the Museum Naturkunde of Berlin (2014: B. Massa), the Naturhistorisches Museum of Vienna (2015: C. Hemp; 2016: B. Massa), the National Museum of Natural History of Prague (2016: B. Massa), the Naturhistoriska Rikmuseet Stockholm, Sweden (2017: C. Hemp) and the Royal Belgian Institute Natural Sciences, Bruxelles (2017: B. Massa). We are especially indebted to Mercedes Paris (Museo Nacional de Ciencias Naturales of Madrid), Michael Ohl (Museum für Naturkunde of Berlin), Susanne Randolf and Harald Bruckner (Naturhistorisches Museum, Vienna), Laure Desutter and Simon Poulain (Muséum National d'Histoire Naturelle, Paris), Martin Fikáček (National Museum Natural History, Prague), Roberto Poggi, Maria Luisa Tavano and Giuliano Doria (Museo Civico di Storia Naturale 'G. Doria' of Genoa), Stefano Maretti and Jessica Maffei (Museo Storia Naturale University of Pavia), Fabrizio Rigato (Museo Civico di Storia Naturale of Milan), Luca Bartolozzi (Museo di Zoologia 'La Specola', University of Florence), Jerome Constant (Royal Belgian Institute of Natural Sciences, Bruxelles), and Gunvi Lindberg (Naturhistoriska Riksmuseet Stockholm, Sweden), who facilitated the study of specimens preserved in their museums. We thank very much Giovanni Boano and Marco Pavia (University of Turin), who sent some specimens from Burkina Faso, and John Hollier (Muséum d'Histoire Naturelle, Genève) for his advices and photographs of Arantia dentata. We are indebted to Max Barclay, Natural History Museum, London for facilitation to study and loan Orthoptera to BM (including some Arantia) collected by Marios Aristophanous, Enrico Ruzzier (Natural History Museum, London) and P. Moretto in Ivory Coast. The collecting and study of the material from Ivory Coast was made possible thanks to the support of the African Natural History Research Trust (Hereford, UK) and Richard E. L. Smith. Finally, we would thank very much Sigfrid Ingrisch, who allowed us to use some of his photographs present on OSF. We thank very much also the managers of the Orthoptera Species File. 
Collecting authorisation were obtained as follows: 019/UB/DSV2012 of 16.I.2012 from Bangui University, Central African Republic; 135/MESRS/DGRSIT/mo of 12.VI.2015, 238/MESRS/DGRSIT/mo of 13.X.2015, 040/ MESRS/DGRSIT/mo of 8.III.2016 from the Ministère de l'Einsegnement Superieur e de la Recherche Scientifique of Ivory Coast, 0429/MINEDD/OIPR/DG of 14.VII.2016, 0505/MINEDD/OIPR/DG of 18.VIII.2016 from the Ministère de l'Environnement et du Développement Durable of Ivory Coast, 021/MESRS/DGRI of 15.II.2017 from the Ministère de l'Einsegnement Superieur e de la Recherche Scientifique of Ivory Coast. We gratefully acknowledge grants by the Deutsche Forschungsgemeinschaft and the Tanzanian Commission for Science and Technology (COSTECH) as well as the Tanzania Wildlife Research Institute (TAWIRI) for permitting research in Tanzania, East Africa.

\section{References}

Bruner, L. (1920) II. Orthoptera from Africa, being a report upon some Saltatoria mainly from Cameroon contained in the Carnegie Museum. Annals Carnegie Museum, 13 (1919), 92-142. Available from: http://www.biodiversitylibrary.org/ item/38118 (Accessed 5 Dec. 2017)

Brunner von Wattenwyl, C. (1878) Monographie der Phaneropteriden. F.A. Brockhaus, Vienna, 401 pp. Available from: http:/ /www.biodiversitylibrary.org/item/49919\#page/141/mode/1up (Accessed 5 Dec. 2017)

Brunner von Wattenwyl, C. (1891) Additamenta zur Monographie der Phaneropteriden. Verhandlungen der ZoologischBotanischen Gesellschaft in Wien, 41, 1-96. Available from: http://www.biodiversitylibrary.org/item/49919\#page/141/ mode/1up (Accessed 5 Dec. 2017)

Chopard, L. (1954) La réserve naturelle intégrale du Mont Nimba. II. Orthoptères Ensifères. Mémoires Institut français Afrique noire, 40, 25-97.

Cigliano, M.M. \& Braun, H., Eades, D.C. \& Otte, D. (2017) Orthoptera Species File Online. Version 2.0/4.0. Available from: http://Orthoptera.SpeciesFile.org (accessed 2 September 2017)

Ebner, R. (1943) Einige Orthoptera Saltatoria von Fernando Poo (Spanisch-Guinea). 28. Beitrag zu den wissenschaftlichen Ergebnissen der Westafrika-Expedition Eidmann 1939-40. Zoologische Anzeiger, 143, 259-274.

Giglio Tos, E. (1907) Ortotteri Africani. Parte II. Blattodea, Mantodea, Phasmodea, Locustodea, Gryllodea. Bollettino Museo Zoologia Anatomia comparata Real Università Torino, 22 (563), 1-26. Available from: http:// www.biodiversitylibrary.org/item/43468\#page/125/mode/1up (Accessed 5 Dec. 2017)

Griffini, A. (1906) Ortotteri raccolti da Leonardo Fea nell'Africa occidentale. 1. Hetrodidi, Conocephalidi, Meconemidi, Pseudophyllidi, Mecopodidi e Fanerotteridi. Annali Museo civico Storia naturale Genova, 2, 358-397.

Griffini, A. (1908) Phasgonuridae africane del R. Museo di Storia Naturale in Bruxelles. 6. Phaneropteridae pars 2a (reliquae species omnes). Mémoires Société entomologique Belgique, 15, 201-226. Available from: http:// www.biodiversitylibrary.org/item/41740\#page/215/mode/1up (Accessed 5 Dec. 2017)

Hadley, A. (2008) Combine Z. Available from: http://www.hadleyweb.pwp.blueyonder.co.uk/ (accessed 20 Feb. 2009)

Heller, K.-G., Hemp, C., Ingrisch, S. \& Liu, C. (2015) Acoustic Communication in Phaneropterinae (Tettigonioidea) - A Global Review with Some New Data. Journal of Orthoptera Research, 24, 7-18. https://doi.org/10.1665/034.024.0103

Heller, K.-G., Hemp, C., Liu, C. \& Volleth, M. (2014) Taxonomic, bioacoustic and faunistic data on a collection of Tettigonioidea from Eastern Congo (Insecta: Orthoptera). Zootaxa, 3785 (3), 343-376. https://doi.org/10.11646/zootaxa.3785.3.2

Hemp, C. (2005) The Chagga Home Gardens - relict areas for endemic Saltatoria Species (Insecta: Orthoptera) on Mt. Kilimanjaro. Biological Conservation, 125, 203-210. https://doi.org/10.1016/j.biocon.2005.03.018

Hemp, C. (2013a) Annotated list of Ensifera (Orthoptera) and further records on Caelifera (Orthoptera) of Mt Kilimanjaro, Tanzania. Zootaxa, 3613 (4), 301-342. https://doi.org/10.11646/zootaxa.3737.4.1

Hemp, C. (2013b) Annotated list of Tettigoniidae (Orthoptera) from the East Usambara Mountains, Tanzania and new Tettigoniidae species from East Africa. Zootaxa, 3737 (4), 301-350. https://doi.org/10.11646/zootaxa.3737.4.1

Karsch, F. (1889) Orthopterologische Beiträge. III. Berliner entomologische Zeitschrift, 32, 415-464. Available from: http:// www.biodiversitylibrary.org/item/34458\#page/475/mode/1up (Accessed 5 Dec. 2017)

Karsch, F. (1890) Verzeichniss der von Herrn Dr. Paul Preuss auf der Barombi-Station in Deutsche-Westafrika 1890 gesammelten Locustoden aus den Familien der Phaneropteriden, Mekonemiden und Gryllakriden. Entomologische Nachrichten Berlin, 16, 353-369. Available from: http://www.biodiversitylibrary.org/item/81935\#page/367/mode/1up (Accessed 5 Dec. 2017)

Karsch, F. (1891) Übersicht der von Dr. Paul Preuss auf der Barombi-Station in Kamerun gesammelten Locustodeen. Berliner Entomologische Zeitschriftm, 36 (2), 317-346. 
Karsch, F. (1893) Springheuschrecken - Orthoptera Saltatoria - von Adeli. Berliner entomologische Zeitschrift, 38, 49-166. Available from: http://www.biodiversitylibrary.org/item/38634\#page/71/mode/1up (Accessed 5 Dec. 2017)

Karsch, F. (1896) Neue Orthopteren aus dem tropischen Afrika. Stettiner entomologische Zeitung, 57, 242-359. Available from: http://www.biodiversitylibrary.org/item/36013\#page/250/mode/1up (Accessed 5 Dec. 2017)

Kirby, W.F. (1906) A synonymic catalogue of Orthoptera. Vol. II. Orthoptera Saltatoria. Part I. (Achetidae et Phasgonuridae). Printed by order of the Trustees [by Taylor and Francis], London, viii + 562 pp. Available from: http:// www.biodiversitylibrary.org/item/29662 (Accessed 5 Dec. 2017)

Liu, C., Liu, X. \& Kang, L. (2008) Review of the genus Holochlora Stål (Orthoptera, Tettigoniidae, Phaneropterinae) from China. Deutsche Entomologische Zeitschrift, 55 (2), 223-240. https://doi.org/10.1002/mmnd.200800023

Massa, B. (2013) Diversity of leaf katydids (Orthoptera: Tettigoniidae: Phaneropterinae) of Dzanga-Ndoki National Park, Central African Republic, with selected records from other African countries. Journal of Orthoptera Research, 22, $125-152$. https://doi.org/10.1665/034.022.0201

Massa, B. (2017) Two new African and Madagascar species of the genus Holochlora (Orthoptera Tettigoniidae Phaneropterinae). Fragmenta Entomologica. [in press]

Naskrecki, P. (2009) A Survey of Katydids (Insecta: Orthoptera: Tettigoniidae) of Ajenjua Bepo and Mamang River Forest Reserves, Eastern Region of Ghana. In: A Rapid Biological Assessment of Ajenjua Bepo and Mamang River Forest Reserves, Ghana. RAP Bulletin Biological Assessment, Conservation International, 2009, pp. 34-39. Available from: http://www.bioone.org/doi/book/10.1896/978-1-934151-26-6 (Accessed 5 Dec. 2017)

Paris, M. (1994) Catalogo de tipos de Ortopteroides (Insecta) de Ignacio Bolivar, I: Blattaria, Mantodea, Phasmoptera y Orthoptera (Stenopelmatoidea, Raphidophoroidea, Tettigonioidea, Grylloidea, Tetrigoidea). Eos, 69 (1993), 143-264.

Poggi, R. (2010) Gli «Annali» pubblicati dal Museo Civico di Storia Naturale "Giacomo Doria" di Genova: storia del periodico ed indici generali dei primi cento volumi (1870-2009). Annali Museo Civico Storia Naturale "Giacomo Doria”, Genova, 101, 1-530.

Ragge, D.R. (1968a) An index-catalogue of African Phaneropterinae (Orthoptera: Tettigoniidae). Bulletin of the British Museum (Natural History) Entomology, 22 (3), 75-108. Available from: http://www.archive.org/details/ bulletinofbritis22entolond (Accessed 5 Dec. 2017)

Ragge, D.R. (1968b) Contributions à la connaissance de la faune entomologique de la Côte-d'Ivoire (J. Decelle, 1961-1964). III. Orthoptera Tettigoniidae. Annales Museum Royale Afrique centrale, Zoologie, 165, 23-26.

Ragge, D.R. \& Roy, R. (1965) Contribution à l'étude de la faune de la basse Casamance (Sénégal). Bulletin Institute français Afrique noire, 27, 185-188.

Ragge, D.R. \& Roy, R. (1971) Le massif des Monts Loma. IX. Orthoptera Tettigoniidae. Mémoires Institute fondamental Afrique noire, 86, 249-259.

Rehn, J.A.G. (1914) Orthoptera I: Mantidae, Phasmidae, Acrididae, Tettigoniidae und Gryllidae aus dem Zentral-Afrikanischen Gebiet, Uganda und dem Ituri-Becken des Kongo. Wissenschaftliche Ergebnisse der deutschen Zentralafrika Expedition 1907-1908, 5, 1-223. Available from: http://www.biodiversitylibrary.org/page/966177\#page/7/mode/1up (Accessed 5 Dec. 2017)

Saussure, H. de (1899) Wissenschaftliche Ergebnisse der Reise in Madagaskar und Ostafrika in den Jahren 1889-95 von Dr. A. Voeltzkow. Orthoptera. Abhandlungen der Senckenbergischen Naturforschenden Gesellschaft, 21, 569-664. [http:// www.biodiversitylibrary.org/item/85045\#page/613/mode/1up (Accessed 5 Dec. 2017)

Sjöstedt, Y. (1902) Beitrage zur Kenntnis der Insektenfauna von Kamerun. 8. Locusten aus Kamerun und Kongo. Bihang Kongliga Svenska Vetenskaps-Akademiens Handlingar, 27 (4, 3), 1-45. Available from: http:// www.biodiversitylibrary.org/item/48743\#page/69/mode/1up (Accessed 5 Dec. 2017)

Sjöstedt, Y. (1912) Zur Orthopterenfauna des Kamerungebirges. Arkiv Zoologi, 7 (37), 1-30. Available from: http:// www.biodiversitylibrary.org/item/30233\#page/857/mode/1up (Accessed 5 Dec. 2017) 